\title{
Alumina Graphene Catalytic Condenser for Programmable Solid Acids
}

Tzia Ming Onn ${ }^{1}$, Sallye R. Gathmann ${ }^{1}$, Yuxin Wang ${ }^{1}$, Roshan Patel ${ }^{1}$, Silu Guo ${ }^{1}$, Han Chen $^{4}$, Jimmy K. Soeherman ${ }^{1}$, Phillip Christopher ${ }^{2}$, Geoffrey Rojas ${ }^{3}$, K. Andre Mkhoyan ${ }^{1}$, Matthew Neurock ${ }^{1}$, Omar A. Abdelrahman ${ }^{4}$, C. Daniel Frisbie ${ }^{1}$, Paul J. Dauenhauer ${ }^{{ }^{*}}$

${ }^{1}$ Department of Chemical Engineering \& Materials Science, University of Minnesota, 421 Washington Ave. SE, Minneapolis, MN, 55455, USA

${ }^{2}$ Department of Chemical Engineering, University of California, Santa Barbara, 3335 Engineering II, Santa Barbara, CA, 93106, USA

${ }^{3}$ Characterization Facility, University of Minnesota, 100 Union Street SE, Minneapolis, MN 55455, USA.

${ }^{4}$ Department of Chemical Engineering, University of Massachusetts Amherst, 686 N. Pleasant Street, Amherst, MA, 01003, USA

*Corresponding Author: hauer@umn.edu

Abstract. Precise control of electron density at catalyst active sites enables regulation of surface chemistry for optimal rate and selectivity to products. Here, an ultrathin catalytic film of amorphous alumina $(4 \mathrm{~nm})$ was integrated into a catalytic condenser device that enabled tunable electron depletion from the alumina active layer and correspondingly stronger Lewis acidity. The catalytic condenser had the following structure: amorphous alumina/graphene/ $\mathrm{HfO}_{2}$ dielectric $(70 \mathrm{~nm}) / \mathrm{p}$-type $\mathrm{Si}$. Application of positive voltages up to $+3 \mathrm{~V}$ between graphene and the p-type Si resulted in electrons flowing

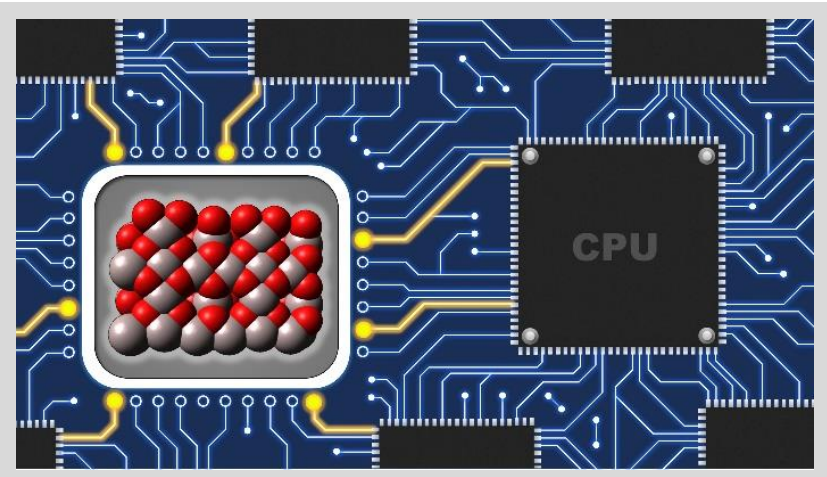
out of the alumina; positive charge accumulated in the catalyst. Temperature programmed surface reaction of thermocatalytic isopropanol dehydration to propene on the charged alumina surface revealed a shift in the propene formation peak temperature of up to $\Delta \mathrm{T}_{\text {peak }} \sim 50^{\circ} \mathrm{C}$ relative to the uncharged film, consistent with a $16 \mathrm{~kJ} \mathrm{~mol}^{-1}(0.17$ $\mathrm{eV})$ reduction in the apparent activation energy. Electrical characterization of the thin amorphous alumina film by ultraviolet photoelectron spectroscopy (UPS) and scanning tunneling microscopy (STM) indicates the film is a defective semiconductor with an appreciable density of in-gap electronic states. Density functional theory calculations of isopropanol binding on the pentacoordinate aluminum active sites indicate significant binding energy changes $(\triangle \mathrm{BE})$ up to $60 \mathrm{~kJ} \mathrm{~mol}^{-1}\left(0.62 \mathrm{eV}\right.$ ) for $0.125 \mathrm{e}^{-}$depletion per active site, supporting the experimental findings. Overall, the results indicate that continuous and fast electronic control of thermocatalysis can be achieved with the catalytic condenser device.

Introduction. Manipulation of charge within catalytic materials permits tunable surface chemistry and electronic optimization of chemical reaction rates. ${ }^{[1]}$ Here we put forward the concept of 'catalytic condensers' that allow reversible tuning of charge density in a catalyst thin film by means of an applied voltage. The catalyst film, in this case an amorphous $4 \mathrm{~nm}$ thick layer of alumina, is deposited on top of a graphene/insulator/conductor stack, and application of a voltage between graphene and the bottom electrode induces charge in the catalyst, thereby tuning the surface catalytic chemistry. The extent of hole/electron density accumulated in the catalyst layer depends on the applied potential, composition, and electronic characteristics of the dielectric and catalyst films, as well as quality of film deposition. We propose this will be a generally applicable strategy for manipulating the reactivity of catalyst thin films that can be tuned for different heterogeneous chemistries under static or dynamic modulation. 


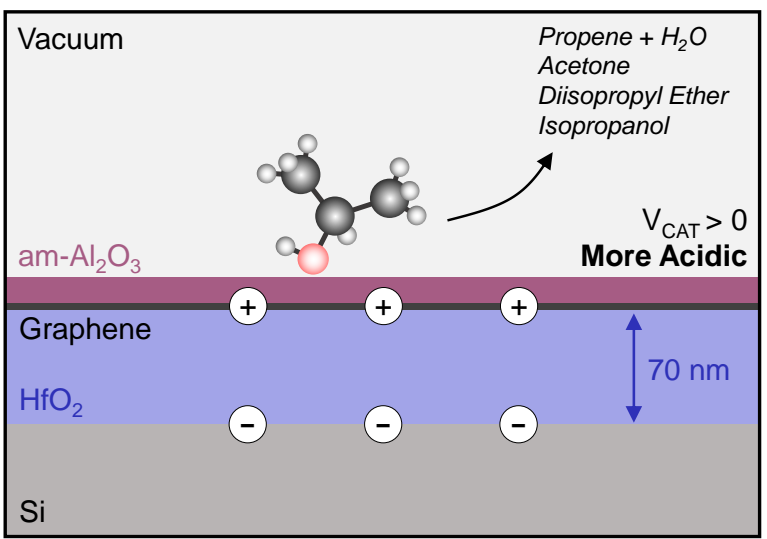

Scheme 1. Charge condensation in the catalyst alumina/graphene active surface layer within a thin film catalytic condenser.

Precedents for this work include the traditional metal-oxide-semiconductor field effect transistor (MOSFET) that alters charge carrier density in semiconductor layers with high- $k$ dielectric oxide layers; gate potential variation manipulates the electronic bands and the charge density of the semiconductor to achieve high and low conductivity ${ }^{[2]}$. This device structure has been used recently to manipulate the conduction band edge position and electron accumulation in ultrathin $\mathrm{ZnO}$ layers in electrochemical devices. In that case, a 5 $\mathrm{nm} \mathrm{ZnO}$ film on a $300 \mathrm{~nm} \mathrm{SiO}_{2}$ dielectric layer allowed for electron accumulation throughout the entire $\mathrm{ZnO}$ layer such that the exposed top surface of $\mathrm{ZnO}$, which was in contact with electrolyte, exhibited tunable rates of electron transfer with a soluble redox agent, tetrabromo-1,4benzoquinone. ${ }^{[3]}$ This transistor methodology was also applied to two-dimensional (2D) semiconductor crystals such as single layer $\mathrm{MoS}_{2}$ incorporated in a $\mathrm{MoS}_{2} / \mathrm{SiO}_{2} / \mathrm{p}$-Si stack, wherein charge modulation of active sites (S vacancies) was shown to increase the activity of electrocatalytic hydrogen evolution by a factor of four ${ }^{[4,5,6]}$. However, to our knowledge, the use of capacitive charging to enhance thermocatalytic activity has not been reported.

Here, we consider a catalytic condenser comprised of an ultrathin film of alumina, a metal oxide catalyst commonly used to carry out acidcatalyzed chemical transformations, such as alcohol dehydration ${ }^{[7,8,9]}$, and as a support for metal catalysts $^{[10,11]}$. As depicted in Scheme 1, the amorphous alumina film (4 $\mathrm{nm})$ supported on graphene is separated from a conductive p-type silicon wafer by $70 \mathrm{~nm}$ of $\mathrm{HfO}_{2}$ dielectric. When a voltage $\mathrm{V}_{\text {CAT }}$ is applied, charge accumulated in the bottom silicon electrode is balanced by a countercharge in the thin catalytic alumina/graphene film (as in a typical capacitor or condenser). Because of the extreme thinness of the alumina layer, its accumulated charge is accessible to reactive fluids (adsorbates in plasmas, vapors, gases, and liquids) on the top surface. The tunable activity of the alumina catalyst derives from the accumulated charge, which is controlled by $\mathrm{V}_{\mathrm{CAT}}$.

Alumina as the active layer within the catalytic condenser is desirable, because it is a commonlyused solid Lewis acid catalyst ${ }^{[12,13]}$. However, bulk alumina is an electronic insulator with a band gap of $8.7 \mathrm{eV}^{[14,15,16]}$, with valence and conduction bands far from the Fermi level. Thus, it is not obvious that charge can be accumulated in an alumina film in a condenser stack. However, the insulating nature of alumina is a function of its structure. For example, the (100) and (110) surfaces of crystalline $\gamma-\mathrm{Al}_{2} \mathrm{O}_{3}$ are predicted to have valence bands near the Fermi level and band gaps of only $\sim 3 \mathrm{eV}^{[17]}$. Similarly, the band gap for ultrathin (7$10 \mathrm{~nm}$ ) films of amorphous alumina has been measured to be $2.5 \mathrm{eV}$, which is in the semiconductor range ${ }^{[15]}$. We will demonstrate below that the alumina we deposit can be viewed as a defective semiconductor, and so charge accumulation is possible.

In this work, the device of Scheme 1 was synthesized and evaluated experimentally and theoretically to understand the degree of electronic control that could be achieved for a model catalytic reaction, isopropanol dehydration. On alumina surfaces, isopropanol is thought to adsorb and react on penta-coordinate Lewis acid sites $\left(\mathrm{Al}_{\mathrm{v}}{ }^{3+}\right)$ with activity that correlates with acid strength, dictated by the partial positive charge $\left(\delta^{+}\right)$on the surface aluminum and partial negative charge on the bonded oxygen $\left(\delta^{-}\right)^{[18]}$. Isopropanol dehydrates on alumina predominately unimolecularly to propene and water with minimal formation of either acetone via dehydrogenation or diisopropyl ether via bimolecular dehydration. Here, electronic modulation of the active site chemistry was 
a

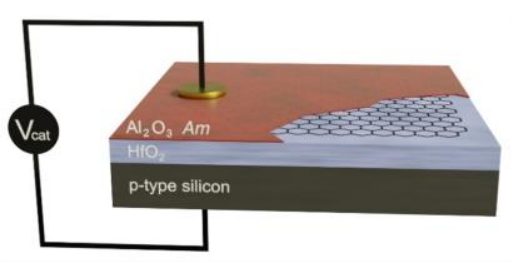

C

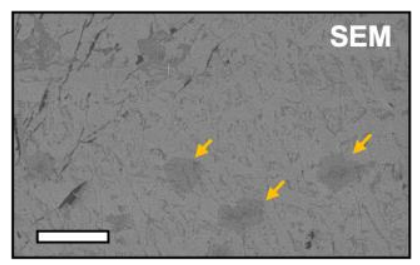

e

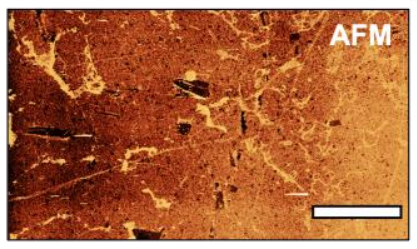

b

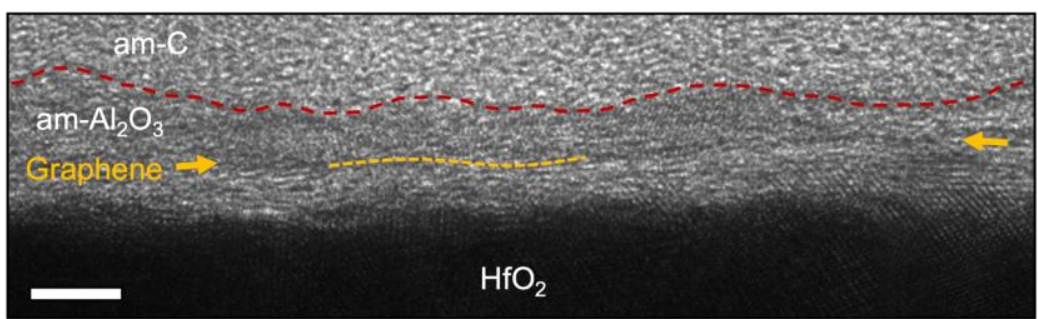

d STEM
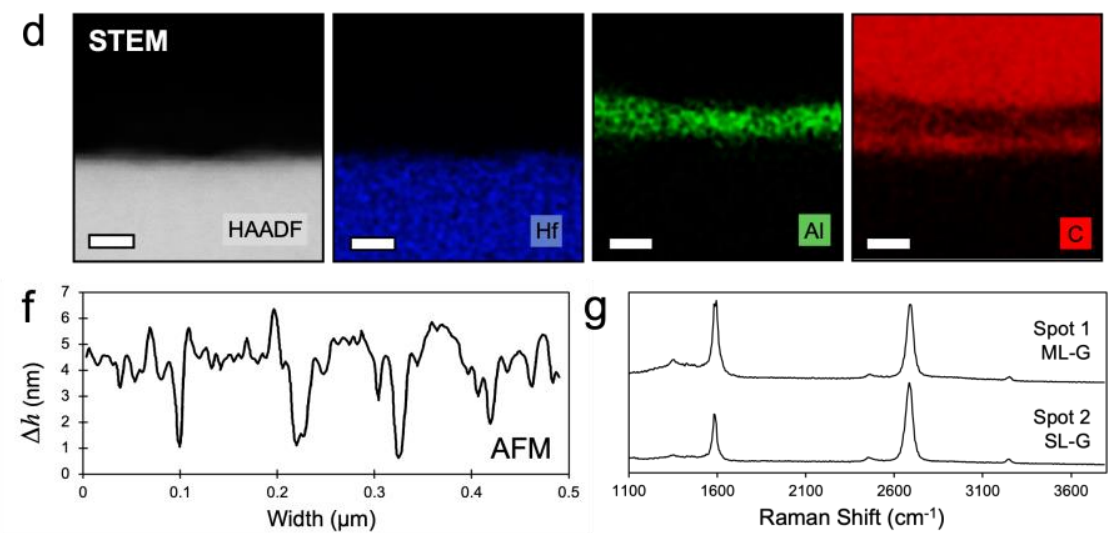

Figure 1. Alumina Catalytic Condenser Design and Composition. (a) Schematic illustration of the device showing $70 \mathrm{~nm}$-thick $\mathrm{HfO}_{2}$ layer sandwiched between the p-type silicon substrate and a thin $(4 \mathrm{~nm})$ graphene/alumina bilayer. (b) Conventional bright-field TEM image of the device cross section showing all the functional layers in the stack: $\mathrm{HfO}_{2}$, graphene and am- $\mathrm{Al}_{2} \mathrm{O}_{3}$. Scale bar is $5 \mathrm{~nm}$. Red dashed line shows the boundary between am- $\mathrm{Al}_{2} \mathrm{O}_{3}$ and deposited protective am-C layer. Yellow arrows and dashed line highlight the location of graphene layer. (c) Topview SEM image of the device. The cracks in the graphene are visible as dark contrast. Yellow arrows show the hexagon-shaped second layers of graphene. Scale bar is $25 \mu \mathrm{m}$. (d) HAADF-STEM image and the complementary EDX elemental maps from layer stack: $\mathrm{Hf}$ (blue), $\mathrm{Al}$ (green), $\mathrm{C}$ (red). The $\mathrm{C}$ signal from graphene can be seen under the am- $\mathrm{Al}_{2} \mathrm{O}_{3}$ layer. The $\mathrm{C}$ signal above am- $\mathrm{Al}_{2} \mathrm{O}_{3}$ is from deposited am-C protection layer. Scale bar is $5 \mathrm{~nm}$. (e) AFM image and (f) height profile of the condenser device. Scale bar is $1 \mu \mathrm{m}$. (g) Raman spectra of graphene collected at different sites on the device. Spot 1 is a representative spectrum of multilayer (ML) graphene, whereas Spot 2 is a representative spectrum of single layer (SL) graphene.

interrogated by experiment and theoretical calculations, evaluating the charge accumulated in the catalytic layer and its effect on isopropanol dehydration kinetics as a function of device design and applied potential bias. Application of potential bias of $+3 \mathrm{~V}$ is shown here to dramatically enhance the surface acidity of the catalytic layer and lower the reaction temperature. These results are presented following a thorough description of the device design and characterization.

Results and Discussion. The alumina-graphene catalytic condenser device depicted in Scheme 1 and Fig. 1a was fabricated with full synthetic details available in the methods section and the Supporting Information (Fig. S1 and S2). On top of the p-type $\mathrm{Si}$ substrate, a $\sim 70 \mathrm{~nm} \mathrm{HfO}_{2}$ dielectric layer was grown by atomic layer deposition (ALD) at $100{ }^{\circ} \mathrm{C}$ using a flow-type ALD reactor. The growth rate of the $\mathrm{HfO}_{2}$ film, as measured by spectroscopic ellipsometry (Fig. S3), was consistent with literature values ${ }^{[19,20]}$. Next, graphene was transferred onto the $\mathrm{HfO}_{2}$ layer using a previously reported polymethyl methacrylate (PMMA)-based method ${ }^{[21,22]}$, leaving a ca. $1.0 \mathrm{~cm}^{2}$ conductive sheet across the device. To make good electrical contact to graphene, a small area $(0.01$ $\mathrm{cm}^{2}$ ) contact ( $\mathrm{Au} / \mathrm{Ti}, 45 \mathrm{~nm} / 5 \mathrm{~nm}$ ) was deposited on the graphene by e-beam evaporation through a shadow-mask. Finally, the $\sim 4 \mathrm{~nm}$ catalytic alumina layer was grown via ALD at $100{ }^{\circ} \mathrm{C}$ using the same flow-type ALD reactor as above.

Cross-sectional TEM and high-angle annular dark-field (HAADF) scanning TEM (STEM) 


\section{Chem Rxiv}

images, combined with compositional analysis using energy dispersive X-ray (EDX) spectroscopy, confirmed the layered structure of the catalytic condenser device, as shown in Fig. 1b-d and Fig. S4. From the cross section, as expected, a multilayer of graphene was observed between the $\mathrm{HfO}_{2}$ and the alumina layer, which was $0.4 \mathrm{~nm}$ thick. The aluminum oxide layer appears to be predominantly amorphous, as anticipated for films made by ALD at low deposition temperatures $^{[19,23,24]}$. There were some regions, as identified in Fig. S5, where surface $\mathrm{HfO}_{2}$ formed crystalline grains $\sim 10 \mathrm{~nm}$ in diameter at the interface, possibly during the device fabrication process. Scanning electron microscopy (SEM) analysis in Fig. 1c and Fig. S6 confirms that the alumina film above the graphene is continuous across the device. The successful growth of the aluminum oxide layer on the graphene could be attributed to the use of $\mathrm{H}_{2} \mathrm{O}$ in ALD, which created $\mathrm{OH}$-sites on the graphene surface at low deposition temperatures ${ }^{[25,26,27]}$. The presence of a continuous alumina layer over large lateral dimensions $(\sim 0.1$ $\mu \mathrm{m})$ with thicknesses of $\sim 4 \mathrm{~nm}$ was further confirmed by atomic force microscopy (AFM). It should be noted that at large lateral scales of order $1 \mathrm{~cm}$, graphene is expected to have wrinkles and folds, which were observed in our SEM-EDX analysis (Fig. 1c and Fig S6), resulting from its chemical vapor deposition (CVD) growth on the initial $\mathrm{Cu}$ substrate ${ }^{[28]}$ and its transfer. Hexagonal domains, also visible on these SEM images (Fig. 1c and Fig. S6), represent additional graphene layers, indicating that these transferred graphenes are comprised of regions of monolayers and bilayers/tri-layers. Raman spectra measured over 30 spot sites on the device (Fig. 1g) validated the existence of monolayer graphene and bilayers/trilayers based on the intensity ratio of the $G$ (1587 $\left.\mathrm{cm}^{-1}\right)$ and 2D $\left(2658 \mathrm{~cm}^{-1}\right)$ band and showed minimal defects due to the weak D band intensity $\left(1350 \mathrm{~cm}^{-}\right.$ $\left.{ }^{1}\right)$. Spot 1 is a representation of bilayer graphene with the ratio of intensity $\mathrm{I}_{2 \mathrm{D}} / \mathrm{I}_{\mathrm{G}}$ of $\sim 1$, whereas spot 2 represents a monolayer of graphene with the $I_{2 D}$ $/ \mathrm{I}_{\mathrm{G}}$ of $\sim 2$.

A high quality $\mathrm{HfO}_{2}$ dielectric layer is important for voltage-tunable thermocatalysis to ensure that charges are distributed uniformly along the graphene-catalyst layer. A particular consideration is a possible change in the $\mathrm{HfO}_{2}$ film structure during programmed temperature ramps which were used in our reaction analysis described later. Consequently, the thermal stability of $\mathrm{HfO}_{2}$ film in the catalytic capacitor device was assessed by measuring the X-ray diffraction (XRD) pattern of the $\mathrm{HfO}_{2}-\mathrm{Si}$ structure as a function of temperature as shown in Fig. 2a. These $\mathrm{HfO}_{2}-\mathrm{Si}$ samples were heated in a muffle furnace under ambient conditions for $1 \mathrm{~h}$ at different temperatures prior to XRD data collection. The $70 \mathrm{~nm} \mathrm{HfO}_{2}$ XRD-amorphous ALD films were heated from 100 ${ }^{\circ} \mathrm{C}$ to $350{ }^{\circ} \mathrm{C}$; the films started to crystallize only after heating above $400{ }^{\circ} \mathrm{C}$. The detected peaks were associated with the monoclinic polymorphs of $\mathrm{HfO}_{2}$, with the crystallites aligning preferentially along certain Miller indices. This is expected since selection of substrate composition, substrate orientation, deposition temperature, and choice of precursors are known to affect the crystallization process and structural orientation of ALD films ${ }^{[29]}$. Crystallite formation above $400{ }^{\circ} \mathrm{C}$ is known to impact the $\mathrm{HfO}_{2}$ structural integrity, increase surface roughness, introduce pinholes, and affect the electronic properties ${ }^{[30,31,32,33,34]}$. So, practically speaking, $400{ }^{\circ} \mathrm{C}$ is an upper bound for examining catalytic behavior in these particular devices.

To further establish a working temperature range for the catalytic condenser, the dielectric constant and capacitance of $\mathrm{HfO}_{2}$ were determined as a function of processing temperature (Fig. 2b). For the electrical measurements, a metal- $\mathrm{HfO}_{2}-\mathrm{Si}$ capacitor was fabricated by depositing a $0.01 \mathrm{~cm}^{2}$ $\mathrm{Au} / \mathrm{Ti}$ metal contact $(45 \mathrm{~nm} / 5 \mathrm{~nm})$ via shadowmasked e-beam evaporation on the $\mathrm{HfO}_{2}-\mathrm{Si}$ after the samples were heat treated at selected temperatures. At low treatment temperatures $(100-$ $300^{\circ} \mathrm{C}$ ), a specific capacitance of $\sim 330 \mathrm{nF} \mathrm{cm}^{-2}$ was calculated from experimental displacement currentvoltage curves (Fig. 2b, Fig. S8 and Fig. S9) at varying sweep rates $(0.25-1.25 \mathrm{~V} / \mathrm{s})$; this specific capacitance decreased to $\sim 200 \mathrm{nF} \mathrm{cm}^{-2}$ for treatment at $400{ }^{\circ} \mathrm{C}$. This corresponds to dielectric constants of $\sim 26$ and $\sim 16$ (Fig. 2b) as the $\mathrm{HfO}_{2}$ layer converted from amorphous to crystalline 

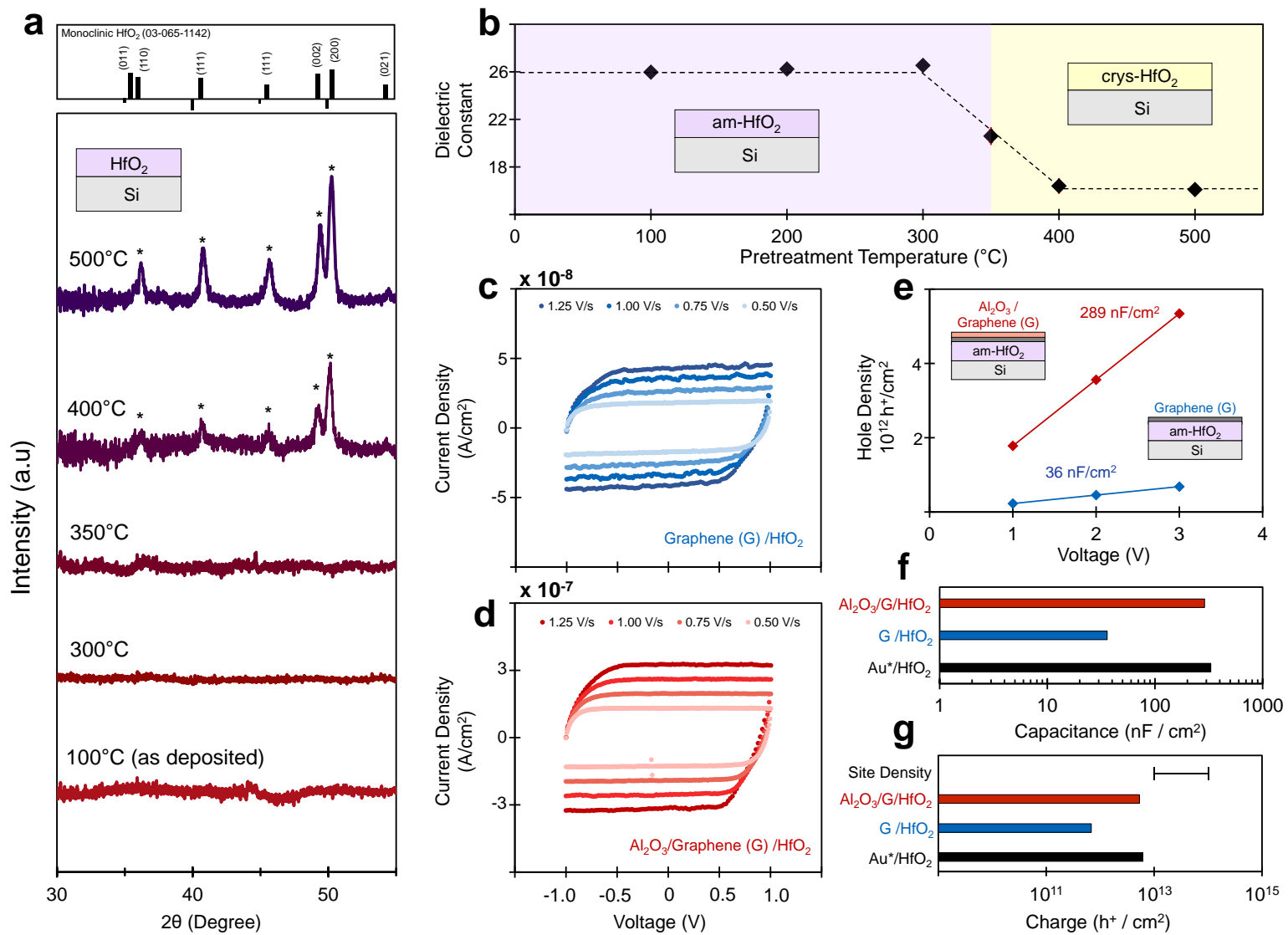

Figure 2. Characterization of Alumina-Graphene Catalytic Condenser Device. (a) X-ray diffraction patterns of ALD- $\mathrm{HfO}_{2}$ on $\mathrm{Si}$ after being heated in air. Peaks associated with crystallized monoclinic $\mathrm{HfO}_{2}$ are shown as reference. (b) Average dielectric constant of $\mathrm{HfO}_{2}$ as a function of annealing pretreatment temperature in air. The capacitive current density for each point can be found in Fig. S8. A change in capacitive current density occurs at $\sim 350{ }^{\circ} \mathrm{C}$ before the ALD $\mathrm{HfO}_{2}$ film begins to crystallize. (c) The capacitive displacement current density of graphene/ $/ \mathrm{HfO}_{2} / \mathrm{Si}$ as a function of voltage bias at different voltage sweep rates. (d) The capacitive current density of alumina/graphene/ $\mathrm{HfO}_{2} / \mathrm{Si}$ as a function of voltage and sweep rates. (e) Average number of induced holes on graphene (blue) and alumina-graphene (red) as a function of $\mathrm{V}_{\mathrm{CAT}}$. Error bars are within the size of the data point. (f) Averaged capacitance of the catalytic condenser with varying active layers above $\mathrm{HfO}_{2}$ : $\mathrm{Au}^{*}$ ( $\mathrm{Au}$ / Ti contact, 45 $\mathrm{nm} / 5 \mathrm{~nm}$ ), graphene (blue), and alumina on graphene $\left(\mathrm{Al}_{2} \mathrm{O}_{3} / \mathrm{G}\right.$, red). (g) Number of holes on the catalytic condenser at $+3 \mathrm{~V}$ with varying active layers above the $\mathrm{HfO}_{2}$ layer; the estimated catalytic active site density of alumina is provided for comparison (purple, sites $\left./ \mathrm{cm}^{2}\right)$. Au*/ $\mathrm{HfO}_{2}$ denotes an Au/Ti contact $(45 \mathrm{~nm} / 5 \mathrm{~nm})$ on $\mathrm{HfO}_{2}$.

states, in agreement with the range of reported dielectric constants of bulk $\mathrm{HfO}_{2}{ }^{[23,24,35]}$. It must be noted that there was significant current leakage only after heating above $400{ }^{\circ} \mathrm{C}$, again confirming that $400{ }^{\circ} \mathrm{C}$ is an upper limit for reaction studies.

To assess charge accumulation in our catalytic condensers we performed additional displacement current measurements on two different condenser stacks, one without aluminum oxide (graphene $/ \mathrm{HfO}_{2} / \mathrm{p}-\mathrm{Si}$ ) and the other being the complete catalytic (alumina/graphene/ $\mathrm{HfO}_{2} / \mathrm{p}-\mathrm{Si}$ ).

Displacement currents as a function of voltage and sweep rate for both stacks are shown in Fig. 2c and 2d, respectively, and analysis of these curves leads to the electron density versus voltage plot in Fig. 2 e. As expected, the stored electron density in the devices increases linearly with voltage, $\mathrm{V}_{\mathrm{CAT}}$. Note that for the alumina/graphene device shown in red that the maximum electron density is nearly $5.3 \cdot 10^{12} \mathrm{e}^{-} / \mathrm{cm}^{2}$. Note also that the slope of the Fig. $\mathbf{2 e}$ is the specific capacitance. It is evident that the 

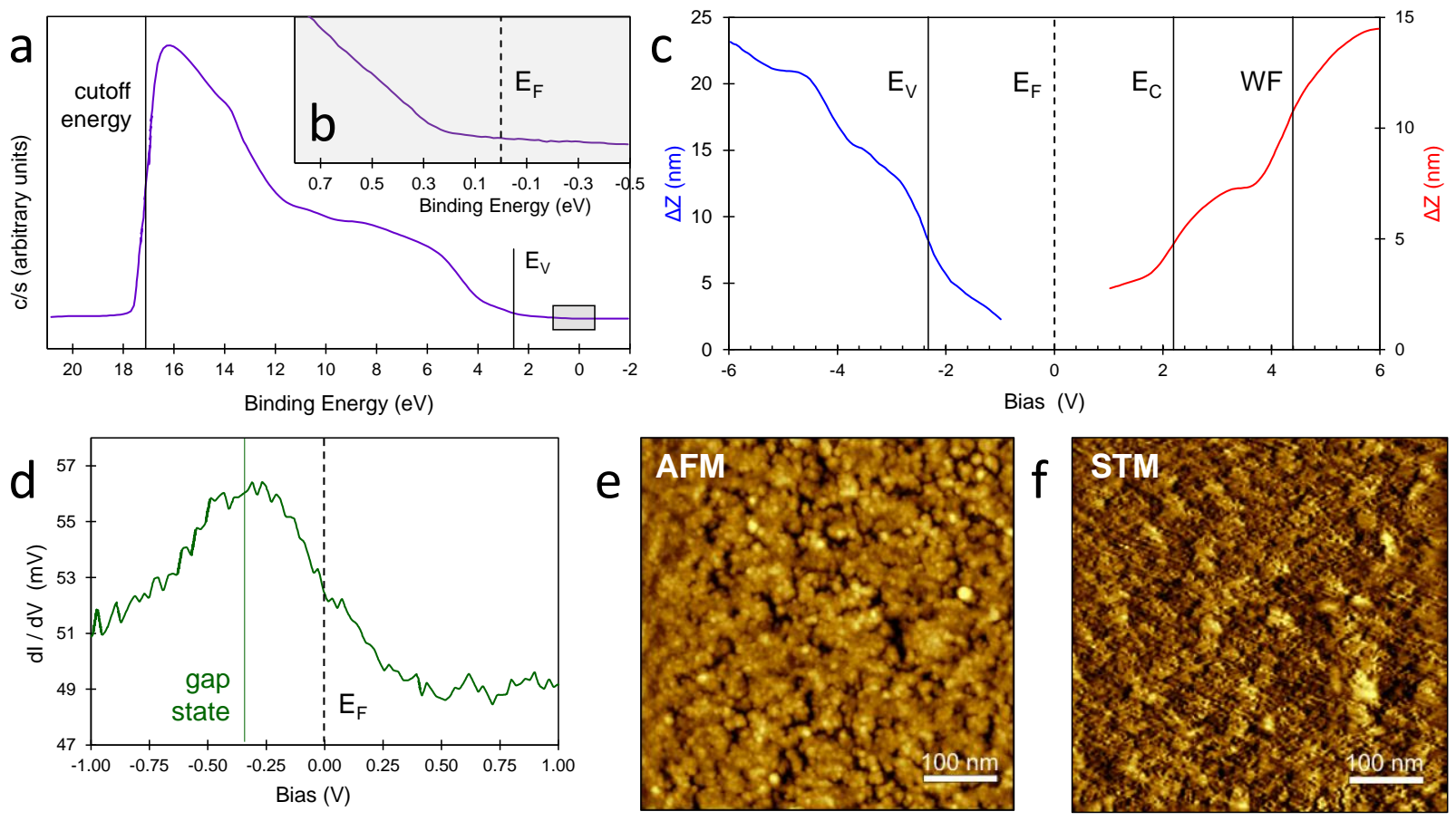

Figure 3. Electronic Characterization of the Alumina/graphene Layer by UPS and STM. (a) UPS with energy cutoff for work function and valence band onset $(2.3 \mathrm{eV})$ highlighted. (b) Magnified view of the UPS data near the Fermi level shown in the inset. The slope change near $0.25 \mathrm{eV}$ indicates the presence of in-gap states above the valence band edge. (c) STM constant-current distance-voltage curves for the alumina/graphene film with valence band edge $\left(\mathrm{E}_{\mathrm{V}}=-2.3 \mathrm{eV}\right)$, conduction band edge $\left(\mathrm{E}_{\mathrm{C}}=2.2 \mathrm{eV}\right)$, and work function $(\mathrm{WF}=4.4 \mathrm{eV})$ identified. (d) Differential conductance near $\mathrm{E}_{\mathrm{F}}$ revealing a discrete gap state $(\sim 300 \mathrm{meV})$. (e) AFM and (f) $\mathrm{STM}$ image (tip bias $=-710 \mathrm{mV}, \mathrm{I}=$ $622 \mathrm{pA})$ of the alumina surface showing similar morphologies.

device with the alumina/graphene top contact has an eight-fold larger capacitance than the device with just graphene as the top contact layer (289 vs. $36 \mathrm{nF} \mathrm{cm}^{-2}$ ). In other words, the charge accumulated in the condenser is substantially larger when alumina is present, which is not unexpected as the electronic density of states in the ultrathin graphene is likely insufficient to fully screen the applied electric field ${ }^{[36]}$. The alumina layer provides additional density of states and thus larger charge accumulation.

A direct comparison of capacitances and maximum charge density at $\mathrm{V}_{\mathrm{CAT}}$ of $+3 \mathrm{~V}$ for the three types of stack devices discussed above is shown in Fig. 2f and 2g. It is noteworthy that the condensers with Au versus alumina/graphene top contacts are comparable in capacitance and charge accumulation. Because the capacitances of the graphene-only versus the alumina/graphene devices are so different, we infer that the majority of the induced charge in the alumina/graphene device is actually in the alumina and therefore available to impact surface thermochemistry.

Alumina Film Electronic Characteristics. The electronic states of the top layer of the aluminagraphene catalytic condenser were characterized by ultraviolet photoelectron spectroscopy (UPS) and scanning tunneling microscopy (STM) as depicted in Fig. 3. Based on the UPS spectra, the ALDdeposited alumina thin film is electronically very different from insulating bulk $\mathrm{Al}_{2} \mathrm{O}_{3}$. The UPS spectrum in Fig. 3a indicates the valence band edge $\left(E_{\mathrm{V}}\right)$ is at $2.3 \mathrm{eV}$ below the Fermi level. However, closer inspection between -0.5 and $+0.8 \mathrm{eV}$ in Fig. 3b indicates the presence of in-gap states near the Fermi level at $\sim 250-350 \mathrm{mV}$. These gap states are present on the surface of the alumina even for devices without graphene, as shown in Fig. S7.

The electronic states of the alumina-graphene catalytic condenser active layer were further probed 
by scanning tunneling microscopy (STM) in Fig. 3c-3f. While bulk crystalline alumina is an insulator, the $\sim 4 \mathrm{~nm}$ alumina film in the condenser was sufficiently conductive for mapping via STM (Fig. 3f); the resulting image was consistent with the morphology of the surface observed by AFM with the same resolution (Fig. 3e). The electronic characteristics of the surface at large biases were evaluated as constant-current distance-voltage curves (Fig. 3c), identifying the valence band edge $\left(\mathrm{E}_{\mathrm{V}}\right.$ of $\left.-2.3 \mathrm{eV}\right)$, the conduction band edge $\left(\mathrm{E}_{\mathrm{C}}\right.$ of $2.2 \mathrm{eV}$ ), and the work function (WF of $4.4 \mathrm{eV}$ ). It is clear from Fig. 3c that the amorphous alumina film has a band gap of $\sim 5 \mathrm{eV}$, much smaller than crystalline $\gamma-\mathrm{Al}_{2} \mathrm{O}_{3}$, which has a band gap over 8 $\mathrm{eV}^{[14,15,16]}$. Furthermore, STM differential conductance measurements under varying bias (Fig. 3d) also indicated a gap state about $300 \mathrm{meV}$ below the Fermi level, in general accordance with the UPS spectrum of Fig. 3b.

The combined spectroscopy data of Fig. 3 point to the existence of in-gap electronic states in the alumina film that can be occupied by (or depleted of) electrons. These in-gap electronic states exist with sufficient density to permit STM imaging via tunneling current between the STM tip and the aluminum oxide film. The ALD-deposited alumina film acts much like a 'poor insulator' or defective semiconductor, allowing charge to pass through the layer to the conductive graphene layer below. Graphene can move charge laterally across the surface of the device, and the aluminum oxide in turn has sufficient defect state densities near the Fermi level to conduct in the normal direction.

\section{Catalytic Condenser Alumina Surface} Chemistry. The unique chemical properties of the catalytic condenser's alumina film were then characterized by thermocatalytic dehydration of isopropanol. Catalytic properties of the aluminagraphene condenser were probed through temperature programmed surface reaction (TPSR) under varying voltage bias; details of the TPSR experimental design and method are provided in the Supplementary Information (Fig. S11-S17). Briefly, the catalytic condenser was housed within a chamber capable of evacuation to ultrahigh vacuum (UHV, $\sim 10^{-9}$ Torr, Fig. S13), where isopropanol was dosed into the chamber to adsorb on the alumina film; $24 \mathrm{~h}$ of pumping removed physisorbed isopropanol from the chamber, leaving chemisorbed isopropanol on the aluminum oxide active sites. As the alumina/graphene condenser surface temperature was increased, aluminum oxide catalyzed the dehydration of chemisorbed isopropanol, which was followed by mass spectrometry. The propene signal was tracked at a mass-to-charge $(\mathrm{m} / \mathrm{z})$ ratio of 41 , correcting for the influence of simultaneously desorbing unreacted isopropanol $(\mathrm{m} / \mathrm{z}=45$, Fig. S19) and subtraction of a sigmoidal baseline derived from the chamber pressure; full details are provided in the Supporting Information. Catalyst surface temperature was measured using a type-K thermocouple placed near the location of the catalytic condenser within the UHV chamber (Fig. S16 and Fig. S17).

Under UHV-TPSR conditions, unimolecular isopropanol dehydration to propene over the alumina catalytic condenser is the dominant pathway, with negligible formation of acetone and diisopropyl ether through dehydrogenation and bimolecular dehydration, respectively. The dominance of unimolecular dehydration was consistent with ambient pressure TPSR over bulk alumina powders, where $99 \%$ selectivity to propene as the product of unimolecular dehydration was observed (Table S1). Additionally, isopropanol dehydration kinetics on the $1 \mathrm{~cm}^{2}$ alumina catalytic condenser, in the absence of applied potential bias, was found to be in agreement with $\gamma$-alumina powder catalysts. Without applied potential bias, the rate of propene formation on the alumina condenser peaked at $\sim 130{ }^{\circ} \mathrm{C}\left(\mathrm{T}_{\text {peak }}\right.$, Fig. $4 a$ and Fig. S18). Applying a first order Polanyi-Wigner equation to the zero-bias experimental TPSR profile, ${ }^{[37]}$ an activation energy $\left(E_{a}\right)$ of $115 \pm 1 \mathrm{~kJ}$ $\mathrm{mol}^{-1}(1.19 \mathrm{eV})$ for isopropanol unimolecular dehydration over the alumina condenser was measured in the absence of a potential bias $\left(\mathrm{V}_{\text {cat }}=\right.$ 0V, Fig. 4c). Similarly, we measured an activation energy of $117 \pm 1 \mathrm{~kJ} \mathrm{~mol}^{-1}(1.21 \mathrm{eV})$ for unimolecular isopropanol dehydration over bulk $\gamma$ alumina powder via ambient pressure TPSR (Fig. 4b), consistent with prior measurements by Gorte and co-workers ${ }^{[13]}$. 

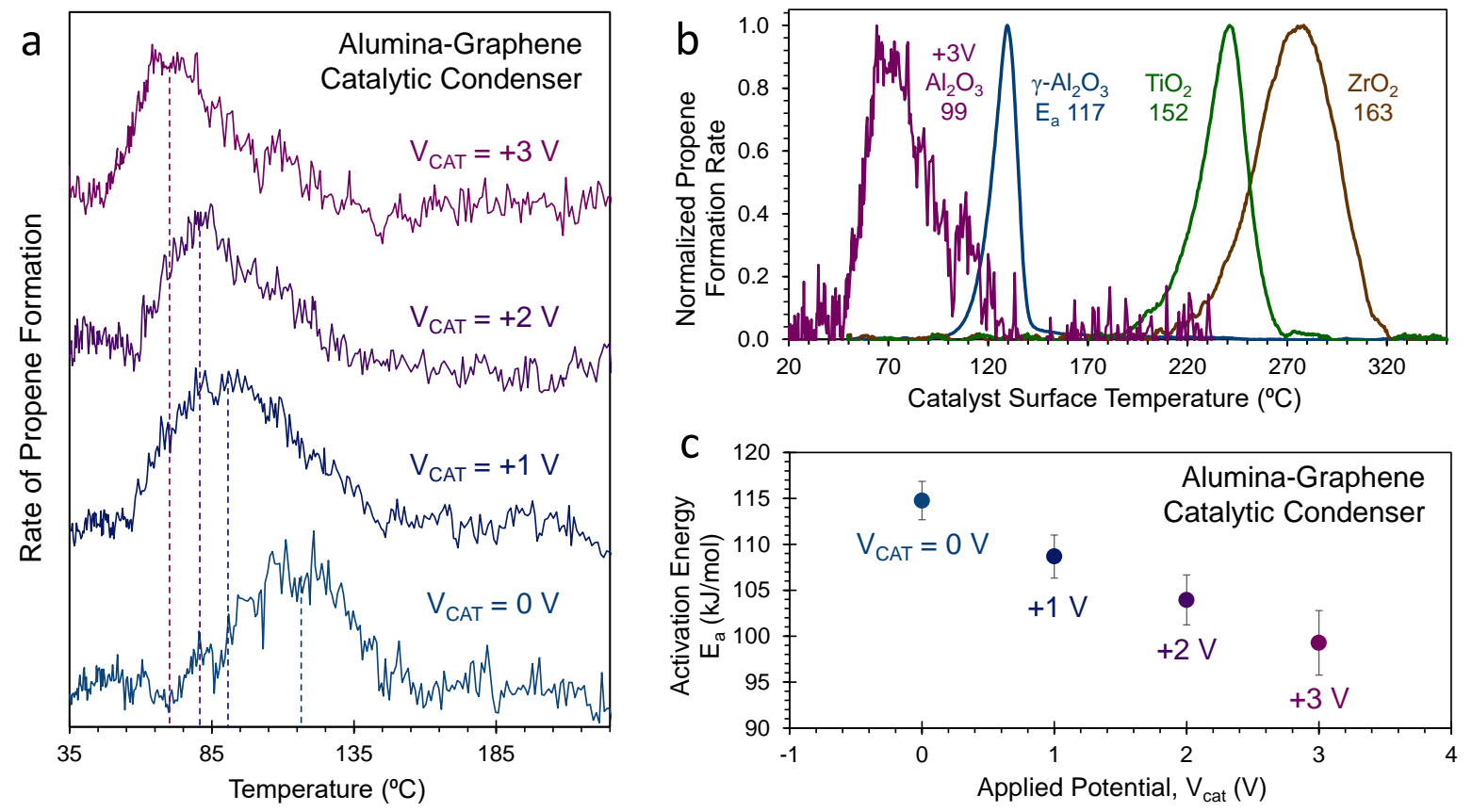

Figure 4. Temperature-Programmed Surface Reaction of Isopropanol Dehydration. (a) Temperature programmed isopropanol dehydration on the alumina catalytic condenser device (4 nm alumina / graphene / $70 \mathrm{~nm}$ $\mathrm{HfO}_{2} /$ p-type $\mathrm{Si}$ ) to form propene at varying applied voltages, $\mathrm{V}_{\text {Сат. }}$ (b) Temperature programmed isopropanol dehydration to propene on the catalytic condenser at $\mathrm{V}_{\mathrm{CAT}}$ of $+3 \mathrm{~V}$ and the powders of $\gamma$-alumina, titania, and zirconia with activation energy, $E_{a}\left(\mathrm{~kJ} \mathrm{~mol}^{-1}\right)$, to form propene determined by the Redhead equation. (c) The activation energy, $E_{a}$, of propene formation from isopropanol on the alumina catalytic condenser as determined by the Redhead equation. Error bars represent a $90 \%$ confidence interval.

Condensation of holes (positive charge) for catalytic modulation of alumina was then evaluated by isopropanol dehydration TPSR under $\mathrm{V}_{\mathrm{CAT}}$ biases of $0,+1,+2$, and $+3 \mathrm{~V}$. Our central result is that application of positive voltage bias $\left(\mathrm{V}_{\mathrm{CAT}}>0\right.$ V) significantly reduced the peak temperature of the rate of propene formation (Fig. 4a). While propene formation peaked at $\sim 130{ }^{\circ} \mathrm{C}$ under zero bias $\left(\mathrm{V}_{\mathrm{CAT}}\right.$ of $\left.0 \mathrm{~V}\right)$, propene formation peak temperatures reduced by as much $\sim 50{ }^{\circ} \mathrm{C}\left(\Delta \mathrm{T}_{\text {peak }}\right)$ at $\mathrm{V}_{\text {CAT }}$ of $+3 \mathrm{~V}$. The change in peak temperature is commensurate with a change in the kinetics of isopropanol unimolecular dehydration; positive potential bias reduced the activation energy to 109 $\pm 2,104 \pm 3$, and $99 \pm 4 \mathrm{~kJ} \mathrm{~mol}^{-1}$ for $\mathrm{V}_{\mathrm{CAT}}$ of $+1,+2$, and $+3 \mathrm{~V}$, respectively, constituting an overall reduction in the activation energy $\left(\Delta \mathrm{E}_{\mathrm{a}}\right)$ from $\mathrm{V}_{\mathrm{CAT}}$ of $0 \mathrm{~V}$ of $\sim 16 \mathrm{~kJ} \mathrm{~mol}^{-1}(0.16 \mathrm{eV}, \mathbf{F i g}$. 4c). It is worth noting that in the absence of an aluminum oxide layer, no propene formation was observed in the course of a TPSR (Fig. S20 and Fig. S21).
One potential explanation for the experimentally observed higher activity for unimolecular isopropanol dehydration over the graphene-alumina catalytic condenser is ohmic heating of the active surface. Charge separation across the $70 \mathrm{~nm} \mathrm{HfO}_{2}$ insulating layer introduces the possibility for 'leakage current' through the dielectric, potentially leading to resistive heating of the catalytic layer. We have demonstrated earlier that leakage current is negligible when $\mathrm{HfO}_{2}$ is maintained below $400{ }^{\circ} \mathrm{C}$. The power supply (Keithley 2450) applying the potential bias to the active device surface during the experiment was limited to $105 \mu \mathrm{A}$ to eliminate thermal artifacts due to ohmic heating. The possibility of ohmic heating of the catalytic condenser was also experimentally evaluated by measuring the surface temperature of the catalytic condenser with an infrared camera (FLIR A655) under varying potential bias (Fig. S22); surface temperature did not vary more than one degree over $10 \mathrm{~min}$ for all considered applied 

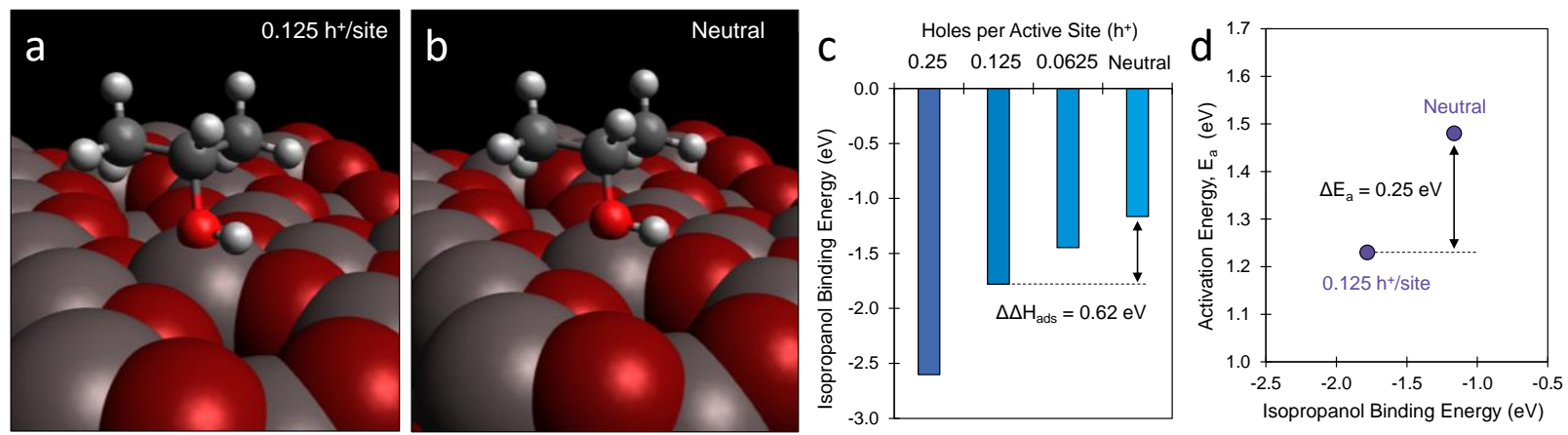

Figure 5. Density Functional Theory Calculations of Isopropanol Adsorption and Dehydration on the Alv ${ }^{3+}$ Site of $\gamma$-Alumina (100) as a Function of Charge. (a) 0.125 holes $\left(\mathrm{h}^{+}\right)$per site with $\mathrm{Al}_{\mathrm{v}}{ }^{+3}-\mathrm{O}^{\mathrm{IPA}}$ bond distance of $1.963 \AA$, (b) neutral with $\mathrm{Al}^{+3}-\mathrm{O}^{\mathrm{IPA}}$ bond distance of $2.016 \AA$, (c) Isopropanol (IPA) binding energy versus hole density, and (d) associated activation energy to form propene and water from isopropanol. Color scheme: $\mathrm{O}$ - red, $\mathrm{C}$ - black, Al - grey, H- white.

potentials $\left(0 \leq \mathrm{V}_{\mathrm{CAT}} \leq+3 \mathrm{~V}\right)$, thereby ruling out potential thermal artifacts.

Alternatively, the enhanced rate of isopropanol unimolecular dehydration under positive bias can be rationalized based on increased electron-hole density in the thin alumina-graphene layer, as indicated by capacitance measurements (Fig. 2) and spectroscopy of the alumina film (Fig. 3). Reduced electron density at the Lewis acid catalytic site of the aluminum oxide surface $\left(\mathrm{Al}_{\mathrm{V}}{ }^{3+}\right)$ increases site acidity, binding isopropanol stronger and reducing the catalytic activation barrier for its unimolecular dehydration to propene and water. The extent of positive charge condensation in the graphenealumina active layer depends on the extent of applied potential bias as well as the design of the catalytic condenser stack. As summarized in Fig. $\mathbf{2 g}$, the number of electrons depleted in the aluminum oxide film at $\mathrm{V}_{\mathrm{CAT}}$ of $+3 \mathrm{~V}$ was measured to be $5.3 \cdot 10^{12} \mathrm{e}^{-} \mathrm{cm}^{-2}$; this is within an order of magnitude of pentacoordinate aluminum active site density available for acid catalysis reported on $\gamma$ $\mathrm{Al}_{2} \mathrm{O}_{3}\left(10^{13}-10^{14} \text { sites } \mathrm{cm}^{-2}\right)^{[13,38,39,40]}$. It is therefore possible to deplete $0.05-0.50$ electrons per active site at a potential bias $\mathrm{V}_{\mathrm{CAT}}$ of $+3 \mathrm{~V}$. It should be noted that the amorphous $4 \mathrm{~nm}$ film atop the condenser may have an active site density distinct from $\gamma-\mathrm{Al}_{2} \mathrm{O}_{3}$, but it is unlikely to vary by more than an order of magnitude. The effect of this charge depletion at the active site can be further evaluated by computation, as described next.
Isopropanol Binding and Dehydration Computed Energy. To simulate direct electron transfer to the alumina layer, we carried out periodic density functional theory (DFT) calculations whereby $0.25,0.50$ and 1.0 electrons were removed from a thin $(6 \AA)$ model $\mathrm{Al}_{2} \mathrm{O}_{3}$ slab. More specifically, we examined the dehydrated $\gamma$ $\mathrm{Al}_{2} \mathrm{O}_{3}$ (100) surface as a model alumina surface, as it is the lowest energy surface at the reaction conditions used in the experiments carried out herein with temperatures greater than $200{ }^{\circ} \mathrm{C}$ and partial pressures of water $\left(\mathrm{P}_{\mathrm{H} 2 \mathrm{O}}\right)>10^{-3}$ bar. $^{[13,41]}$

The removal of electrons from the thin $\mathrm{Al}_{2} \mathrm{O}_{3}$ slab increases the positive charge on the active $\mathrm{Alv}^{3+}$ sites and increases the Lewis acidity. Isopropanol then binds to the surface stronger. The adsorption energy decreases from $-1.16 \mathrm{eV}(112 \mathrm{~kJ}$ $\mathrm{mol}^{-1}$, at zero charge) to $-1.78 \mathrm{eV}\left(-172 \mathrm{~kJ} \mathrm{~mole}^{-1}\right)$ as positive charge increases from 0 to $0.125 \mathrm{~h}^{+}$site 1 , Fig. 5a-5c. The isopropanol binding energy further strengthens as additional electron density is removed (Fig. 5c). Naturally, the increased charge also results in shorter isopropanol $\mathrm{O}^{\mathrm{IPA}}-\mathrm{Alv}_{\mathrm{v}}{ }^{3+}$ bond distances; the $\mathrm{O}^{\mathrm{IPA}}-\mathrm{Al}_{\mathrm{V}}{ }^{3+}$ bond decreases from $2.016 \AA$ under neutral conditions to $1.963 \AA$ for $0.125 \mathrm{~h}^{+} /$site as shown in Fig. 5a and $\mathbf{5 b}$.

Alcohol dehydration over alumina has been proposed to proceed over the $\mathrm{Al}_{\mathrm{Va}}{ }^{3+}-\mathrm{O}_{3 \mathrm{~b}}{ }^{2-}$ site pairs in a concerted $\mathrm{E} 2$ mechanism in which the $\mathrm{C}-\mathrm{OH}$ and $\mathrm{C}-\mathrm{H}$ bonds are simultaneously activated by the $\mathrm{Al}_{\mathrm{V}}{ }^{3+}-\mathrm{O}^{2-}$ acid-base site pairs to directly eliminate propene, which then desorbs ${ }^{[13,38]}$. The Al- $(\mathrm{OH})^{\delta-}$ 
and $\mathrm{AlO}-(\mathrm{H})^{\delta+}$ subsequently react to form and eliminate water. The calculated reactant, transition, and product states on the dehydrated $\gamma-\mathrm{Al}_{2} \mathrm{O}_{3}$ (100) surface are shown in Fig. S29. The energetic pathways to form propene and water from isopropanol are summarized in Fig. 5d, depicting the activation energy as a function of the isopropanol binding energy. The neutral alumina site dehydrates isopropanol with $E_{a}$ of $143 \mathrm{~kJ} \mathrm{~mol}^{-}$ ${ }^{1}$, while the depleted alumina site $\left(0.125 \mathrm{~h}^{+} /\right.$site $)$ which has a higher Lewis acidity has a lower barrier $\mathrm{E}_{\mathrm{a}}$ of $119 \mathrm{~kJ} \mathrm{~mol}^{-1}$. The barriers decrease linearly with the positive charge (i.e., acidity) of the $\mathrm{Al}_{\mathrm{V}}{ }^{3+}$ sites and show the same trends as those found experimentally and shown in Fig. 3c. The calculated barriers also decrease linearly with the heat of isopropanol adsorption.

Catalytic Condenser Performance. The combined device characterization, spectroscopy, reaction experiments, and computation suggest that the active site of alumina has tunable acidity with the applied voltage, $\mathrm{V}_{\mathrm{CAT}}$. As suggested in Scheme $\mathbf{1}$, positive $\mathrm{V}_{\text {CAT }}$ depletes electrons in the catalytic alumina layer, most likely from the occupied in-gap states. The resulting electron-deficient aluminum site then binds isopropanol stronger and dehydrates it to propene with a lower activation barrier as larger $\mathrm{V}_{\mathrm{CAT}}$ is applied. Calculated activation energies (Fig. 5d) indicated that the isopropanol-topropene activation barrier should reduce about 24 $\mathrm{kJ} \mathrm{mol}^{-1}$ when $12.5 \%$ of an electron is depleted from an $\mathrm{Al}_{\mathrm{v}}{ }^{3+}$ active site. Comparison with experimental activation energies (Fig. 3c) exhibiting $\Delta \mathrm{E}_{\mathrm{a}}$ of $16 \mathrm{~kJ}$ $\mathrm{mol}^{-1}$ for differences in applied biases of $0 \mathrm{~V}$ and $+3 \mathrm{~V}$ indicates that about $5 \%-10 \%$ of an electron has been depleted per active site at an applied $\mathrm{V}_{\mathrm{CAT}}$ of $+3 \mathrm{~V}$; this is consistent with the ratio of charge depletion $\left(\sim 5 \cdot 10^{12} \mathrm{e}^{-} \mathrm{cm}^{-2}\right.$, Fig. 2) and alumina active site density $\left(\sim 5 \cdot 10^{13}\right.$ sites $\left.\mathrm{cm}^{-2}\right)$.

Enhancing charge depletion at the active site for more acidic solid materials beyond the current catalytic condenser requires application of higher voltages, higher quality insulating (e.g., $\mathrm{HfO}_{2}$ ) films, or alternative device design. The considered alumina/graphene catalytic condenser $(70 \mathrm{~nm}$ $\mathrm{HfO}_{2}$ ) stabilizes charge in a $4 \mathrm{~nm}$ alumina film. Thicker alumina films reduce the capability for electronically altering the surface acid site strength, as shown by experiments with a $\sim 50 \mathrm{~nm}$ alumina film on the alumina/graphene/ $/ \mathrm{HfO}_{2} / \mathrm{p}-\mathrm{Si}$ catalytic condenser (Fig. S20); alternatively, thinner alumina films can potentially stabilize more charge per active site. Additionally, application of a higher voltage $\mathrm{V}_{\mathrm{CAT}}$ to the considered catalytic condenser (4 $\mathrm{nm}$ alumina film, graphene, $70 \mathrm{~nm} \mathrm{HfO}_{2}$ ) is problematic, since leakage current through the device becomes substantial; this concept can be extended to higher voltages by further improving the quality of the $\mathrm{HfO}_{2}$ film by reduction of pinholes, for example. As a third design option, the condenser design can utilize different insulating materials such as higher- $k$ dielectric materials (e.g., ferroelectrics) in thinner $(<70 \mathrm{~nm})$ insulating layers, both of which yield higher device capacitance and charge accumulation at the active site.

The electronically tunable nature of the alumina site in the catalytic condenser offers new capability for enhancing catalysis. While catalytic materials are conventionally tuned by precise synthesis of catalyst active sites, the limitation of material composition and stable structures only allows discrete options in active site design. In contrast, the bias potentials $\left(\mathrm{V}_{\mathrm{CAT}}\right)$ to the active layer of a catalytic condenser can span a continuum of voltage bias values. Precise selection of the active site electronic state can potentially allow for optimization of selectivity to products or maximization of catalytic rate.

Finally, the catalytic condenser design also allows for the capability to program catalysts that operate under continuous forced dynamic conditions ${ }^{[1,42]}$. Oscillation of the catalyst state yielding variation in the binding energy of the reactants and products has been predicted to increase the catalytic rate orders of magnitude at resonance conditions ${ }^{[43]}$, control the extent of reaction $^{[44]}$, and allow for significant selectivity control to products ${ }^{[45]}$. Resonance conditions of maximum catalytic rate are predicted to occur at varying frequencies depending on the extent of reactant binding energy variation $(\triangle \mathrm{BE})$, the composition and structure of the active site, and the nature of the chemistry of interest; but simulations have predicted catalytic resonance to occur for 
frequencies of $\sim 100 \mathrm{~Hz}$ up to $1 \mathrm{MHz}^{[42,43,44,45,46,47]}$. For the considered catalytic condenser device, this requires depleting and replacing the electrons in the active sites at a comparable frequency. The time constant associated with electrons moving across the bare graphene surface (length of $1 \mathrm{~cm}$ ) on $\mathrm{HfO}_{2}$ was calculated to be $625 \mu \mathrm{s}$ using the electron mobility (1600 $\left.\mathrm{cm}^{2} \mathrm{~V}^{-1} \mathrm{~s}^{-1}\right)$, corresponding to a device operational frequency of $1600 \mathrm{~Hz}$. Upon adding the alumina layer to the graphene device, electron mobility in the full device still permitted operation at $\sim 1000 \mathrm{~Hz}$ (see Supporting Information for the full calculations). The capability to program a repeating electronic perturbation of the catalyst (e.g., sinusoidal waveform of voltage bias) surface at high frequency $(>1000 \mathrm{~Hz})$ and amplitude $(\Delta \mathrm{BE}$ $>0.4 \mathrm{eV}$ ) opens a new possibility for catalysts that change at the time scale of the catalytic turnover frequency.

Conclusions. A $1.0 \mathrm{~cm}^{2}$ multilayer catalytic condenser device was synthesized by sequential deposition of $70 \mathrm{~nm}$ of amorphous $\mathrm{HfO}_{2}$ on a conductive p-type Si wafer, followed by transfer of a graphene layer, on top of which was grown a $4 \mathrm{~nm}$ amorphous layer of alumina catalyst. The $\mathrm{HfO}_{2}$ layer remained amorphous below $400{ }^{\circ} \mathrm{C}$ with a dielectric constant of 26, providing a capacitance of

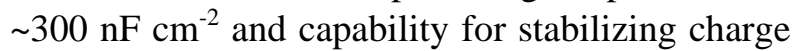
up to $\sim 5 \cdot 10^{12} \mathrm{e}^{-} / \mathrm{cm}^{2}$. Comparison of capacitance between two devices, one with graphene only and the other with alumina on graphene, indicated that the majority of the induced charge in the alumina/graphene device was actually in the aluminum oxide film. The alumina/graphene catalytic condenser with $\mathrm{HfO}_{2}$ insulator was observed to be conductive by scanning-tunneling microscopy with gap states located $\sim 0.3 \mathrm{eV}$ below the Fermi level as determined by ultra-violet photoelectron spectroscopy. Dehydration of isopropanol on the alumina/graphene catalytic condenser top surface exhibited variable peak temperature of propene formation in temperature programmed surface reaction experiments. Propene

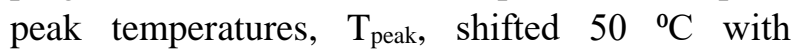
different potential biases $\left(\mathrm{V}_{\mathrm{CAT}}\right.$ of $\left.0,+1,+2,+3 \mathrm{~V}\right)$, corresponding to a difference in activation energy of $\Delta \mathrm{E}_{\mathrm{a}}=16 \mathrm{~kJ} \mathrm{~mol}^{-1}(0.17 \mathrm{eV})$. Enhanced Lewis acidity with positive $\mathrm{V}_{\mathrm{CAT}}$ bias was consistent with increased isopropanol binding energy and reactivity to propene due to lower activation barriers as electrons were depleted at the surface active site, as calculated via density functional theory. The performance of the alumina/graphene catalytic condenser under bias indicates substantial potential for improving catalytic activity and tuning thermocatalytic selectivity, while oscillation of the alumina/graphene catalytic condenser via applied potential with large variation in surface acidity at frequencies as high as $1000 \mathrm{~Hz}$ achieves the conditions required for catalytic resonance.

Methods. The alumina-graphene catalytic condenser was synthesized and then evaluated by electron microscopy, spectroscopy, experimental catalytic reaction, atomic force microscopy, and computation. Full research methods are described in the supporting information.

Catalytic Condenser Fabrication. Devices were fabricated on a p-type Si substrate (WaferPro) using sequential deposition of $\mathrm{HfO}_{2}$, graphene, an $\mathrm{Au} / \mathrm{Ti}$ contact, and a thin amorphous alumina active layer. $\mathrm{HfO}_{2}$ and alumina layers were grown within a flow-type atomic layer deposition (ALD) reactor (Kurt J Lesker ALD-150 LE). The 70-nm $\mathrm{HfO}_{2}$ dielectric layer was grown via $500 \mathrm{HfO}_{2} \mathrm{ALD}$ cycles at $100{ }^{\circ} \mathrm{C}$. Each $\mathrm{HfO}_{2}$ ALD cycle was comprised of alternating exposures to Tetrakis(dimethylamido) hafnium (TDMAH, $\mathrm{t}=13$ $\mathrm{ms})$ and $\mathrm{H}_{2} \mathrm{O}(\mathrm{t}=200 \mathrm{~ms})$ with purges in between each step. Graphene, obtained commercially on a $\mathrm{Cu}$ foil (Graphene Supermarket), was transferred on top of the $\mathrm{HfO}_{2}$ layer using an existing PMMAbased method ${ }^{[21,22]}$ and retained electrical conductivity (Fig. S10). A small area $\left(0.01 \mathrm{~cm}^{2}\right)$ contact ( $\mathrm{Au} / \mathrm{Ti}, 45 \mathrm{~nm} / 5 \mathrm{~nm}$ ) was then grown on the graphene by e-beam evaporation through a shadow-mask. Finally, the catalytic alumina layer of $4-\mathrm{nm}$, based on $\mathrm{Al}_{2} \mathrm{O}_{3}$ growth rate, was deposited via $50 \mathrm{Al}_{2} \mathrm{O}_{3}$ ALD cycles at $100{ }^{\circ} \mathrm{C}$ using the same flow-type ALD reactor as above. Each $\mathrm{Al}_{2} \mathrm{O}_{3}$ ALD cycle was comprised of alternating exposures to trimethylaluminum (TMA, $\mathrm{t}=12 \mathrm{~ms}$ ) and $\mathrm{H}_{2} \mathrm{O}(\mathrm{t}=10,000 \mathrm{~ms})$ with purges in between 
each step. Devices retained their structure after experimental reaction trials (Fig. S23 and S24).

STEM, TEM and SEM analysis. Focused Ion Beam (FEI Helios NanoLab G4 dual-beam) was employed to prepare an electron-transparent crosssectional lamella for TEM and STEM study. An am-C layer $(\sim 50 \mathrm{~nm})$ was deposited on the device using sputter coater as a protection layer. Additional protection layer consisted of am-C (2 $\mu \mathrm{m})$ and $\mathrm{Pt}(2 \mu \mathrm{m})$ was deposited on the region of interest. FIB was operated at $30 \mathrm{kV}$ with $5 \mathrm{kV}$ electron beam. Conventional TEM, HAADFSTEM images and STEM-EDX elemental maps were obtained using Thermo Fisher Talos F200X G2 S-TEM equipped with Super-X energydispersive X-ray spectrometer. TEM and HAADFSTEM images were acquired at $200 \mathrm{kV}$. Camera length was set to be $125 \mathrm{~mm}$ with probe convergence angle of $10.5 \mathrm{mrad}$ for HAADFSTEM imaging. For EDX-mapping, beam current ranged from $300 \mathrm{pA}$ to $400 \mathrm{pA}$. SEM images and SEM-EDX maps were acquired using JEOL 6500 FEG-SEM. SEM images and SEM-EDX elemental maps were obtained under $5 \mathrm{kV}$. The EDX maps were quantified using the Aztec EDX analytical system (Oxford Instruments). For more details, refer to the Supporting Information.

Spectroscopy. Raman spectra were obtained from a Witec Alpha 300R confocal Raman microscope equipped with a UHTS300 spectrometer and a DV401 CCD detector. XRD patterns were recorded on a Bruker D8 Discover 2D diffractometer equipped with a Co $\mathrm{K} \alpha$ source $(\lambda=0.179 \mathrm{~nm})$. Full details available in the Supporting Information. XPS measurements were performed on a PHI Versa Probe III XPS system (ULVAC-PHI) using a monochromated $\mathrm{Al} \mathrm{K \alpha} \mathrm{X}$ ray source $(1486.6 \mathrm{eV})$. The base pressure was $4.0 \bullet 10^{-8} \mathrm{~Pa}$. During data collection, the pressure was ca. $2.0 \bullet 10^{-6} \mathrm{~Pa}$. All samples were mounted on the holder using a $\mathrm{Cu}$ pin. The measurements were conducted using an X-ray spot size of $0.1 \times 0.1 \mathrm{~mm}^{2}$ with a power of $25 \mathrm{~W}$ under $15 \mathrm{kV}$. The survey spectra were measured using $280 \mathrm{eV}$ pass energy and $1.0 \mathrm{eV} / \mathrm{step}$. The data was processed with Multipak software. UPS measurements were performed on the same XPS system using ultraviolet radiation from an ionized He source. The base pressure was $8.0 \bullet 10^{-7} \mathrm{~Pa}$ during measurement. The measurement spot size was approximately $6 \times 6$ $\mathrm{mm}^{2}$. Survey spectra were measured using $1.3 \mathrm{eV}$ pass energy and $0.025 \mathrm{eV}$ per step.

Temperature Programmed Surface Reaction (TPSR). Temperature programmed surface reaction was carried out in a customized ultra-high vacuum chamber reactor with isopropanol dehydration to propene as a reaction probe. The propene signal was monitored during the temperature ramp of the device while voltage was applied. Full description of the equipment setup, device handling, temperature calibration, and the full TPSR process can be found in the supporting information.

Atomic Force Microscopy (AFM). AFM measurements were performed using a Bruker Dimension Icon closed-loop atomic force microscope using the force-modulation technique with a force feedback setpoint of $581 \mathrm{pN}$. Probes were standard $\mathrm{Si}$ cantilevers calibrated before measurement with a spring constant of $0.674 \mathrm{~N} \mathrm{~m}^{-1}$.

Scanning Tunneling Microscopy (STM). STM measurements were made using an Omicron lowtemperature scanning tunneling microscope (LTSTM) at room temperature under a vacuum of $8.0 \bullet 10^{-10} \mathrm{mBar}$ using a $\mathrm{Pt} / \mathrm{Ir}$ probe. Samples were grounded through the alumina/graphene film. Differential spectra were collected from a Stanford Research Systems lock-in amplifier with a modulation signal of $\mathrm{V}_{\text {mod }}=10 \mathrm{mV}$ and $\mathrm{f}_{\text {mod }}=10$ $\mathrm{kHz}$. Data were processed using the WSxM software.

Computation. First principles periodic density functional theory (DFT) calculations were carried out to determine the binding energies and the activation barriers using the plane wave implementation of DFT in the Vienna ab initio simulation package (VASP) $)^{[48,49,50]}$. The generalized gradient approximation form of the Perdew, Burke, and Ernzerhof (PBE) functional was used to determine the energies, and dispersion corrections were included via the D3 corrections developed by Grimme ${ }^{[51,52]}$. An energy cutoff of $400 \mathrm{eV}$ was used in the construction of plane waves, and projector augmented wave potentials (PAW) were used to model interactions between core and 
valence electrons ${ }^{[3,54]}$. A periodic slab of $2 \times 2$ times the primitive unit cell and consisting of seven layers of $\gamma-\mathrm{Al}_{2} \mathrm{O}_{3}$ (100) was used for all calculations, with the bottom-most layer held fixed. All electronic energies were converged to within a tolerance of $10^{-6} \mathrm{eV}$ using a $2 \times 1 \times 1$ gamma-centered $k$-point grid. The geometries of the structures were optimized until the maximum force on each atom was calculated to be less than $0.05 \mathrm{eV} \AA^{-1}$. Additional details are provided in the Supporting Information.

Acknowledgements. We acknowledge financial support from the U.S. Department of Energy, Basic Energy Sciences Catalysis program (DESC0021163) and the National Science Foundation CBET-Catalysis program (Award \#1937641). S.R.G. was supported by the National Science Foundation Graduate Research Fellowship under Grant CON-75851, Project 00074041. S.G. and K.A.M. were supported by University of Minnesota (UMN) MRSEC program DMR-2011401. The electron microscopy work was carried out in the Characterization Facility of University of Minnesota supported in part by the NSF through the UMN MRSEC. Thank you to Keith and Amy Steva for their generous support of this project through their donor advised fund. We thank Professor Aditya Bhan for helpful conversations.

Keywords. Catalysis, Dehydration, Alumina, Catalytic Condenser, Graphene

Supporting Information. The Supporting Information is available free of charge at $\mathrm{X}$ and contains: Catalytic condenser fabrication methods, TEM and SEM characterization, reactor setup, reaction process and control experiments, electronic characterization, X-Ray diffraction, Redhead analysis of temperature programmed surface reactions, and additional references ${ }^{[55,56]}$.

ORCID. Tzia Ming Onn (0000-0002-7523-0746), Sallye R. Gathmann (0000-0002-1001-6650), Yuxin Wang (0000-0002-6590-6087), Roshan A. Patel (0000-0003-4826-1536), Silu Guo (00000001-9930-6242), Han Chen (0000-0002-8262-
4196), Jimmy K. Soeherman (0000-0001-97648310), Phil Christopher (0000-0002-4898-5510), Geoffrey Rojas (0000-0002-4458-9844), K. Andre Mkhoyan (0000-0003-3568-5452), Matthew Neurock (0000-0003-1458-7837), Omar Abdelrahman (0000-0001-6023-857X), C. Daniel Frisbie (0000-0002-4735-2228), Paul Dauenhauer (0000-0001-5810-1953)

\section{References}

(1) Shetty, M.; Walton, A.; Gathmann, S. R.; Ardagh, M. A.; Gopeesingh, J.; Resasco, J.; Birol, T.; Zhang, Q.; Tsapatsis, M.; Vlachos, D. G.; Christopher, P.; Frisbie, C. D.; Abdelrahman, O. A.; Dauenhauer, P. J. The Catalytic Mechanics of Dynamic Surfaces: Stimulating Methods for Promoting Catalytic Resonance. ACS Catal. 2020, 12666-12695. https://doi.org/10.1021/acscatal.0c03336.

(2) Alves, L. F. S.; Lefranc, P.; Jeannin, P. O.; Sarrazin, B. Review on SiC-MOSFET Devices and Associated Gate Drivers. Proc. IEEE Int. Conf. Ind. Technol. 2018, 2018-Febru, 824829.

https://doi.org/10.1109/ICIT.2018.8352284.

(3) Kim, C. H.; Frisbie, C. D. Field Effect Modulation of Outer-Sphere Electrochemistry at Back-Gated, Ultrathin $\mathrm{ZnO}$ Electrodes. $J$. Am. Chem. Soc. 2016, 138 (23), 7220-7223. https://doi.org/10.1021/jacs.6b02547.

(4) Wang, Y.; Kim, C. H.; Yoo, Y.; Johns, J. E.; Frisbie, C. D. Field Effect Modulation of Heterogeneous Charge Transfer Kinetics at Back-Gated Two-Dimensional MoS2 Electrodes. Nano Lett. 2017, 17 (12), 75867592. https://doi.org/10.1021/acs.nanolett.7b03564.

(5) Wang, Y.; Udyavara, S.; Neurock, M.; Daniel Frisbie, C. Field Effect Modulation of Electrocatalytic Hydrogen Evolution at BackGated Two-Dimensional MoS2 Electrodes. Nano Lett. 2019, 19 (9), 6118-6123. https://doi.org/10.1021/acs.nanolett.9b02079.

(6) Wu, Y.; Ringe, S.; Wu, C. L.; Chen, W.; Yang, A.; Chen, H.; Tang, M.; Zhou, G.; Hwang, H. Y.; Chan, K.; Cui, Y. A Two-Dimensional MoS2 Catalysis Transistor by Solid-State Ion Gating Manipulation and Adjustment (SIGMA). Nano Lett. 2019, 19 (10), 7293 7300 . https://doi.org/10.1021/acs.nanolett.9b02888.

(7) Shi, B.; Davis, B. H. Alcohol Dehydration: Mechanism of Ether Formation Using an Alumina Catalyst. J. Catal. 1995, 157 (2), 359- 
(8)

367. https://doi.org/10.1006/jcat.1995.1301.

Narayanan, C. R.; Srinivasan, S.; Datye, A. K.; Gorte, R.; Biaglow, A. The Effect of Alumina Structure on Surface Sites for Alcohol Dehydration. J. Catal. 1992, 138 (2), 659-674. https://doi.org/10.1016/0021-9517(92)90314-8. de Boer, J. H.; Fahim, R. B.; Linsen, B. G.; Visseren, W. J.; de Vleesschauwer, W. F. N. M. Kinetics of the Dehydration of Alcohol on Alumina. J. Catal. 1967, 7 (2), 163-172. https://doi.org/10.1016/0021-9517(67)90055-3.

(10) Pines, H.; Haag, W. O. Alumina: Catalyst and Support. I. Alumina, Its Intrinsic Acidity and Catalytic Activity. J. Am. Chem. Soc. 1960, 82 (10), 2471-2483. https://doi.org/10.1021/ja01495a021.

(11) Trueba, M.; Trasatti, S. P. $\gamma$-Alumina as a Support for Catalysts: A Review of Fundamental Aspects. Eur. J. Inorg. Chem. 2005, No. 17, 3393-3403. https://doi.org/10.1002/ejic.200500348.

(12) Arai, H.; Take, J. I.; Saito, Y.; Yoneda, Y. Ethanol Dehydration on Alumina Catalysts. I. The Thermal Desorption of Surface Compounds. J. Catal. 1967, 9 (2), 146-153. https://doi.org/10.1016/0021-9517(67)90193-5.

(13) Roy, S.; Mpourmpakis, G.; Hong, D. Y.; Vlachos, D. G.; Bhan, A.; Gorte, R. J. Mechanistic Study of Alcohol Dehydration on $\gamma$-Al 2O 3. ACS Catal. 2012, 2 (9), 1846-1853. https://doi.org/10.1021/cs300176d.

(14) Balzarotti, A.; Bianconi, A. Electronic Structure of Aluminium Oxide as Determined by X-Ray Photoemission. Phys. Status Solidi 1976, 76 (2), 689-694.

https://doi.org/10.1002/pssb.2220760230.

(15) Ealet, B.; Elyakhloufi, M. H.; Gillet, E.; Ricci, M. Electronic and Crystallographic Structure of $\gamma$-Alumina Thin Films. Thin Solid Films 1994, 250 (1-2), 92-100. https://doi.org/10.1016/0040-6090(94)90171-6.

(16) Jimenéz-Gonzaléz, A.; Schmeisser, D. Preparation and Spectroscopic Characterization of $\gamma$-Al2O3 Thin Films. Surf. Sci. 1991, 250 (13), 59-70. https://doi.org/10.1016/00396028(91)90709-2.

(17) Jenness, G. R.; Christiansen, M. A.; Caratzoulas, S.; Vlachos, D. G.; Gorte, R. J. Site-Dependent Lewis Acidity of $\gamma$-Al2O3 and Its Impact on Ethanol Dehydration and Etherification. J. Phys. Chem. C 2014, 118 (24), 12899-12907. https://doi.org/10.1021/jp5028349.

(18) Hu, J. Z.; Xu, S.; Kwak, J. H.; Hu, M. Y.; Wan, C.; Zhao, Z.; Szanyi, J.; Bao, X.; Han, X.; Wang, Y.; Peden, C. H. F. High Field 27Al
MAS NMR and TPD Studies of Active Sites in Ethanol Dehydration Using Thermally Treated Transitional Aluminas as Catalysts. J. Catal. 2016, 336, 85-93. https://doi.org/10.1016/j.jcat.2016.01.006.

(19) Blaschke, D.; Munnik, F.; Grenzer, J.; Rebohle, L.; Schmidt, H.; Zahn, P.; Gemming, S. A Correlation Study of Layer Growth Rate, Thickness Uniformity, Stoichiometry, and Hydrogen Impurity Level in $\mathrm{HfO} 2$ Thin Films Grown by ALD between $100^{\circ} \mathrm{C}$ and $350^{\circ} \mathrm{C}$. Appl. Surf. Sci. 2020, 506. https://doi.org/10.1016/j.apsusc.2019.144188.

(20) Gierałtowska, S.; Sztenkiel, D.; Guziewicz, E.; Godlewski, M.; Łuka, G.; Witkowski, B. S.; Wachnicki, L.; Łusakowska, E.; Dietl, T.; Sawicki, M. Properties and Characterization of ALD Grown Dielectric Oxides for MIS Structures. Acta Phys. Pol. A 2011, 119 (5), 692-695.

https://doi.org/10.12693/APhysPolA.119.692.

(21) Suk, J. W.; Kitt, A.; Magnuson, C. W.; Hao, Y.; Ahmed, S.; An, J.; Swan, A. K.; Goldberg, B. B.; Ruoff, R. S. Transfer of CVD-Grown Monolayer Graphene onto Arbitrary Substrates. ACS Nano 2011, 5 (9), 6916-6924. https://doi.org/10.1021/nn201207c.

(22) Reina, A.; Son, H.; Jiao, L.; Fan, B.; Dresselhaus, M. S.; Liu, Z. F.; Kong, J. Transferring and Identification of Single- and Few-Layer Graphene on Arbitrary Substrates. $J$. Phys. Chem. C 2008, 112 (46), 17741-17744. https://doi.org/10.1021/jp807380s.

(23) Böscke, T. S.; Govindarajan, S.; Kirsch, P. D.; Hung, P. Y.; Krug, C.; Lee, B. H.; Heitmann, J.; Schröder, U.; Pant, G.; Gnade, B. E.; Krautschneider, W. H. Stabilization of Higher$\kappa$ Tetragonal $\mathrm{Hf} \mathrm{O} 2$ by Si O2 Admixture Enabling Thermally Stable Metal-InsulatorMetal Capacitors. Appl. Phys. Lett. 2007, 91 (7). https://doi.org/10.1063/1.2771376.

(24) Böscke, T. S.; Govindarajan, S.; Fachmann, C.; Heitmann, J.; Avellán, A.; Schröder, U.; Kudelka, S.; Kirsch, P. D.; Krug, C.; Hung, P. Y.; Song, S. C.; Ju, B. S.; Price, J.; Pant, G.; Gnade, B. E.; Krautschneider, W.; Lee, B. H.; Jammy, R. Tetragonal Phase Stabilization by Doping as an Enabler of Thermally Stable HfO2 Based MIM and MIS Capacitors for Sub 50nm Deep Trench DRAM. Tech. Dig. - Int. Electron Devices Meet. IEDM 2006. https://doi.org/10.1109/IEDM.2006.347011. Vervuurt, R. H. J.; Karasulu, B.; Verheijen, M. A.; Kessels, W. M. M.; Bol, A. A. Uniform Atomic Layer Deposition of Al2O3 on Graphene by Reversible Hydrogen Plasma 
Functionalization. Chem. Mater. 2017, 29 (5), 2090-2100.

https://doi.org/10.1021/acs.chemmater.6b04368

(26) Schilirò, E.; Lo Nigro, R.; Roccaforte, F.; Giannazzo, F. Substrate-Driven Atomic Layer Deposition of High- $\kappa$ Dielectrics on $2 \mathrm{~d}$ Materials. Appl. Sci. 2021, 11 (22). https://doi.org/10.3390/app112211052. Zhang, Y.; Qiu, Z.; Cheng, X.; Xie, H.; Wang, H.; Xie, X.; Yu, Y.; Liu, R. Direct Growth of High-Quality A12O3 Dielectric on Graphene Layers by Low-Temperature H2O-Based ALD. J. Phys. D. Appl. Phys. 2014, 47 (5). https://doi.org/10.1088/00223727/47/5/055106.

(28) Wang, M.; Huang, M.; Luo, D.; Li, Y.; Choe, M.; Seong, W. K.; Kim, M.; Jin, S.; Wang, M.; Chatterjee, S.; Kwon, Y.; Lee, Z.; Ruoff, R. S. Single-Crystal, Large-Area, Fold-Free Monolayer Graphene. Nature 2021, 596 (7873), 519-524. https://doi.org/10.1038/s41586-02103753-3.

(29) Johnson, R. W.; Hultqvist, A.; Bent, S. F. A Brief Review of Atomic Layer Deposition: From Fundamentals to Applications. Mater. Today 2014, 17 (5), 236-246. https://doi.org/10.1016/j.mattod.2014.04.026.

(30) Jeong, S. J.; Gu, Y.; Heo, J.; Yang, J.; Lee, C. S.; Lee, M. H.; Lee, Y.; Kim, H.; Park, S.; Hwang, S. Thickness Scaling of Atomic-LayerDeposited HfO2 Films and Their Application to Wafer-Scale Graphene Tunnelling Transistors. Sci. Rep. 2016, 6 . https://doi.org/10.1038/srep20907.

(31) Jung, H. S.; Jang, J. H.; Cho, D. Y.; Jeon, S. H.; Kim, H. K.; Lee, S. Y.; Hwang, C. S. The Effects of Postdeposition Annealing on the Crystallization and Electrical Characteristics of $\mathrm{HfO} 2$ and $\mathrm{ZrO} 2$ Gate Dielectrics. Electrochem. Solid-State Lett. 2011, 14 (5). https://doi.org/10.1149/1.3551460.

(32) Xie, Y.; Ma, Z.; Su, Y.; Liu, Y.; Liu, L.; Zhao, H.; Zhou, J.; Zhang, Z.; Li, J.; Xie, E. The Influence of Mixed Phases on Optical Properties of HfO2 Thin Films Prepared by Thermal Oxidation. J. Mater. Res. 2011, 26 (1), 50-54. https://doi.org/10.1557/jmr.2010.61.

(33) He, G.; Liu, M.; Zhu, L. Q.; Chang, M.; Fang, Q.; Zhang, L. D. Effect of Postdeposition Annealing on the Thermal Stability and Structural Characteristics of Sputtered HfO2 Films on Si (1 0 0). Surf. Sci. 2005, 576 (1-3), 67-75. https://doi.org/10.1016/j.susc.2004.11.042.
Y.; Ou, S. L.; Chen, S. Y.; Huang, W.; Zhu, W. Z.; Xiong, F. B.; Zhang, S. TemperatureDependent HfO2/Si Interface Structural Evolution and Its Mechanism. Nanoscale Res. Lett. 2019, 14. https://doi.org/10.1186/s11671019-2915-0.

(35) Vargas, M.; Murphy, N. R.; Ramana, C. V. Structure and Optical Properties of Nanocrystalline Hafnium Oxide Thin Films. Opt. Mater. (Amst). 2014, 37 (C), 621-628. https://doi.org/10.1016/j.optmat.2014.08.005.

(36) Moon, J. Y.; Kim, M.; Kim, S. Il; Xu, S.; Choi, J. H.; Whang, D.; Watanabe, K.; Taniguchi, T.; Park, D. S.; Seo, J.; Cho, S. H.; Son, S. K.; Lee, J. H. Layer-Engineered Large-Area Exfoliation of Graphene. Sci. Adv. 2020, 6 (44).

https://doi.org/10.1126/sciadv.abc6601.

(37) Redhead, P. A. Thermal Desorption of Gases. Vacuum 1962, 12 (4), 203-211. https://doi.org/10.1016/0042-207X(62)90978-8. Kostestkyy, P.; Yu, J.; Gorte, R. J.; Mpourmpakis, G. Structure-Activity Relationships on Metal-Oxides: Alcohol Dehydration. Catal. Sci. Technol. 2014, 4 (11), 3861-3869. https://doi.org/10.1039/c4cy00632a.

(39) Guillaume, D.; Gautier, S.; Despujol, I.; Alario, F.; Beccat, P. Characterization of Acid Sites on $\gamma$-Alumina and Chlorinated $\gamma$-Alumina By31P NMR of Adsorbed Trimethylphosphine. Catal. Letters 1997, 43 (3), 213-218. https://doi.org/10.1023/a:1018955025955.

(40) Zhai, Y.; Pierre, D.; Si, R.; Deng, W.; Ferrin, P.; Nilekar, A. U.; Peng, G.; Herron, J. A.; Bell, D. C.; Saltsburg, H.; Mavrikakis, M.; FlytzaniStephanopoulos, M. Alkali-Stabilized Pt-OHx Species Catalyze Low-Temperature Water-Gas Shift Reactions. Science (80-. ). 2010, 329 (5999), 1633-1636. https://doi.org/10.1126/science.1192449.

(41) Kwak, J. H.; Mei, D.; Peden, C. H. F.; Rousseau, R.; Szanyi, J. (100) Facets of $\gamma$ Al2O3: The Active Surfaces for Alcohol Dehydration Reactions. Catal. Letters 2011, 141 (5), 649-655. https://doi.org/10.1007/s10562-010-0496-8. (42) Gathmann, S. R.; Ardagh, M. A.; Dauenhauer, P. J. Catalytic Resonance Theory: Negative Dynamic Surfaces for Programmable Catalysts. Chem Catal. 2022. https://doi.org/10.1016/j.checat.2021.12.006. Ardagh, M. A.; Abdelrahman, O. A.; Dauenhauer, P. J. Principles of Dynamic Heterogeneous Catalysis: Surface Resonance and Turnover Frequency Response. ACS Catal. 2019, 9 (8), 6929-6937. 
Ardagh, M. A.; Birol, T.; Zhang, Q.;

Abdelrahman, O. A.; Dauenhauer, P. J.

Catalytic Resonance Theory: SuperVolcanoes,

Catalytic Molecular Pumps, and Oscillatory

Steady State. Catal. Sci. Technol. 2019, 9 (18),

5058-5076.

https://doi.org/10.1039/c9cy01543d.

(45) Dauenhauer, P. J.; Ardagh, M. A.; Shetty, M.;

Kuznetsov, A.; Zhang, Q.; Christopher, P.;

Vlachos, D. G.; Abdelrahman, O. A. Catalytic

Resonance Theory: Parallel Reaction Pathway

Control. Chem. Sci. 2020, 11 (13), 3501-3510.

https://doi.org/10.1039/c9sc06140a.

(46) Gopeesingh, J.; Ardagh, M. A.; Shetty, M.;

Burke, S. T.; Dauenhauer, P. J.; Abdelrahman, O. A. Resonance-Promoted Formic Acid Oxidation via Dynamic Electrocatalytic Modulation. ACS Catal. 2020, 10 (17), 99329942. https://doi.org/10.1021/acscatal.0c02201.

(47) R., W. G.; Shizhong, L.; J., D. P.; G., V. D.

Catalytic Resonance of Ammonia Synthesis by Simulated Dynamic Ruthenium Crystal Strain. Sci. Adv. 2022, 8 (4), eabl6576.

https://doi.org/10.1126/sciadv.abl6576.

(48) Kresse, G.; Hafner, J. Ab Initio Molecular Dynamics for Liquid Metals. Phys. Rev. B 1993, 47 (1), 558-561. https://doi.org/10.1103/PhysRevB.47.558.

Kresse, G.; Hafner, J. Ab Initio MolecularDynamics Simulation of the Liquid-Metal-Amorphous-Semiconductor Transition in Germanium. Phys. Rev. B 1994, 49 (20), 14251-14269. https://doi.org/10.1103/PhysRevB.49.14251.

(50) Kresse, G.; Furthmüller, J. Efficient Iterative Schemes for Ab Initio Total-Energy

Calculations Using a Plane-Wave Basis Set. Phys. Rev. B - Condens. Matter Mater. Phys. 1996, 54 (16), 11169-11186.

https://doi.org/10.1103/PhysRevB.54.11169.

(51) Perdew, J. P.; Burke, K.; Ernzerhof, M. Generalized Gradient Approximation Made Simple. Phys. Rev. Lett. 1996, 77 (18), 38653868. https://doi.org/10.1103/PhysRevLett.77.3865.

(52) Grimme, S.; Antony, J.; Ehrlich, S.; Krieg, H. A Consistent and Accurate Ab Initio Parametrization of Density Functional Dispersion Correction (DFT-D) for the 94 Elements H-Pu. J. Chem. Phys. 2010, 132 (15). https://doi.org/10.1063/1.3382344.

(53) Joubert, D. From Ultrasoft Pseudopotentials to the Projector Augmented-Wave Method. Phys. Rev. B - Condens. Matter Mater. Phys. 1999, 59 (3), 1758-1775.
https://doi.org/10.1103/PhysRevB.59.1758. Blöchl, P. E. Projector Augmented-Wave Method. Phys. Rev. B 1994, 50 (24), 1795317979. https://doi.org/10.1103/PhysRevB.50.17953. Blanck, S.; Martí, C.; Loehlé, S.; Steinmann, S. N.; Michel, C. (Dis)Similarities of Adsorption of Diverse Functional Groups over Alumina and Hematite Depending on the Surface State. J. Chem. Phys. 2021, 154 (8). https://doi.org/10.1063/5.0038412.

Henkelman, G.; Jónsson, H. Improved Tangent Estimate in the Nudged Elastic Band Method for Finding Minimum Energy Paths and Saddle Points. J. Chem. Phys. 2000, 113 (22), 99789985. https://doi.org/10.1063/1.1323224. 


\section{SUPPORTING INFORMATION}

\section{Alumina Graphene Catalytic Condenser for Programmable Solid Acids}

Tzia Ming Onn ${ }^{1}$, Sallye R. Gathmann ${ }^{1}$, Yuxin Wang ${ }^{1}$, Roshan Patel ${ }^{1}$, Silu Guo ${ }^{1}$, Han Chen ${ }^{4}$, Jimmy Soeherman ${ }^{1}$, Phillip Christopher ${ }^{2}$, Geoffrey Rojas ${ }^{3}$, K. Andre Mkhoyan ${ }^{1}$, Matthew Neurock $^{1}$, Omar A. Abdelrahman ${ }^{4}$, C. Daniel Frisbie ${ }^{1}$, Paul J. Dauenhauer ${ }^{1 *}$

${ }^{1}$ Department of Chemical Engineering \& Materials Science, University of Minnesota, 421 Washington Ave. SE, Minneapolis, MN, 55455, USA

${ }^{2}$ Department of Chemical Engineering, University of California, Santa Barbara, 3335 Engineering II, Santa Barbara, CA 93106

${ }^{3}$ Characterization Facility, University of Minnesota, 100 Union Street SE, Minneapolis, MN 55455, USA.

${ }^{4}$ Department of Chemical Engineering, University of Massachusetts Amherst, 686 N. Pleasant Street, Amherst, MA, 01003

*Corresponding Author: hauer@umn.edu

\section{Table of Contents}

$\begin{array}{ll}\text { Device Fabrication } & \text { S2 }\end{array}$

Characterization Methodology - Catalytic Condenser $\quad$ S3

$\begin{array}{ll}\text { Supplementary TEM, SEM, EDX characterization } & \text { S7 }\end{array}$

Supplementary UPS Measurement (Control) S9

Electronic Characterization - Catalytic Condenser $\quad$ S10

Temperature Programmed Surface Reaction Setup and Process $\quad$ S13

$\begin{array}{ll}\text { TPSR Mass Fragment Analysis } & \text { S21 }\end{array}$

$\begin{array}{ll}\text { TPSR Control Experiments } & \text { S22 }\end{array}$

$\begin{array}{ll}\text { Surface Temperature Measurements with Infrared Camera } & \text { S25 }\end{array}$

$\begin{array}{ll}\text { Post TPSR Device Characterization } & \text { S26 }\end{array}$

$\begin{array}{ll}\text { Powder TPSR: Zirconia, Titania, Alumina } & \text { S28 }\end{array}$

Data Processing - Temperature Programmed Surface Reaction $\quad$ S29

Calculations - Dielectric Constant, Capacitance, Charge S31

$\begin{array}{ll}\text { Calculations - Device Speed } & \text { S33 }\end{array}$

Additional description of computational methods $\quad$ S34

Effect of charge modulation on energetics for isopropanol dehydration $\quad$ S35

$\begin{array}{ll}\text { Supporting Information References } & \text { S38 }\end{array}$ 


\section{Device Fabrication:}

Si wafer (WaferPro, Item \#C04014, B-doped, <1-1-0>) was used as the substrate for all the device fabrication. A schematic of the fabrication process is shown in Fig. S1. Preliminary cleaning on the substrate involved repeated washing with acetone, methanol, and isopropanol for three times before drying with $\mathrm{N}_{2}$. First, 500 ALD cycles of dielectric $\mathrm{HfO}_{2}$ film was deposited on the Si substrate at $100^{\circ} \mathrm{C}$ using a flow-reactor based ALD system (Equipment: KJL ALD-150 LE) and the precursor, Tetrakis(dimethylamido)hafnium (IV) (Sigma Aldrich CAS Number: 1978268-4). Each $\mathrm{HfO}_{2}$ ALD cycle comprises of a precursor exposure $(\mathrm{t}=13 \mathrm{~ms})$, a purge $(\mathrm{t}=1000$ $\mathrm{ms}$ ), an oxidant exposure (oxidant: $\mathrm{H}_{2} \mathrm{O}, \mathrm{t}=200 \mathrm{~ms}$ ), and a purge $(\mathrm{t}=1500 \mathrm{~ms}$ ). Based on the growth rate of $\mathrm{HfO}_{2}$ at $\sim 1.4 \AA$ /cycle (as shown in Fig. S3), the final thickness of the $\mathrm{HfO}_{2}$ film, as verified by a variable angle spectroscopic ellipsometer (VASE, J.A. Woollam), was around $70 \mathrm{~nm}$.

A $1-\mathrm{cm}^{2}$ monolayer/multilayer of graphene was then transferred onto the $\mathrm{HfO}_{2}$ dielectric using an established graphene-transfer procedure ${ }^{[1,2]}$. A detailed illustration and description of the graphene transfer process is shown in Fig. S2. Double-sided (ds) CVD graphene on copper foil (SKU: CVD-Cu-2X2) was purchased from the Graphene Supermarket. A specific side of the $\mathrm{Cu}-$ graphene was selected for the graphene transfer per recommendation from the vendor for a betterquality film. The process involves (1) spin-coating Poly(methyl methacrylate) (PMMA, 950 C4, GPC $\sim 350 \mathrm{kDa}, 3000 \mathrm{rpm}$ ) for 1 minute on the desired side of the ds-graphene-Cu foil, (2) etching the unprotected side of the graphene with $\mathrm{O}_{2}$-plasma (AV Etch, gas flow rate: $100 \mathrm{sccm}$, chamber pressure: 0.100 mTorr, time: $60 \mathrm{~s}$, RF power: $100 \mathrm{~W}$ ), (3) etching/removing the exposed Cu surface with an ammonium persulfate solution bath $\left(0.03 \mathrm{~mol} / \mathrm{dm}^{3}\right)$ for 14 hours, (4) rinsing the PMMAprotected graphene in DI- $\mathrm{H}_{2} \mathrm{O}$ bath three times, (5) transferring the PMMA-protected graphene onto the substrate and baking the sample at $180^{\circ} \mathrm{C}$ for $15 \mathrm{~min}$, and (6) removing the PMMA in an acetone bath at room temperature for $\sim 24 \mathrm{hr}$. The final substrate requires repeated washing with methanol and IPA before the next processing step.

A protective $\mathrm{Au} / \mathrm{Ti}$ contact layer $(45 \mathrm{~nm} / 5 \mathrm{~nm})$ with an area of around $0.01 \mathrm{~cm}^{2}$ was then deposited on top of the graphene by a shadow-mask assisted e-beam evaporation (CHA) using an $\mathrm{Au}$ source and a $\mathrm{Ti}$ source. Finally, 50 ALD cycles of the catalytic layer $\mathrm{Al}_{2} \mathrm{O}_{3}$ (Precursor: Trimethylaluminum, Sigma Aldrich, Equipment: KJL ALD-150 LE), which corresponds to an overlayer of $\sim 4 \mathrm{~nm}$ amorphous film, was deposited on the graphene at $100^{\circ} \mathrm{C}$. One $\mathrm{Al}_{2} \mathrm{O}_{3} \mathrm{ALD}$ cycle comprises of the precursor exposure $(\mathrm{t}=12 \mathrm{~ms})$, a purge $(\mathrm{t}=10000 \mathrm{~ms})$, an oxidant exposure (oxidant $\left.=\mathrm{H}_{2} \mathrm{O}, \mathrm{t}=11 \mathrm{~ms}\right)$, and a purge $(\mathrm{t}=10000 \mathrm{~ms})$. 


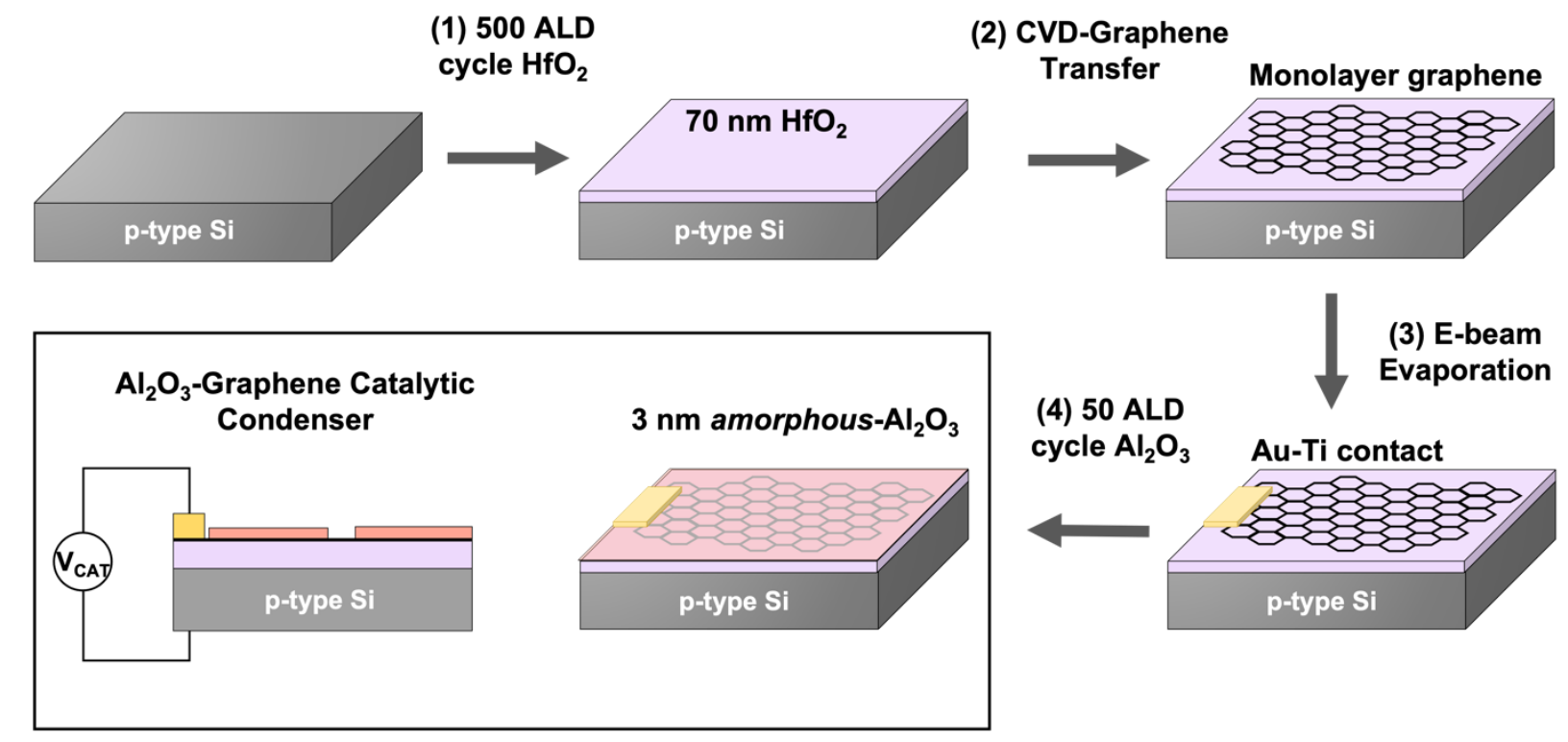

Figure S1. A schematic illustration of the alumina-graphene catalytic condenser preparation. Preliminary work (not shown) on the p-type Si substrate involves repeated washing with acetone, methanol, and isopropanol for three times before drying with air. (1) A 70 nm $\mathrm{HfO}_{2}$ (500 cycles) film was first deposited on the p-type Si substrate by Atomic Layer Deposition (ALD) at $100^{\circ} \mathrm{C}$. (2) A monolayer of graphene was then transferred onto the $\mathrm{HfO}_{2}$ surface using an established graphene-transfer procedure ${ }^{[1,2]}$. A detailed illustration and description of the graphene transfer process is shown in Fig. S2. (3) An Au/Ti contact (45 nm/5 nm) with an area of around $0.01 \mathrm{~cm}^{2}$ was then deposited on top of the graphene by a shadow-mask assisted e-beam evaporation. (4) Finally, an overlayer of $\sim 3 \mathrm{~nm} \mathrm{Al}_{2} \mathrm{O}_{3}$ amorphous film (50 cycles) was deposited on the graphene surface by $\mathrm{ALD}$ at $100^{\circ} \mathrm{C}$. 


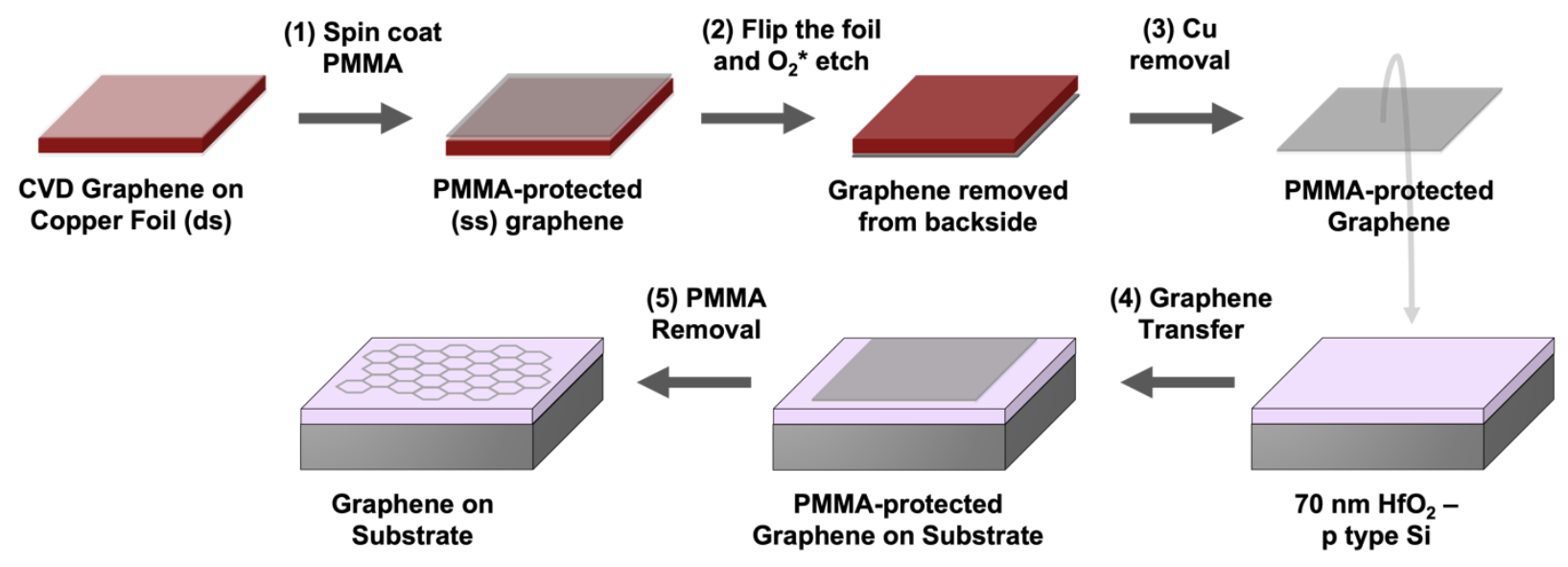

Figure S2. A schematic illustration of the graphene transfer process on a Si-based substrate. Double-sided (ds) CVD graphene on copper foil was purchased from the Graphene Supermarket. A specific side of the $\mathrm{Cu}$-graphene was selected for the graphene transfer per recommendation from the vendor for a better-quality film. The process involved: (1) spin coating PMMA (950 C4) at $3000 \mathrm{rpm}$ on the desired side of the ds-graphene-Cu foil, (2) etching the unprotected side of the graphene with $\mathrm{O}_{2}$-plasma, (3) etching/removing the $\mathrm{Cu}$ with an ammonium persulfate solution for 14 hours, (4) transferring the PMMA-protected graphene onto the substrate, and (5) removing the PMMA in an acetone bath for 24 hours. The final substrate requires repeated washing with methanol and IPA before the next processing step.

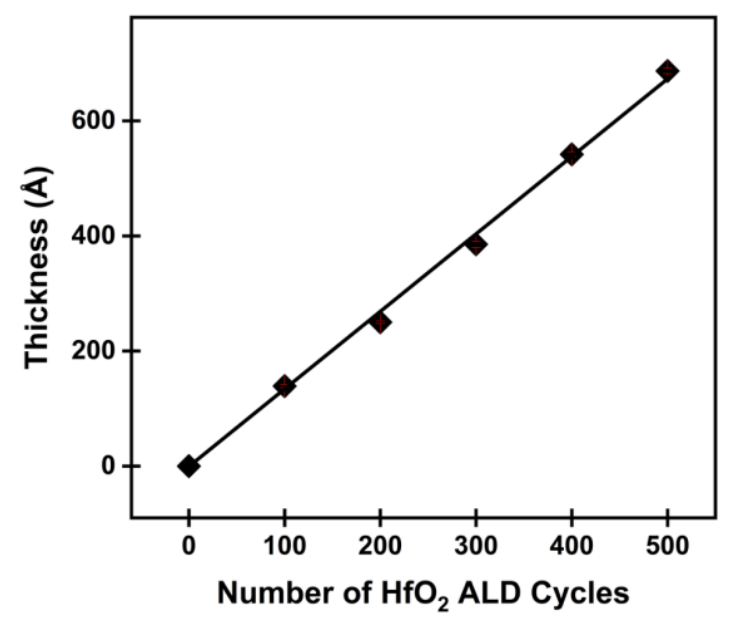

Figure S3. The thickness of $\mathrm{HfO}_{2}$ film versus the number of $\mathrm{HfO}_{2} \mathrm{ALD}$ cycles as measured by an ellipsometer. The growth rate is approximately $1.4 \AA$ per cycle. Error bars are shown in red. 


\section{Characterization Methodology - Catalytic Condenser:}

S-TEM and SEM analysis: An Amorphous-Carbon layer (am-C, $\sim 50 \mathrm{~nm}$ ) was deposited on the device via a SEM sputter coater. Focused Ion Beam (FEI Helios NanoLab G4 dual-beam focused ion beam) was employed to prepare an electron-transparent cross-sectional lamella for STEM study. The protection layer consisted of am-C (2 mm) and Pt $(2 \mathrm{~mm})$ was deposited on the region of interest. FIB was operated at $30 \mathrm{kV}$ with $5 \mathrm{kV}$ electron beam. Conventional TEM, HAADF-STEM images and STEM-EDX maps were obtained using Thermo Fisher Talos F200X G2 S-TEM with Super-X energy-dispersive X-ray spectrometer. TEM and HAADF-STEM images were acquired at $200 \mathrm{kV}$. Camera length was set at $125 \mathrm{~mm}$ with probe convergence angle of 10.5 mrad for HAADF-STEM imaging. For EDX-mapping, the beam current ranged from $300 \mathrm{pA}$ to 400 pA. SEM images and SEM-EDX maps were acquired using JEOL 6500 FEG-SEM. SEM images and SEM-EDX elemental maps were obtained under $5 \mathrm{kV}$. The EDX maps were quantified using the Aztec EDX analytical system (Oxford Instruments).

Ellipsometry Measurement: The thickness profile of the film was measured using a variable angle spectroscopic ellipsometer (VASE, J.A. Woollam). Monochromatic polarized light (500-1100 $\mathrm{nm}$ in wavelength) at two different incident angles $\left(60^{\circ}\right.$ and $\left.75^{\circ}\right)$ was used, and the data was fitted to the Cauchy model.

X-Ray Diffraction (XRD): XRD patterns were recorded on a Bruker D8 Discover 2D diffractometer equipped with a Co $\mathrm{K} \alpha$ source $(\lambda=0.179 \mathrm{~nm})$. Patterns were replotted using Bragg's Law for comparison against available standards measured with $\mathrm{Cu} \mathrm{K} \alpha$ source.

Raman Spectroscopy: Raman spectra were obtained from a Witec Alpha 300R confocal Raman microscope equipped with a UHTS300 spectrometer and a DV401 CCD detector. The spectra collection was carried out with an excitation laser wavelength of $532 \mathrm{~nm}$ at 100x lens (laser spot size of $0.5 \mu \mathrm{m}$ in the $\mathrm{x}-\mathrm{y}$ directions and $1 \mu \mathrm{m}$ in the $\mathrm{z}$ direction).

X-Ray Photoelectron Spectroscopy (XPS): XPS measurements were performed on a PHI Versa Probe III XPS system (ULVAC-PHI) using a monochromated A1 K $\alpha$ X-ray source (1486.6 $\mathrm{eV})$. The base pressure of the chamber was $4.0 \times 10^{-8} \mathrm{~Pa}$. During data collection, the pressure was ca. $2.0 \times 10^{-6} \mathrm{~Pa}$. All samples were mounted on the holder using a $\mathrm{Cu}$ pin. The measurements were conducted using an X-ray spot size of $0.1 \times 0.1 \mathrm{~mm}^{2}$ with a power of $25 \mathrm{~W}$ under $15 \mathrm{kV}$. The survey spectra were measured using $280 \mathrm{eV}$ pass energy and $1.0 \mathrm{eV} / \mathrm{step}$. Multipak software was used to process the data. Energies were referenced to the $\mathrm{Ca} 2 \mathrm{p} 3 / 2$ peak at $349.0 \mathrm{eV}$

Ultraviolet Photoelectron Spectroscopy (UPS): UPS measurements were performed on the same XPS system using ultraviolet radiation from an ionized He source. The base pressure was $8.0 \times 10^{-7} \mathrm{~Pa}$ during measurement. The measurement spot size was approximately $6 \times 6 \mathrm{~mm}^{2}$. Survey spectra were measured using $1.3 \mathrm{eV}$ pass energy and $0.025 \mathrm{eV} / \mathrm{step}$. 
Atomic Force Microscopy (AFM): AFM measurements were performed using a Bruker Dimension Icon closed-loop atomic force microscope operating in the using the force-modulation technique with a force feedback setpoint of $581 \mathrm{pN}$. Probes were standard Si cantilevers calibrated before measurement with a spring constant of $0.674 \mathrm{~N} / \mathrm{m}$.

Scanning tunneling microscopy (STM): STM measurements were made using an Omicron low-temperature scanning tunneling microscope (LT-STM) at room temperature using a $\mathrm{Pt} / \mathrm{Ir}$ probe. Differential spectra were collected from a Stanford Research Systems lock-in amplifier with a modulation signal of $\mathrm{V} \_$mod $=10 \mathrm{mV}$ and f_mod $=10 \mathrm{kHz}$. 


\section{Supplementary TEM-EDX, SEM-EDX characterization:}
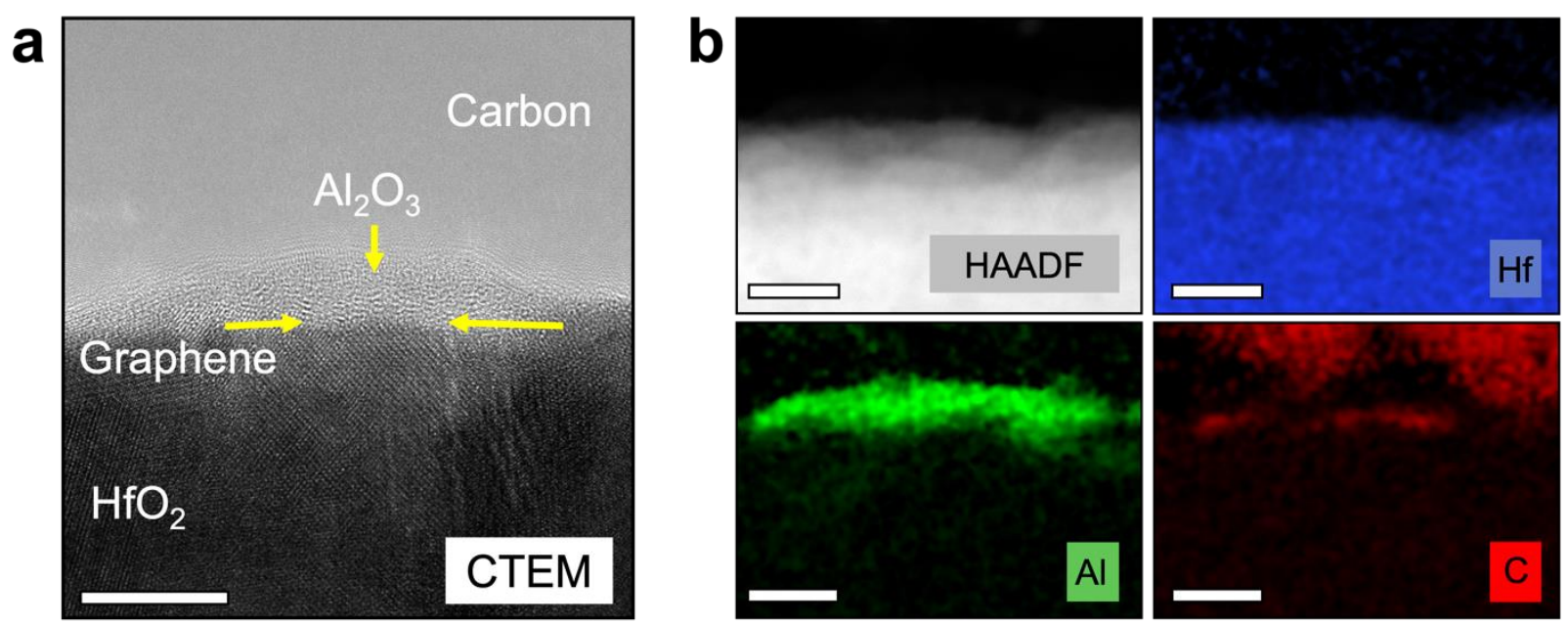

Figure S4. (a) Cross-sectional CTEM image of the alumina-graphene catalytic condenser device. The cross section has been thinned until at least $10 \mathrm{~nm}$ width of $\mathrm{Al}_{2} \mathrm{O}_{3}$ exists. Scale bar: $10 \mathrm{~nm}$. (b) STEM-EDX elemental maps: Hf (blue), Al (green), C (red). A layer of carbon that can be attributed to graphene beneath the $\mathrm{Al}_{2} \mathrm{O}_{3}$ layer can be observed. Scale bar: $10 \mathrm{~nm}$. 

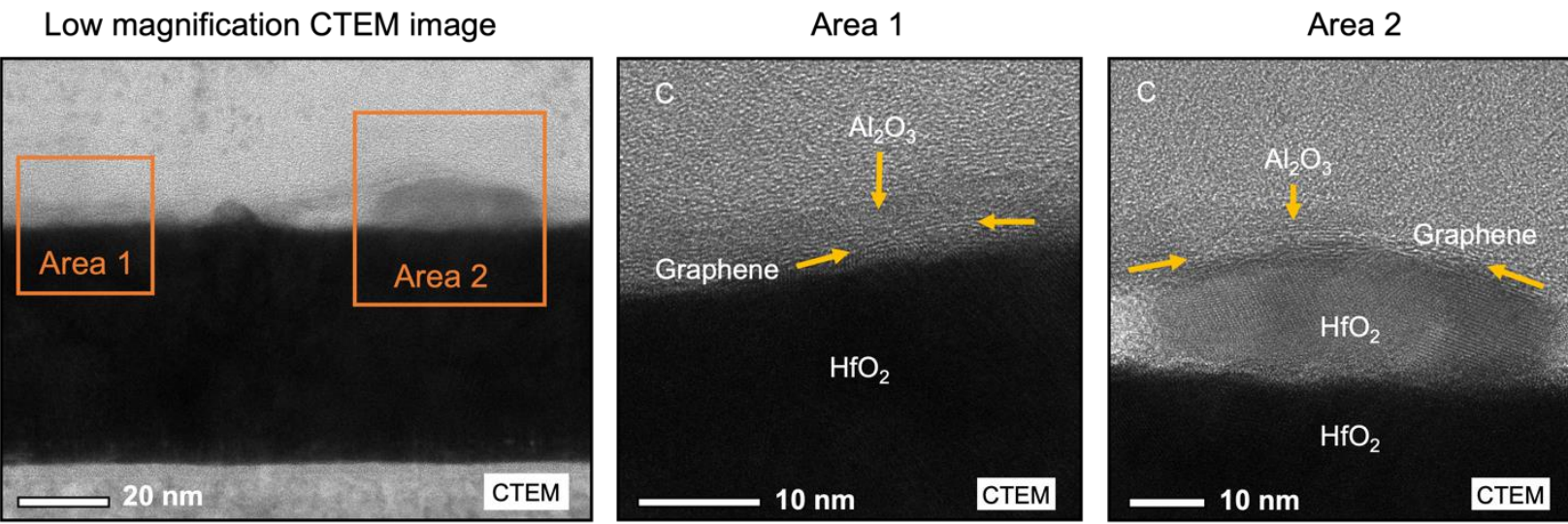

Figure S5. Low magnification cross-sectional CTEM image of the Alumina-Graphene catalytic condenser device. Area 1 and Area 2 shows a graphene layer and $\mathrm{Al}_{2} \mathrm{O}_{3}$ thin film layer on the top of $\mathrm{HfO}_{2}$. From Area 2, there are some regions where the surface $\mathrm{HfO}_{2}(\sim 10 \mathrm{~nm})$ appears crystalline.

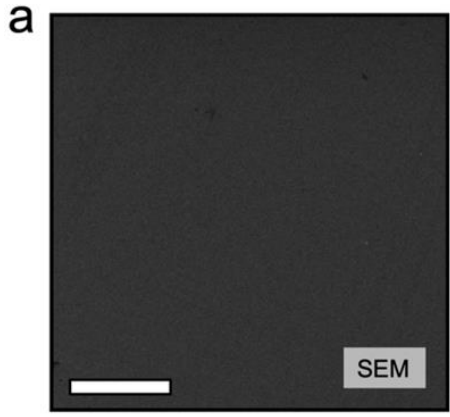

Substrate $+\mathrm{HfO}_{2}$ b

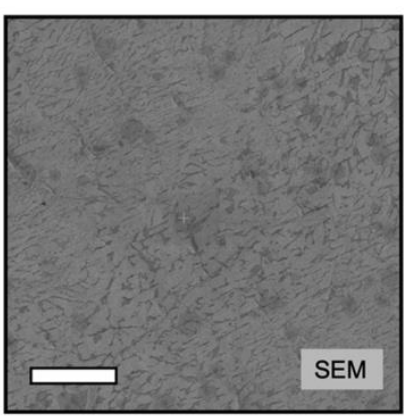

Substrate + $\mathrm{HfO} 2+$ graphene
C

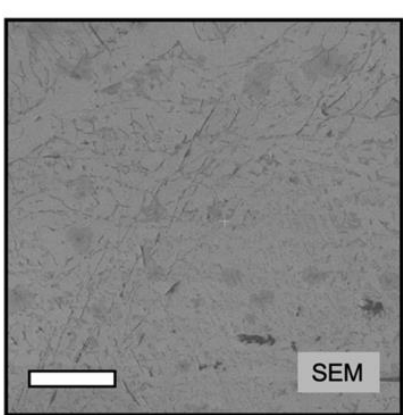

Substrate + $\mathrm{HfO} 2+$ graphene $+\mathrm{Al} 2 \mathrm{O} 3$
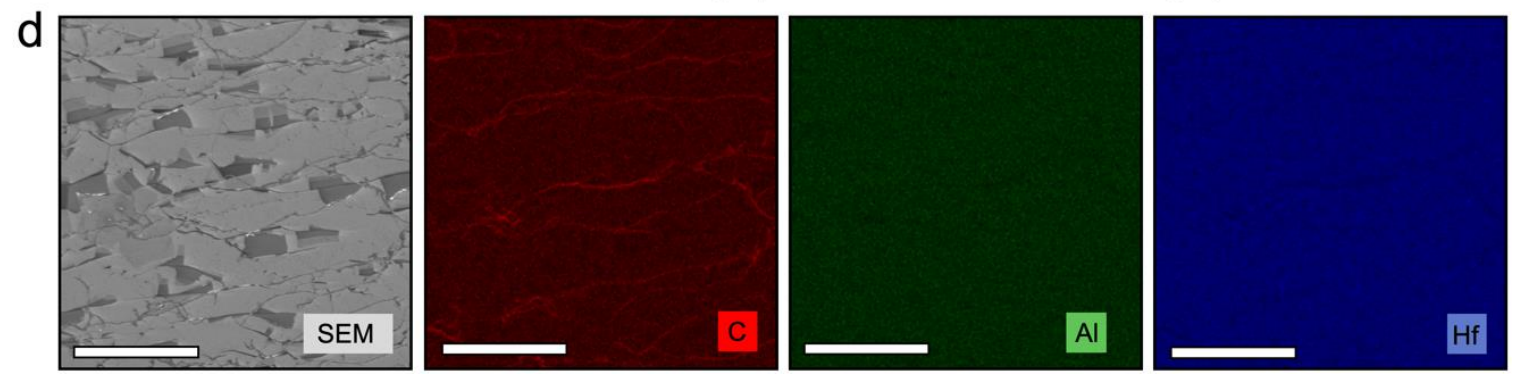

Figure S6. (a) Top view SEM image of the $\mathrm{Si}$ substrate $+\mathrm{HfO}_{2}$. Scale bar is $10 \mu \mathrm{m}$. (b) Top view SEM image of the Si substrate $+\mathrm{HfO}_{2}+$ Graphene. Scale bar is $50 \mu \mathrm{m}$. (c) Top view SEM image of the Si substrate $+\mathrm{HfO}_{2}+\mathrm{Graphene}+\mathrm{Al}_{2} \mathrm{O}_{3}$. Scale bars are $50 \mu \mathrm{m}$. (d) SEM top-view image of the device with $\mathrm{Si}$ Substrate, $\mathrm{HfO}_{2}$, graphene and $\mathrm{Al}_{2} \mathrm{O}_{3}$ and its complementary SEM-EDX maps: $\mathrm{Hf}$ (blue), $\mathrm{Al}$ (green), $\mathrm{C}$ (red). Graphene folds and wrinkles are observed as expected. Scale bar is $25 \mu \mathrm{m}$. 
Supplementary UPS measurements (Control):

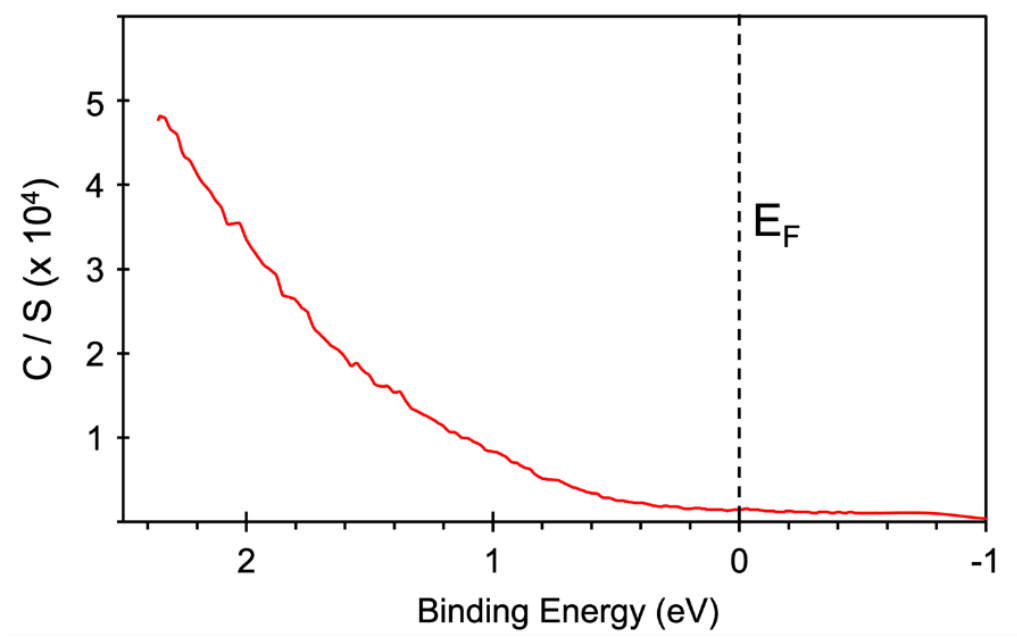

Figure S7. Onset of in-gap occupied states near the Fermi level of an alumina/ $/ \mathrm{HfO}_{2} / \mathrm{p}-\mathrm{Si}$ device where the graphene layer is absent 


\section{Electronic Characterization - Catalytic Condenser:}

Capacitances of the dielectric material $\mathrm{HfO}_{2}$ per area were obtained by measuring capacitive/displacement currents as a function of voltage applied across a metal-insulatorsemiconductor $\left(\mathrm{Au} / \mathrm{HfO}_{2} / \mathrm{p}\right.$-type $\left.\mathrm{Si}\right)$ structure at different voltage sweep rates. A $0.01 \mathrm{~cm}^{2} \mathrm{Au} / \mathrm{Ti}$ metal contact $(45 \mathrm{~nm} / 5 \mathrm{~nm})$ was used in these measurements, and it was prepared via a shadowmask assisted e-beam evaporation as described previously. A probe station equipped with a source meter (Keithley 2611B and Keithley Test Script Builder), also used in previous works, was used for the electrical measurements ${ }^{[3]}$. For graphene-based devices, similar capacitance measurements were performed across a graphene-insulator-semiconductor (graphene/ $\mathrm{HfO}_{2} / \mathrm{p}$-type $\mathrm{Si}$ ) structure and a catalyst-graphene-insulator-semiconductor $\left(\mathrm{Al}_{2} \mathrm{O}_{3} /\right.$ graphene/ $\mathrm{HfO}_{2} / \mathrm{p}$ - type $\left.\mathrm{Si}\right)$ structure at different voltage sweep rates: $1.25 \mathrm{~V} / \mathrm{s}, 1.00 \mathrm{~V} / \mathrm{s}, 0.75 \mathrm{~V} / \mathrm{s}$, and $0.50 \mathrm{~V} / \mathrm{s}$.

Conductance measurements of the condenser devices were obtained by measuring the current across the graphene layer from end to end as a function of voltage applied. The same source meter (Keithley 2611B) as above was used. To validate the graphene transferred on the condenser device, its conductance was compared against a commercially purchased graphene-insulator $\left(\mathrm{SiO}_{2}\right)$ device. From Fig. S10, both devices have the same conductance.
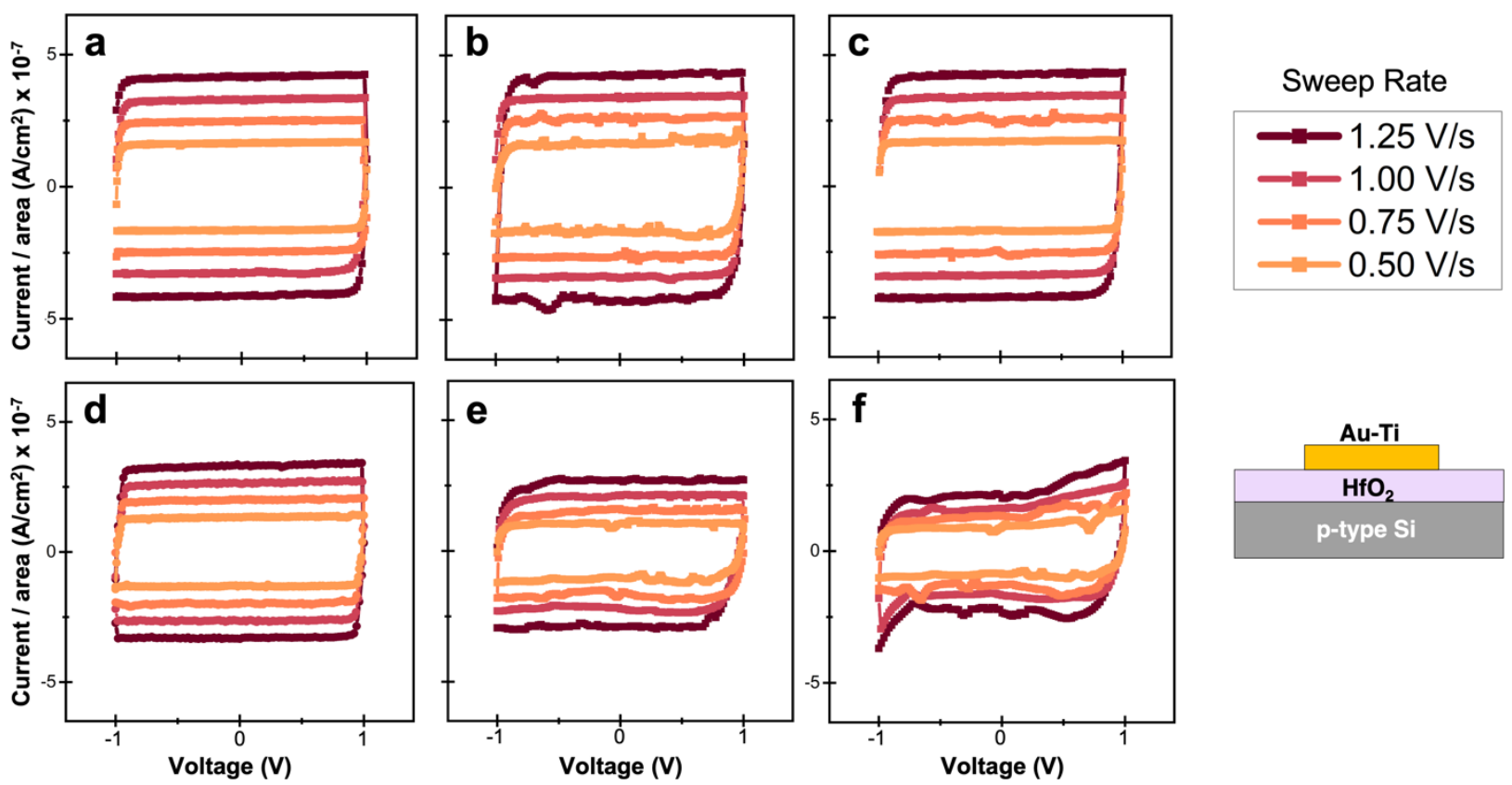

Figure S8. Capacitive current densities measured by sweeping voltage bias on an $\mathrm{Au} / \mathrm{HfO}_{2} / \mathrm{Si}$ structure at different voltage sweep rates after various temperature treatments. The $\mathrm{HfO}_{2} / \mathrm{Si}$ structure was prepared by ALD at (a) $100^{\circ} \mathrm{C}$, and they were heated in a muffle furnace under ambient condition for 1 hour at (b) $200^{\circ} \mathrm{C}$, (c) $300^{\circ} \mathrm{C}$, (d) $350^{\circ} \mathrm{C}$, (e) $400^{\circ} \mathrm{C}$, and (f) $500^{\circ} \mathrm{C}$. After the temperature treatment, a $0.01 \mathrm{~cm}^{2}$ metal contact was deposited onto the device by a shadowmask assisted e-beam evaporation of $\mathrm{Au} / \mathrm{Ti}(45 \mathrm{~nm} / 5 \mathrm{~nm}$ thick). 

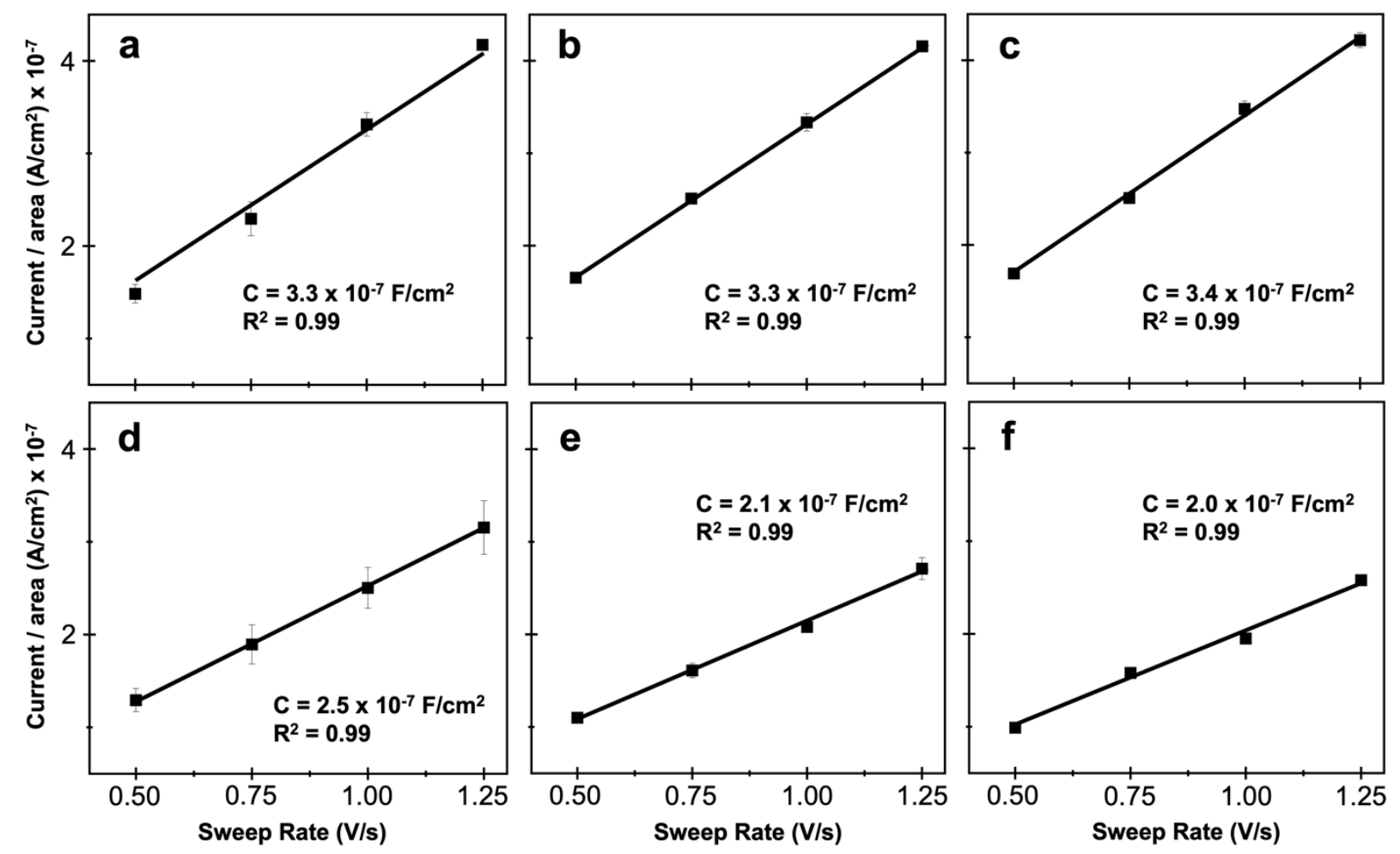

Figure S9. Averaged capacitive current density as a function of voltage sweep rates corresponding to (a)-(f) respectively in Fig. S7. The averaged capacitance density calculated from the gradient and the error bars are shown. 

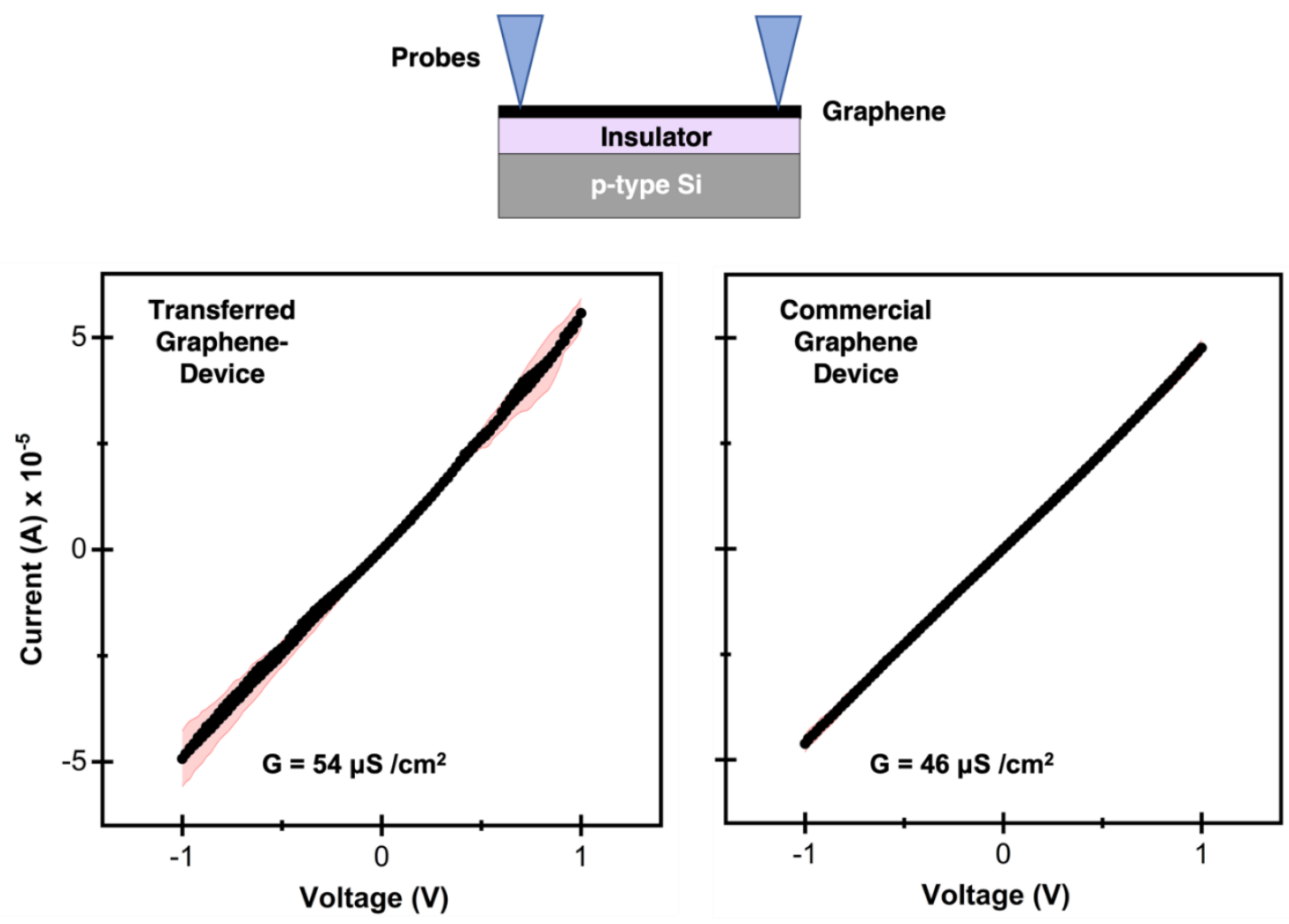

Figure S10. Conductance comparison between our transferred graphene-device and a commercial graphene device without any voltage back-gating. Current was measured across the $1 \mathrm{~cm}^{2}$ surface of the graphene by two metal probes. Error bars are shown. 


\section{$\underline{\text { Temperature Programmed Surface Reaction (TPSR) Setup and Process: }}$}

Isopropanol dehydration to propene, a well-established Lewis acid reaction system, was chosen as the probe reaction for the TPSR experiments. TPSR profiles were obtained from a customized ultra-high vacuum (UHV) voltage bias-capable setup equipped with a mass spectrometer as shown in Fig. S11 and S12. The setup comprised of three stations: (1) the dosing station, which allows the introduction of isopropanol vapor to the sample, (2) the TPSR station, which holds the sample and allows heating and electrical input, and (3) the turbopump/ mass spectrometer station, which captures the mass fragments from the reaction. These stations, separated by valves, operate under different vacuum conditions. The dosing station, which is evacuated by a mechanical roughing pump, has a baseline pressure of around $10^{-3} \mathrm{Torr}$, whereas the turbopump/mass spectrometer station, which is evacuated by a turbomolecular pump, has a baseline pressure of around $10^{-8}$ to $10^{-9}$ Torr (See Fig. S13).

During sample loading, the device is attached to the TPSR chamber via two customized stainless-steel toothless alligator clips connected to the electric feedthrough via tantalum wires, as shown in Fig. S14. Each customized clip is composed of a side/jaw insulated by a quartz shield and a conductive side/jaw to allow introduction of voltages to either the frontside or backside of the sample device. These materials (tantalum wires, stainless-steel alligator clips, and quartz shields) do not participate in the isopropanol dehydration reaction (also verified in a control experiment, see Fig. S20). A Keithley 2450 source meter was used to introduce the different voltage biases.

For temperature measurement, a K-type thermocouple (Nickel-Chromium / NickelAlumel) was fixed on the exterior wall of the reactor chamber as close to the sample as possible. It was not fitted inside the sample chamber to prevent any participation in the dehydration reaction and to prevent any electrical shorting from the voltage bias application. To accurately capture the temperature of the sample, a standard temperature calibration curve was made between the interior temperature ( $\mathrm{T}_{\text {int }}$ ) on the sample and the exterior temperature ( $\left.\mathrm{T}_{\mathrm{ext}}\right)$. See Fig. S15 and S16. Tint increased linearly with $T_{\text {ext }}$ within a certain temperature range though it is important to note that there were discrepancies between the two values due to the separation in medium.

A schematic of a typical TPSR process is shown in Fig. S17. During the first step of a TPSR experiment, approximately 33 Torr of isopropanol vapor was introduced under static (no carrier gas) condition into the TPSR chamber, where the sample device was held at room temperature $\left(\sim 21^{\circ} \mathrm{C}\right)$. The total static exposure time was $10 \mathrm{~min}$ to ensure complete saturation of the sample's surface. The TPSR reactor chamber would then be evacuated via the roughing pump whilst being heated to $80{ }^{\circ} \mathrm{C}$ for $30 \mathrm{~min}$ to remove any excess isopropanol from the sample and the chamber wall. Only the chemisorbed alcohol species on the catalytic $\mathrm{Al}_{2} \mathrm{O}_{3}$ layer would remain bound during this heated evacuation. After the TPSR reactor had cooled to room temperature, the 
station was then closed to the roughing pump and was further evacuated via the turbomolecular pump for 48 hours. The chamber walls were kept warm $\left(\sim 120^{\circ} \mathrm{C}\right)$ during these steps.

The 48-hour turbopump evacuation ensured any physiosorbed isopropanol species on the surface were removed and the system achieved UHV conditions. The chamber walls then had to be cooled to room temperature to remove any the effects of $\mathrm{H}_{2} \mathrm{O}$ adsorption-desorption on the chamber walls and the total chamber pressure i.e., to improve the quality of the mass fragment collection. Next, during a TPSR run, a voltage bias $(0 \mathrm{~V}, 1 \mathrm{~V}, 2 \mathrm{~V}$, or $3 \mathrm{~V})$ was first introduced to the system for $3 \mathrm{~min}$ before the sample was heated to $\mathrm{T}_{\mathrm{ext}}=400^{\circ} \mathrm{C}$ at a ramp rate $10^{\circ} \mathrm{C} / \mathrm{min}$. A quadrupole mass spectrometer (SRS RGA100) was used to simultaneously monitor and collect several mass fragments (mass/charge $[\mathrm{m} / \mathrm{z}]$ ratio) that desorbed from the catalyst surface during the temperature ramp. To validate the system, we compared the TPSR of propene formed by bulk $\mathrm{Al}_{2} \mathrm{O}_{3}$ powder and $\mathrm{Al}_{2} \mathrm{O}_{3}$-graphene catalytic condenser at $\mathrm{V}_{\mathrm{CAT}}=0 \mathrm{~V}$. As shown in Fig. S18, the temperature of propene formation for both samples are matched. 


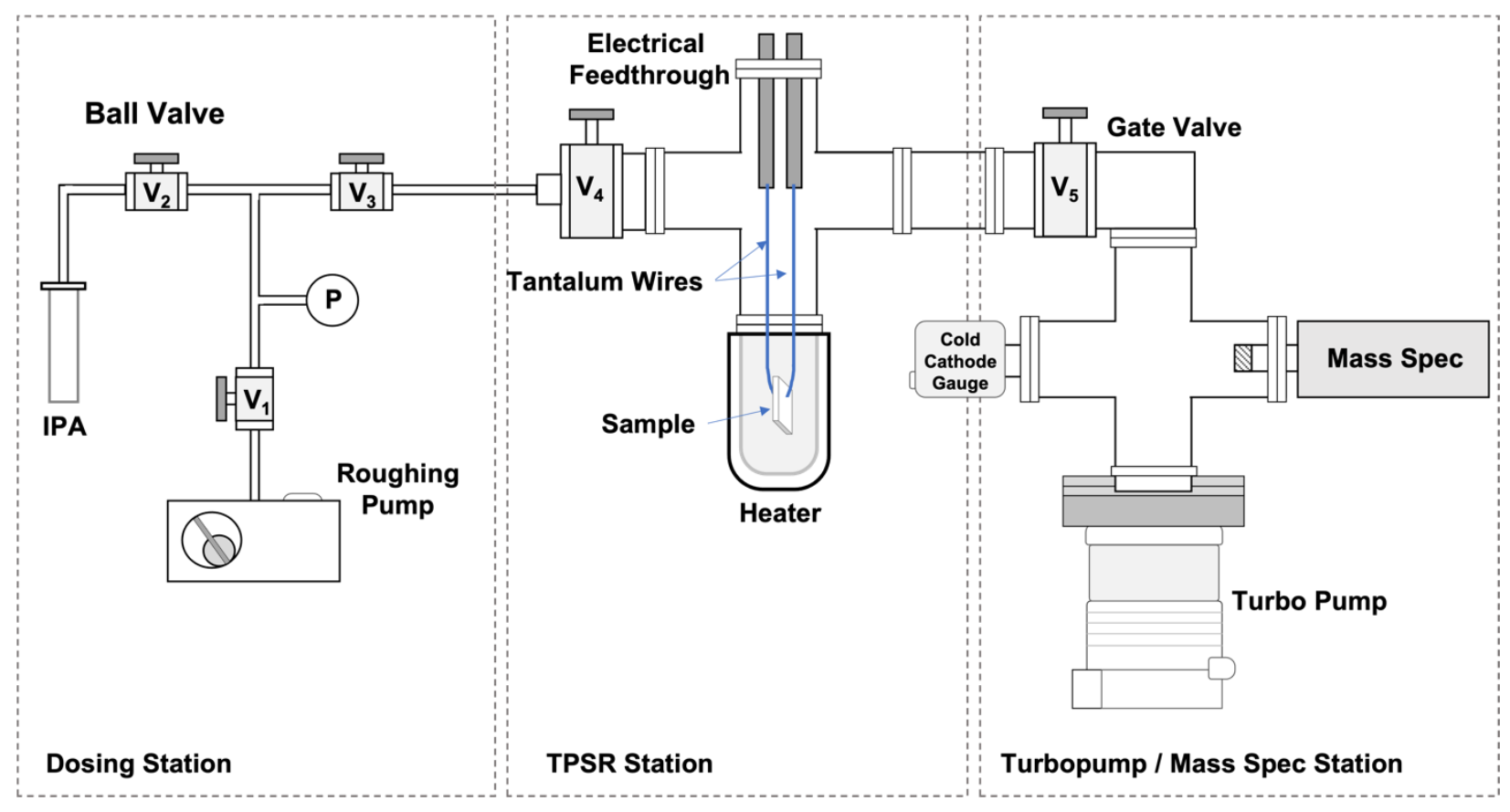

Figure S11. A schematic of the customized Temperature Programmed Surface Reaction (TPSR) system. The system comprised of three stations: (1) the dosing station, (2) the TPSR station, and (3) the turbopump/ mass spectrometer station. The sample is held by two conductive tantalum wire-alligator clips-quartz shield, as illustrated in Fig. S14 below. 


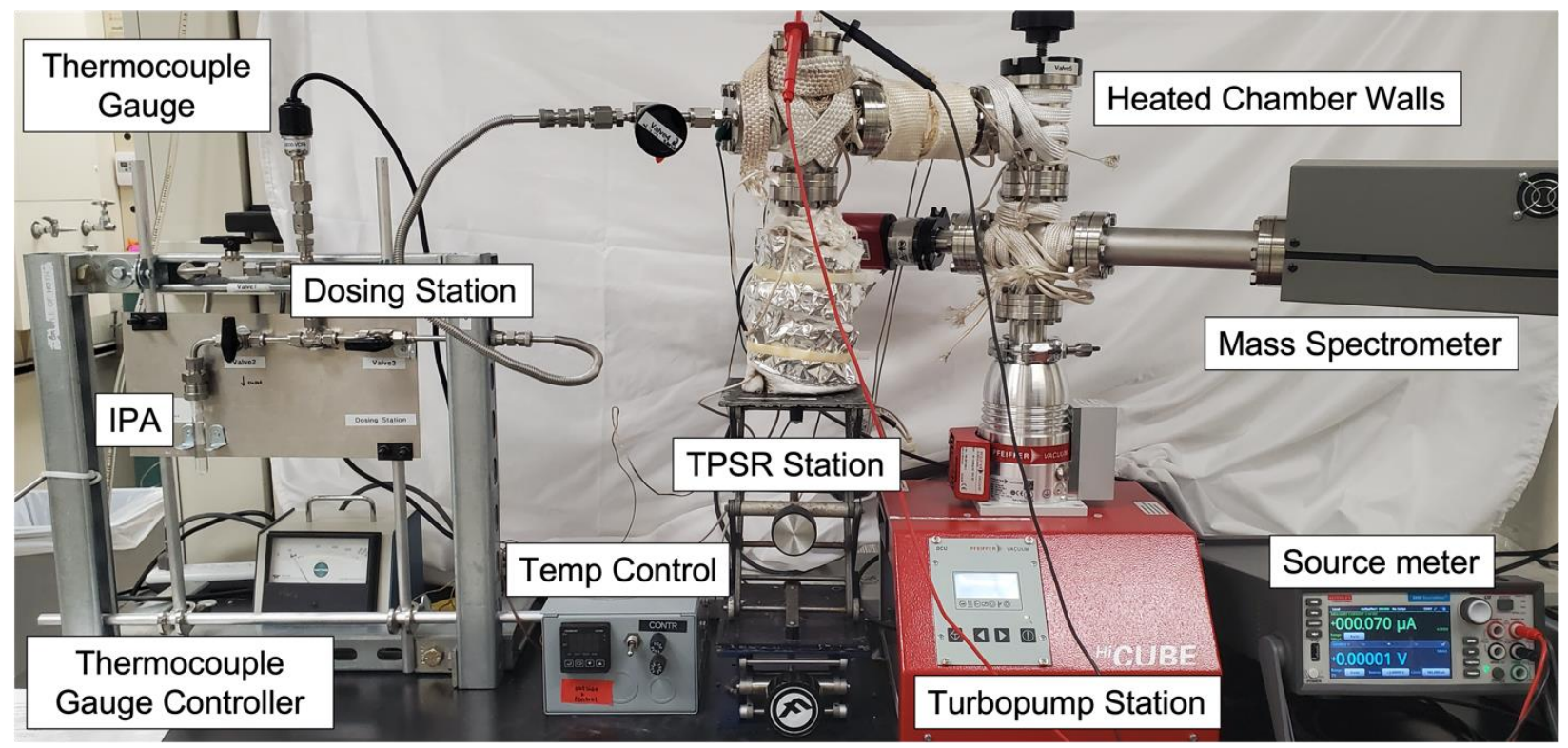

Figure S12. A photograph of the customized Temperature Programmed Surface Reaction (TPSR) system. The system comprised of three stations: (1) the dosing station, (2) the TPSR station, and (3) the turbopump/ mass spectrometer station. The dosing station, under a roughing pump evacuation, has a baseline pressure of $\sim 0.01$ Torr, while the turbopump / mass spectrometer station, under a turbopump evacuation, has a baseline pressure of $\sim 10^{-9}$ Torr. The chamber walls of the TPSR and turbopump / mass spectrometer station are kept heated to prevent any condensation. 


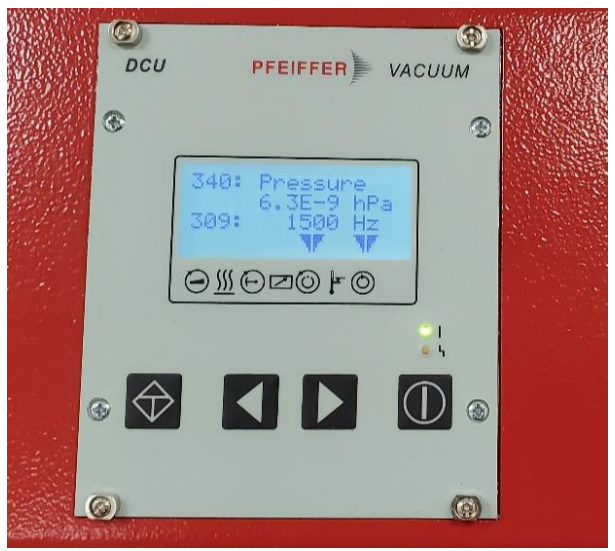

Figure S13. The baseline pressure of the turbopump station. The cold-cathode gauge of the turbopump station reads $4.7 \times 10^{-9}$ Torr $\left(6.3 \times 10^{-9} \mathrm{hPa}\right)$. This value is in good agreement with the turbomolecular pump's (Pfeiffer HiCube 30 Eco) specification sheet.

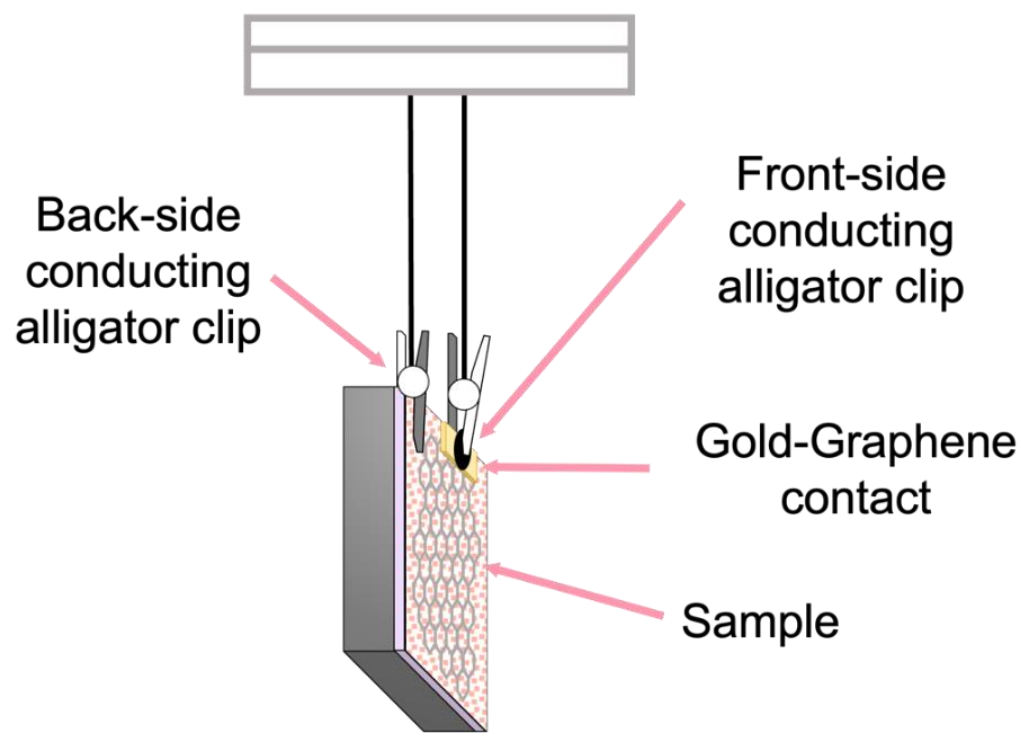

Figure S14. An illustration of the alumina-graphene catalytic condenser device attached to the TPSR system with voltage bias capability. The customized alligator clip comprises of a side insulated by a quartz shield and a conductive side to allow introduction of voltage biases of a clip to only one of the sample's surfaces. The tantalum wires, stainless-steel alligator clips, and quartz shields do not participate in the TPSR of isopropanol dehydration. 

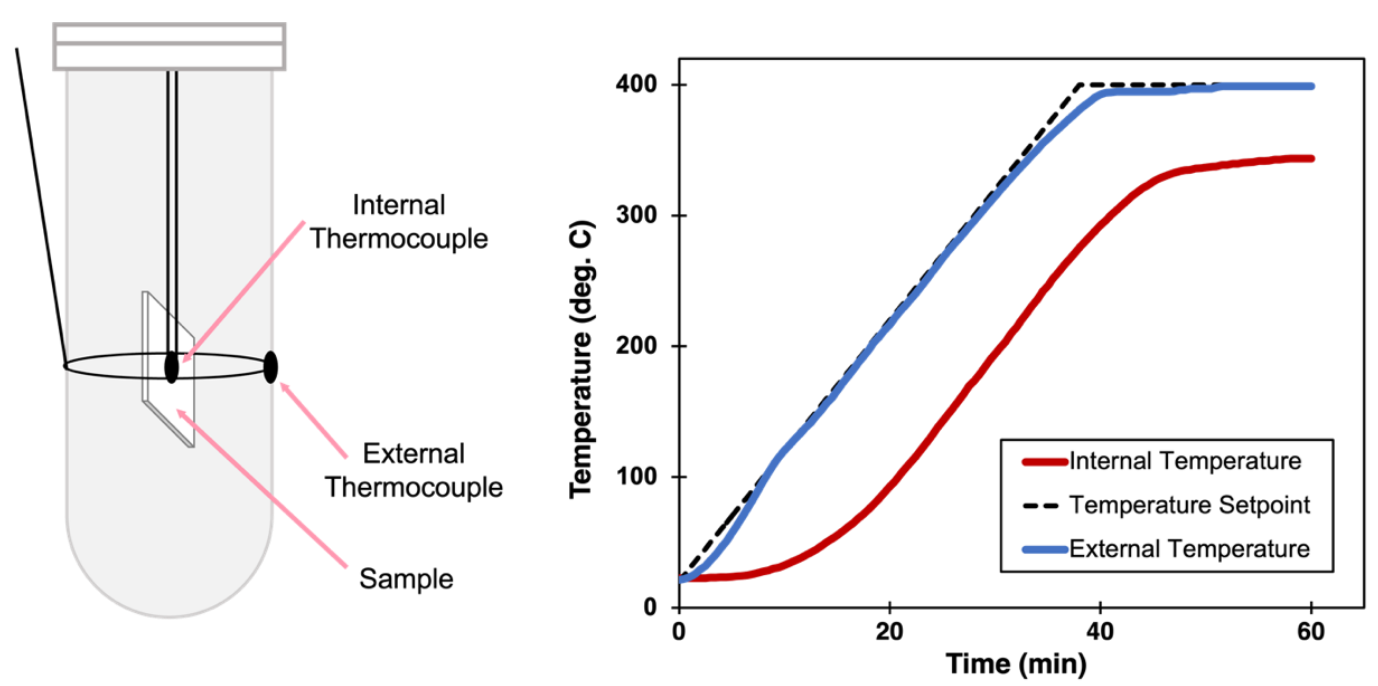

Figure S15. Temperature calibration between the external temperature and internal temperature. The internal thermocouple is placed on the sample during the external temperature ramp of $10^{\circ} \mathrm{C}$ per minute to a final $\mathrm{T}_{\mathrm{ext}}=400^{\circ} \mathrm{C}$. The internal thermocouple is removed during a voltage-biased TPSR experiment to prevent any electrical short circuiting and participation in the TPSR of isopropanol dehydration.

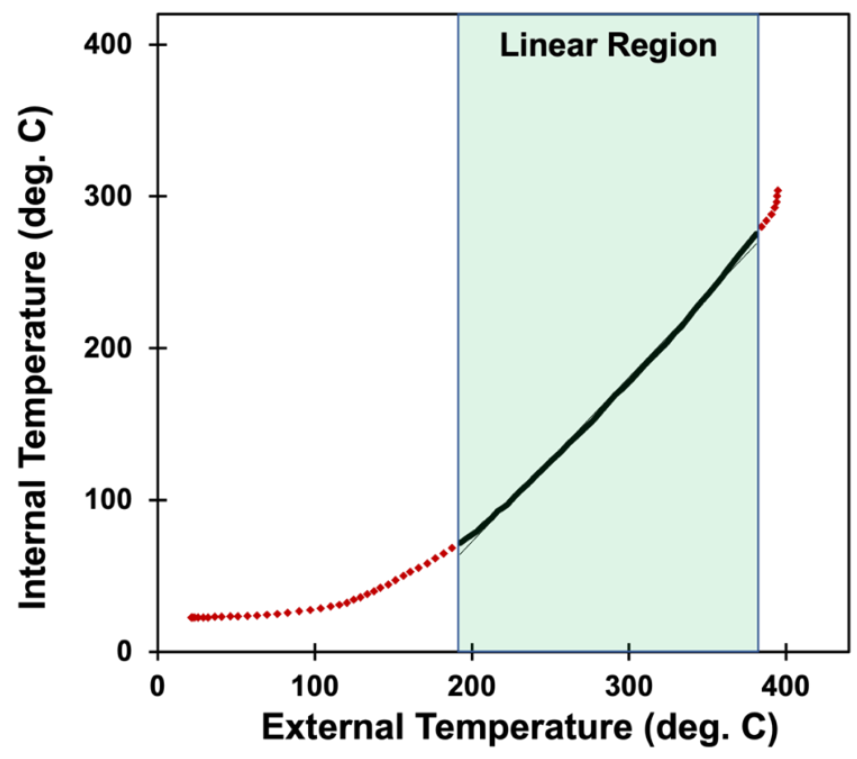

Figure S16. A temperature calibration curve measured by the internal thermocouple versus the external thermocouple. The region, where the relationship between the temperatures is linear, is approximately between $\mathrm{T}_{\mathrm{ext}}=190^{\circ} \mathrm{C}$ and $\mathrm{T}_{\mathrm{ext}}=380^{\circ} \mathrm{C}$. Error bars are shown. 

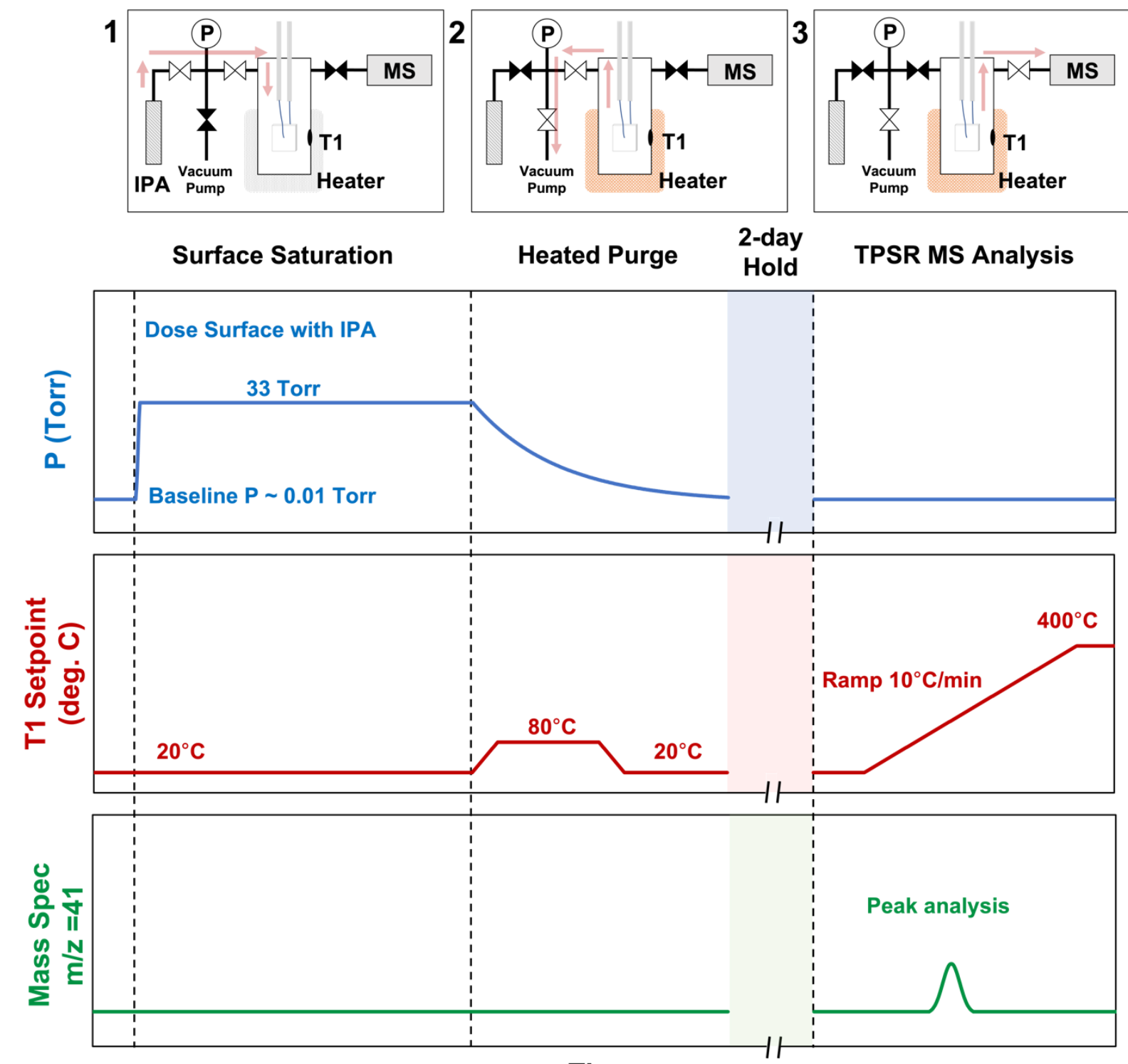

Time
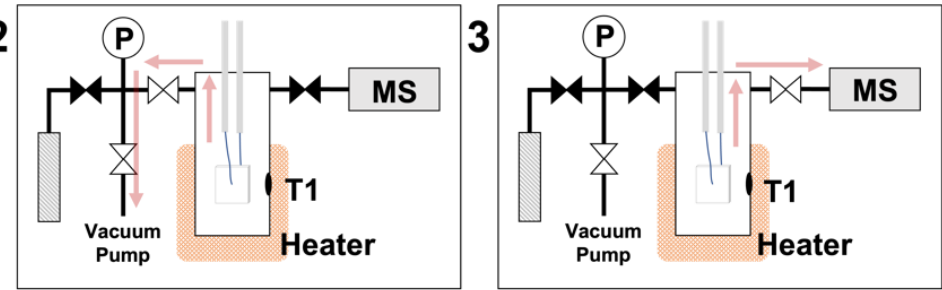

TPSR MS Analysis 


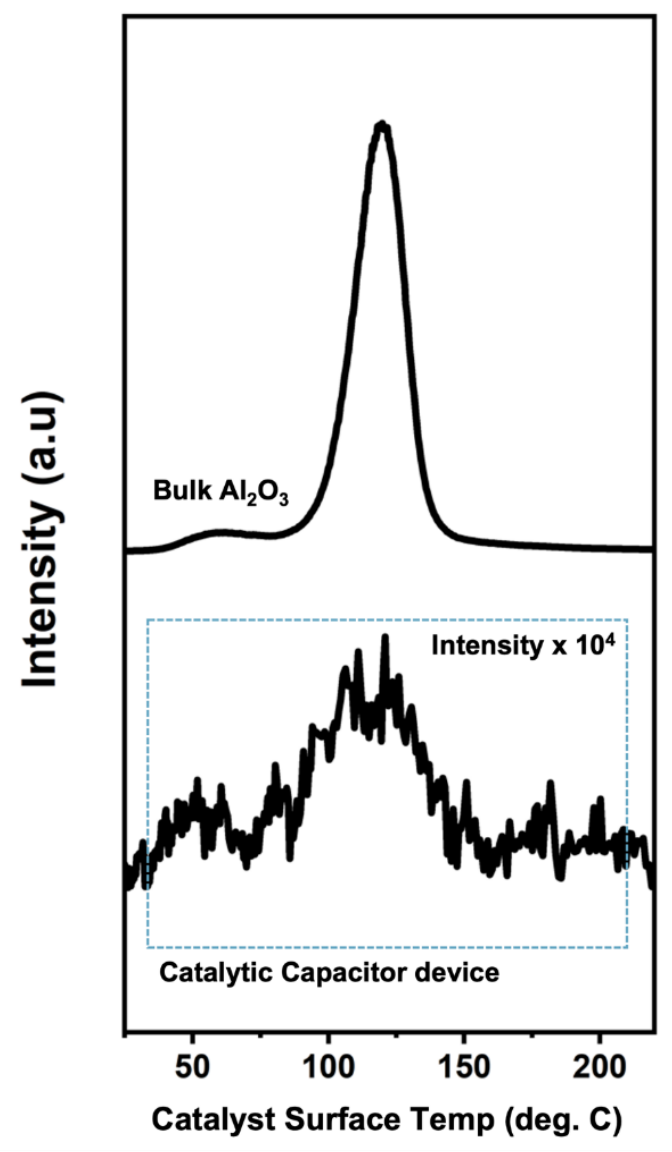

Figure S18. TPSR profile of propene formation compared between an alumina-graphene catalytic condenser device at $0 \mathrm{~V}$ and a bulk $\mathrm{Al}_{2} \mathrm{O}_{3}$ sample. The temperature of propene formation for the two samples are the same. 


\section{TPSR Mass Fragment Analysis:}

To subtract the contribution of isopropanol to the propene's major mass fragment $(\mathrm{m} / \mathrm{z}=$ 41), we measured the ratio of the mass fragments for pure isopropanol on our mass spectrometer as shown in Fig. S19. Isopropanol has a major mass fragment at $\mathrm{m} / \mathrm{z}=45$ and a minor fragment at $\mathrm{m} / \mathrm{z}=41$. Isopropanol's ratio of $\mathrm{m} / \mathrm{z}=41$ to $\mathrm{m} / \mathrm{z}=45$ on our system was found to be 0.12 . This value was used to subtract the excess isopropanol contribution in all the TPSR profiles of propene. It is important to note that this value is in close agreement with the National Institute of Standards and Technology (NIST) value.

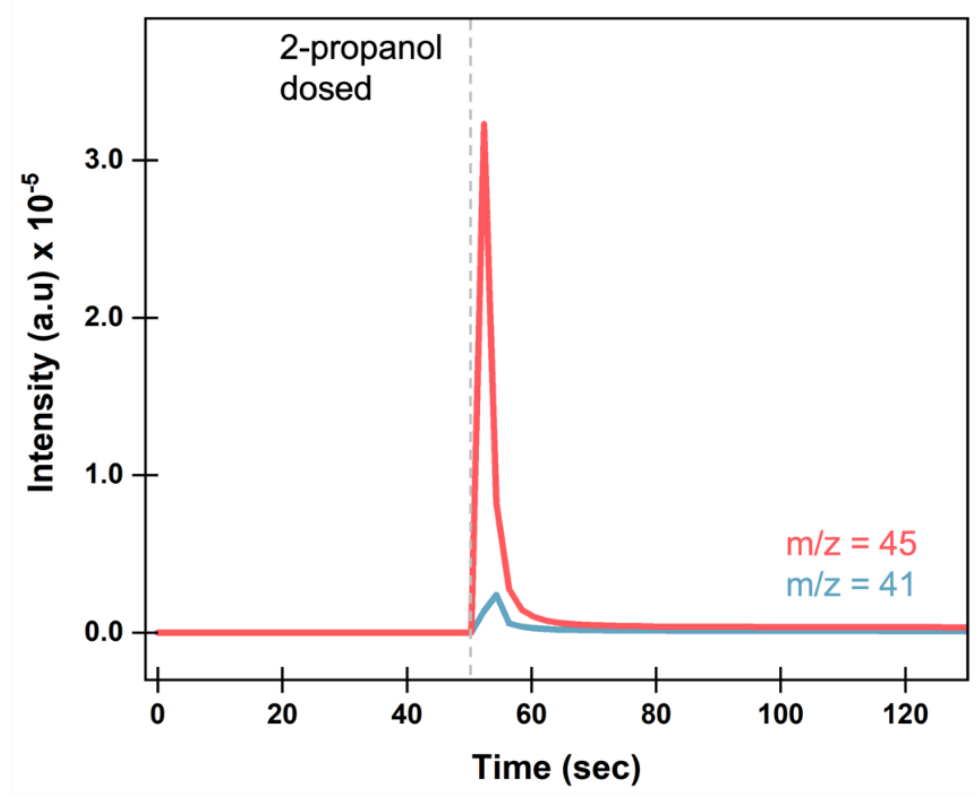

Figure S19. Mass fragments of isopropanol. The ratio of the main fragment of isopropanol at $\mathrm{m} / \mathrm{z}$ $=45$ to a minor fragment at $\mathrm{m} / \mathrm{z}=41$ is obtained to be 0.12 . This value is used to subtract any excess desorbed isopropanol's contribution to the propene signal during a TPSR run. 


\section{TPSR Control Experiments:}

Control experiments, as shown in Fig. S20 and S21, were performed to validate the propene formation from the voltage-biased TPSR experiments. From Fig. S20, there was no propene formation from three TPSR control runs: (a) IPA dosed to a device without the $\mathrm{Al}_{2} \mathrm{O}_{3}$ catalytic layer, (b) IPA dosed to an empty reaction chamber, and (c) a device without any introduction of IPA. From Fig. S20 (a), $\mathrm{Al}_{2} \mathrm{O}_{3}$ was confirmed to be an essential catalytic layer, on which the isopropanol chemisorbed and underwent reaction. Without $\mathrm{Al}_{2} \mathrm{O}_{3}$, no reaction would occur. From Fig. S20 (b), chamber components such as tantalum wires, quartz shields, and stainless-steel clips were confirmed to not participate in the reaction, and from Fig. S20 (c), it was shown that IPA is required for the reaction and the propene signal was not a result of other adsorbates desorbing from the device's surface.

From Fig. S21, two important TPSR control experiments were performed to validate the importance of graphene to transfer charge to the catalytic $\mathrm{Al}_{2} \mathrm{O}_{3}$ layer. The two control samples were: a non-graphene $\left(\mathrm{Al}_{2} \mathrm{O}_{3} / \mathrm{HfO}_{2} / \mathrm{Si}\right)$ device, and a thick $(50 \mathrm{~nm})$ catalytic layer $\left(\mathrm{Al}_{2} \mathrm{O}_{3} /\right.$ graphene/ $\left.\mathrm{HfO}_{2} / \mathrm{Si}\right)$ device. A voltage bias of $\mathrm{V}_{\mathrm{CAT}}=3 \mathrm{~V}$ was applied to these two samples during the TPSR runs. The temperature of propene formation did not show any major shift with the voltage application. This implies that graphene was essential for charge distribution and the charges were localized to the $\mathrm{Al}_{2} \mathrm{O}_{3}$ on the surface of the graphene and dielectric layer. From the control TPSR run with the thick $\mathrm{Al}_{2} \mathrm{O}_{3}$, there was a small shift in the peak temperature of propene formation, which can be attributed to some porosity of the thick amorphous $\mathrm{Al}_{2} \mathrm{O}_{3}$ layer, so IPA was able to chemisorbed onto $\mathrm{Al}_{2} \mathrm{O}_{3}$ sites touching the graphene. 


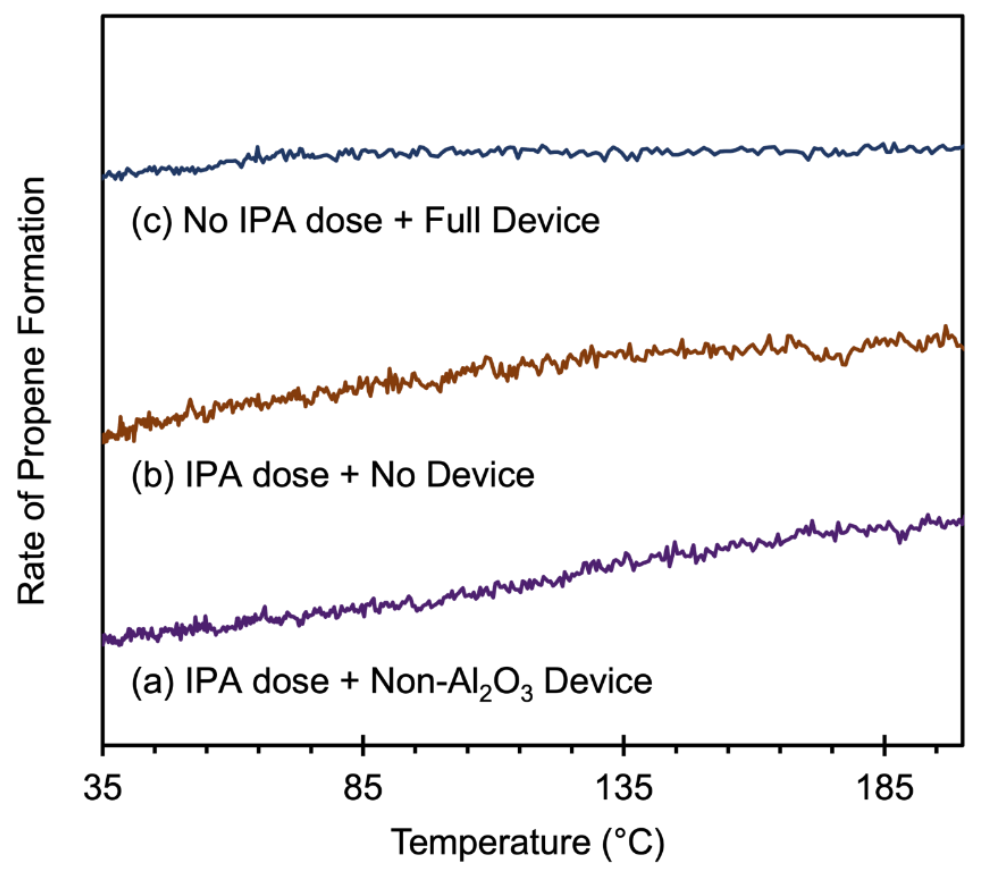

Figure S20. TPSR profile of propene formation for several control experiments. The three control experiments are: (a) isopropanol (IPA) dosed to a device without the catalytic $\mathrm{Al}_{2} \mathrm{O}_{3}$ layer, (b) isopropanol (IPA) dosed to an empty chamber without any device, and (c) a device without any introduction of isopropanol (IPA). The three control experiments show no propene formation. The propene formation data is shown without any baseline subtraction. 


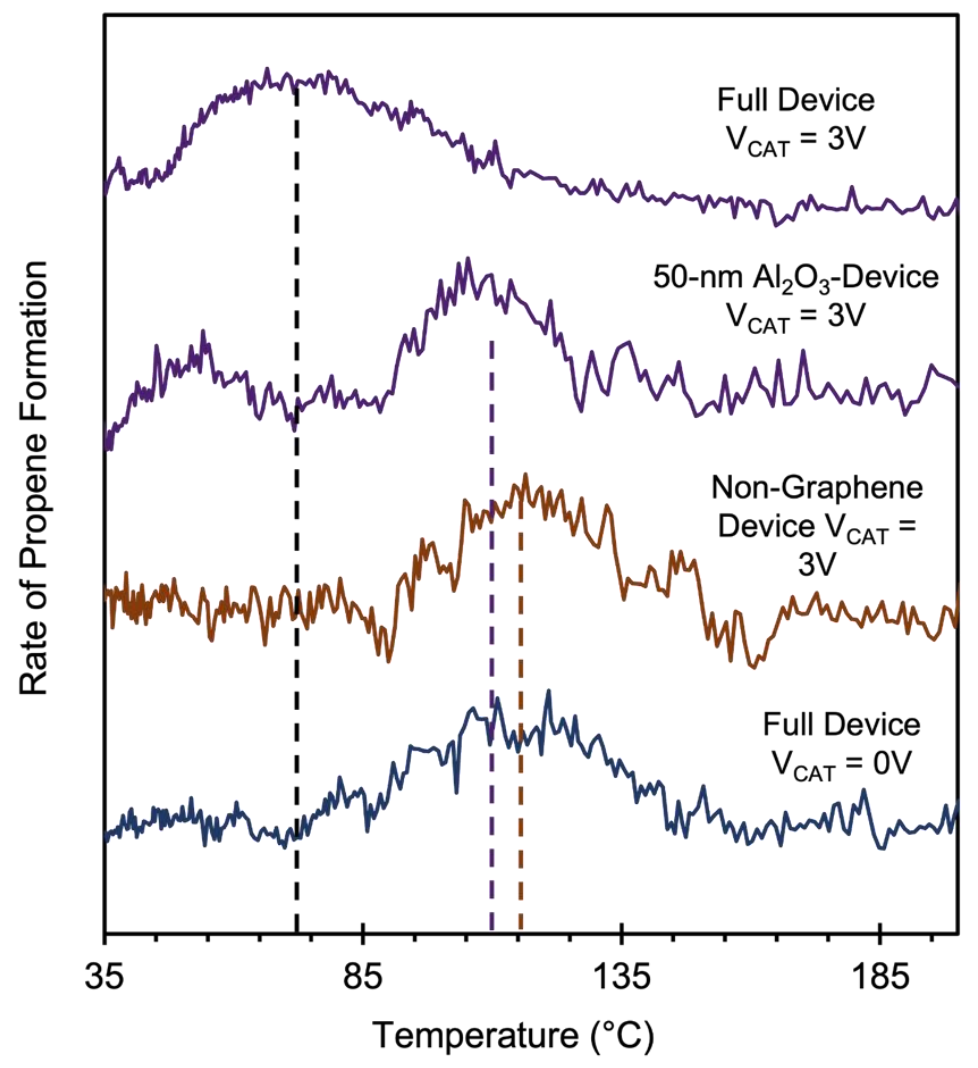

Figure S21. TPSR profile of propene formation for several control experiments under voltage bias. The two control samples are: a non-graphene $\left(\mathrm{Al}_{2} \mathrm{O}_{3} / \mathrm{HfO}_{2} / \mathrm{Si}\right)$ device, and a thick catalytic layer device $\left(50 \mathrm{~nm} \mathrm{Al}_{2} \mathrm{O}_{3} /\right.$ graphene $\left./ \mathrm{HfO}_{2} / \mathrm{Si}\right)$. A voltage bias of $\mathrm{V}_{\mathrm{CAT}}=3 \mathrm{~V}$ is applied to these two samples during the TPSR runs. Temperature of the propene formation peak did not show any major shift with the voltage application. This implies that graphene is essential for charge distribution and the charges are localized to the $\mathrm{Al}_{2} \mathrm{O}_{3}$ on the surface of the graphene and dielectric layer. These charged sites are buried in the thick $\mathrm{Al}_{2} \mathrm{O}_{3}$ layer. TPSR profiles for full devices $\left(\mathrm{Al}_{2} \mathrm{O}_{3} /\right.$ graphene $/ \mathrm{HfO}_{2} / \mathrm{Si}$ where $\mathrm{Al}_{2} \mathrm{O}_{3}$ layer is $5 \mathrm{~nm}$ thick $)$ at $\mathrm{V}_{\mathrm{CAT}}=0 \mathrm{~V}$ and $3 \mathrm{~V}$ are shown for comparison. 


\section{Surface Temperature Measurements with Infrared Camera:}

Surface measurements of the alumina-graphene condenser device under different voltage biases were assessed using a FLIR infrared camera (FLIR A655) as shown in Fig. S22. The same Keithley 2450 source meter, used in the TPSR experiments, was used to introduce the different voltage biases while the infrared camera monitored the surface temperature simultaneously for ten minutes at room temperature and pressure conditions. To validate the infrared camera's settings, it was first used to measure the surface temperature of a Si wafer heated to a known temperature on a heating plate. As shown in Fig. S22, there was no significant change in the device's surface temperature when voltage was applied.
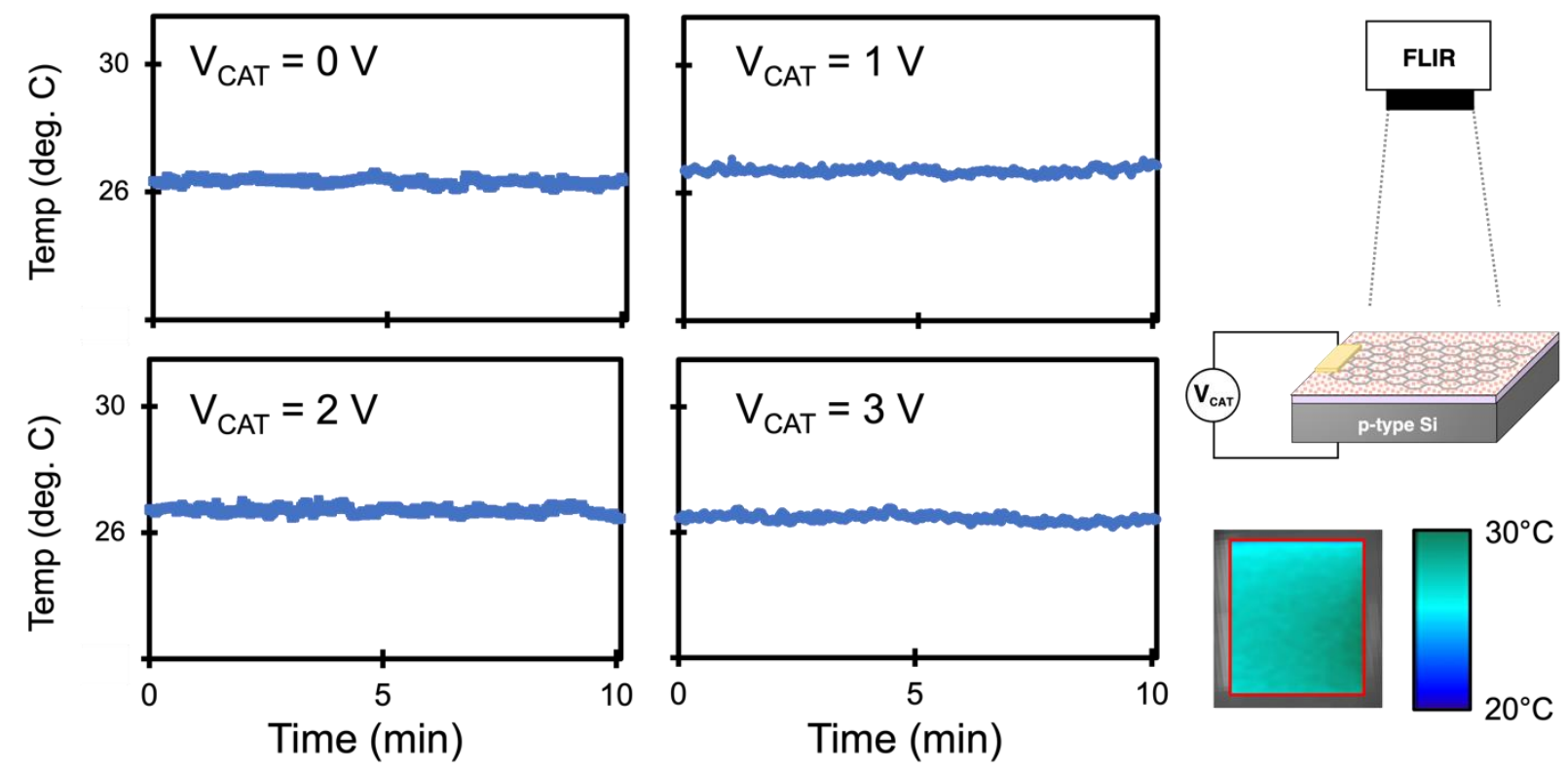

Figure S22. Surface thermal imaging of the alumina-graphene catalytic condenser device under different $\mathrm{V}_{\text {САT }}$ over time. A schematic of the setup and a representative thermal map of the device's surface under different $\mathrm{V}_{\mathrm{CAT}}$ are shown. 


\section{Post TPSR Device Characterization:}

SEM-EDX maps and XRD were used to characterize the alumina-graphene condenser device before and after the TPSR experiments. From Fig. S23, the EDX-maps showed no indication of $\mathrm{HfO}_{2}$, graphene, or $\mathrm{Al}_{2} \mathrm{O}_{3}$ deactivation or material agglomeration. Graphene folds and wrinkles, as expected from a low magnification top-down view of the device, can be observed from both samples. There were no evidence of coking or crystallization of $\mathrm{HfO}_{2}$ or $\mathrm{Al}_{2} \mathrm{O}_{3}$ from the EDX maps. XRD measurements from Fig. S24 validated that the materials remained amorphous with no crystallite or large particle formation after the voltage-biased TPSR experiments.
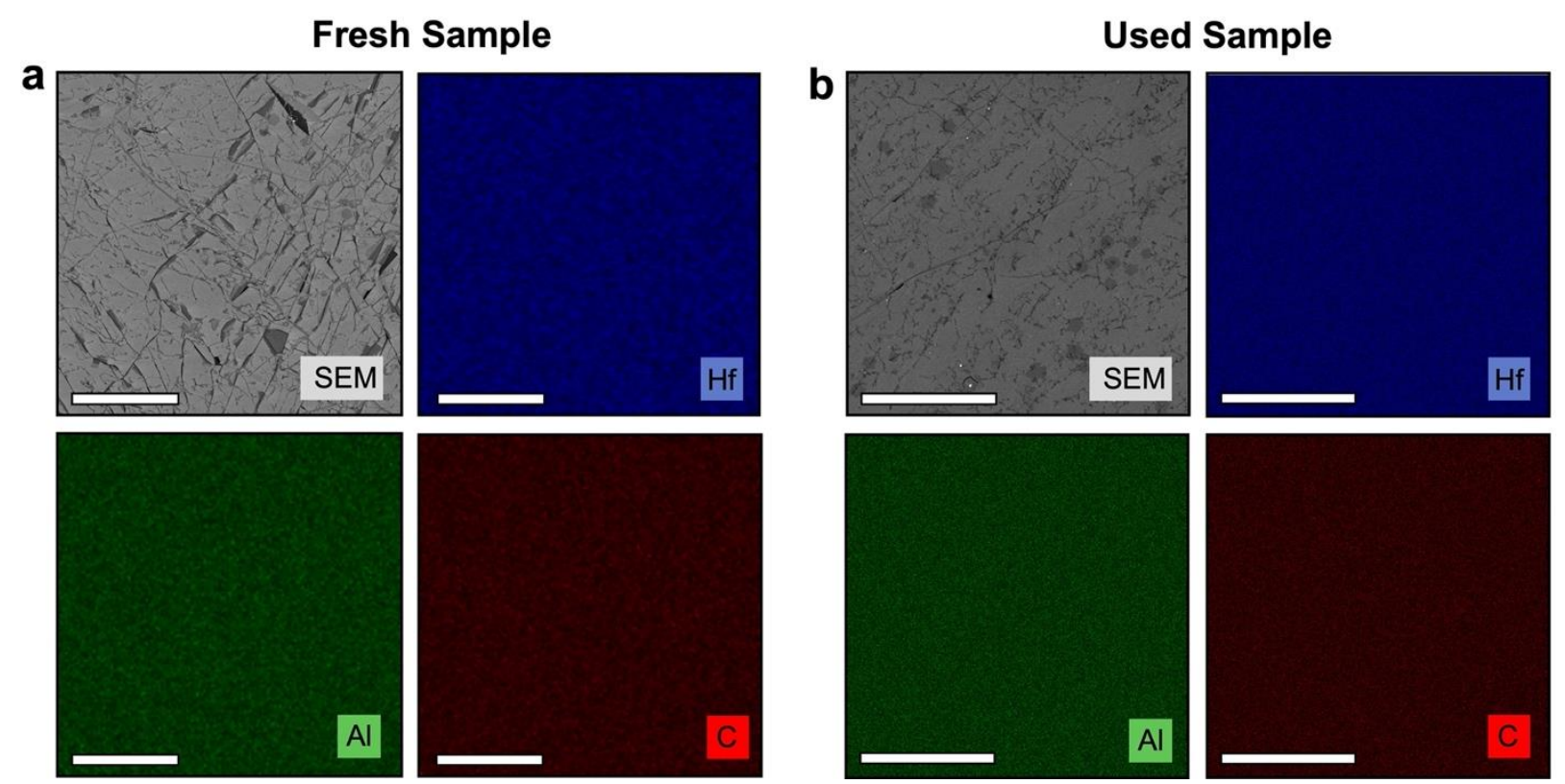

Figure S23. SEM and EDX comparison between (a) a fresh alumina-graphene catalytic condenser device and (b) a used device after multiple TPSR runs. Graphene folds and wrinkles are observed on both samples as expected. There is no clear indication of $\mathrm{HfO}_{2}$, graphene, or $\mathrm{Al}_{2} \mathrm{O}_{3}$ deactivation. Scale bar is $25 \mu \mathrm{m}$. 


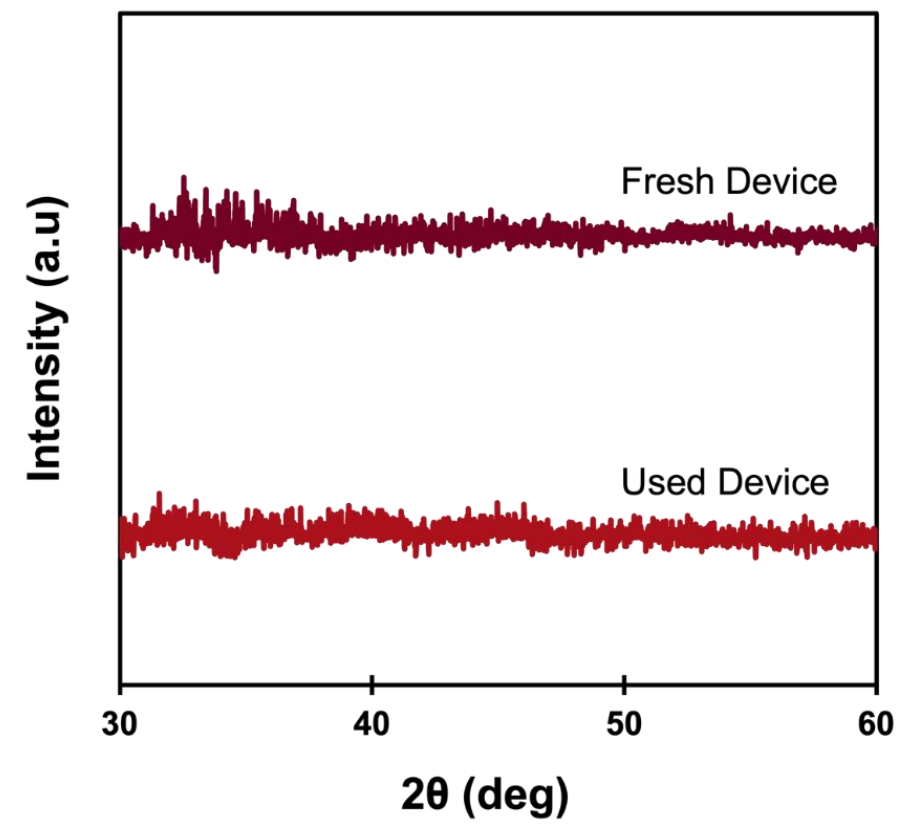

Figure S24. XRD comparison between a fresh alumina-graphene catalytic condenser device and a used device after multiple voltage-biased TPSR runs. 


\section{Powder TPSR: Zirconia, Titania, Alumina}

The selectivity to dehydration and dehydrogenation products in the course of isopropanol TPSR was measured using the method of reactive gas chromatography. Approximately $40 \mathrm{mg}$ of catalyst was placed in quartz liner (Agilent, 5190-3162), housed in the inlet of a gas chromatograph (Agilent, 7890A). The catalyst was calcined ex-situ at $400{ }^{\circ} \mathrm{C}$ for one hour, in a $10 \mathrm{sccm}$ stream of air (ultra zero air, Airgas) and a ramp rate of $12.5{ }^{\circ} \mathrm{C} \mathrm{min}{ }^{-1}$. Isopropanol (Sigma Aldrich, $\geq 99.5 \%$ ) was injected at $1 \mathrm{uL} \mathrm{min}^{-1}$ using an automated liquid sampler, into a $32 \mathrm{sccm}$ stream of He (ultrahigh purity, $99.999 \%$, Airgas). The vaporized stream of isopropanol in He was brought into contact with the catalyst held at $50{ }^{\circ} \mathrm{C}$ until a total of $20 \mu \mathrm{L}$ of liquid isopropanol had been vaporized, followed by an 80 minute purge in He. The temperature of the chromatography column was then increased to $270{ }^{\circ} \mathrm{C}$, to purge any excess isopropanol prior to the TPSR. After being cooled down to $30{ }^{\circ} \mathrm{C}$, the temperature of the catalyst was then linearly increased to $400{ }^{\circ} \mathrm{C}$ at a ramp rate of 10 ${ }^{\circ} \mathrm{C} \mathrm{min}{ }^{-1}$, followed by a 30 minute hold, while maintaining the column temperature at $30{ }^{\circ} \mathrm{C}$ to trap molecules desorbing from the catalyst surface. The column temperature was then ramped to 270 ${ }^{\circ} \mathrm{C}$ to elute the desorbed products and unconverted isopropanol, quantified with a flame ionization detector equipped with a quantitative carbon detector (polyarc, activated research company).

Table S1 - Selectivity to propene, acetone, and diisopropyl ether (DIPE) over powder metal oxide catalysts during ambient pressure temperature programmed surface reaction.

\begin{tabular}{cccc}
\hline \multirow{2}{*}{ Catalyst } & \multicolumn{3}{c}{ Selectivity [\%] } \\
\cline { 2 - 4 } & Propene & Acetone & DIPE \\
\hline $\mathrm{Al}_{2} \mathrm{O}_{3}$ & 98.8 & 0.3 & 1.0 \\
$\mathrm{TiO}_{2}$ & 99.7 & 0.0 & 0.1 \\
$\mathrm{ZrO}_{2}$ & 97.5 & 0.7 & 0.6 \\
\hline
\end{tabular}




\section{Data Processing - Temperature Programmed Surface Reaction}

The goal of processing the TPSR curves was to extract the activation energy of isopropanol dehydration using the Redhead analysis. In order to fit the Redhead equation to the TPSR curves, a baseline first had to be subtracted. Both steps are detailed below, and Fig. S25 shows the data processing of a $\mathrm{V}_{\mathrm{CAT}}=+3 \mathrm{~V}$ experiment as a representative example.

\section{Background Subtraction}

A sigmoidal background was subtracted from all TPSR data sets. This background shape was selected by measuring the TPSR chamber total pressure increase during a TPSR experiment using the cold cathode Pirani gauge. The isopropanol contribution to the propene signal $(\mathrm{m} / \mathrm{z}=41)$ was removed using the correction factor extracted from Fig. S19, after which the corrected signal was scaled by a factor of $10^{10}$ to ensure that sample temperature and propene signals had similar orders of magnitude for better fit results. Eq. S1 was then fit to the propene signal, excluding the TPSR peak region, using nonlinear least squares regression (MATLAB R2021b built-in function lsqcurvefit, Levenberg-Marquardt algorithm, $10^{-9}$ function tolerance). To ensure accurate fit of the sigmoid curve to the data, midpoint parameter $\mathrm{T}_{0}$ was bounded at $[62.98,88.15]$ (units: sample temperature, ${ }^{\circ} \mathrm{C}$ ); these bounds were determined by fitting Eq. S1 to five total chamber pressure data sets acquired at different $\mathrm{V}_{\mathrm{CAT}}$ values $(0 \mathrm{~V}$ and $3 \mathrm{~V})$. This sigmoidal background was then subtracted from the corrected data to yield the final background-subtracted propene data.

$$
\text { Background }=R_{\min }+\frac{\left(R_{\max }-R_{\min }\right)}{1+\exp \left(-\left[T-T_{0}\right] / b\right)} \quad \text { Eq. } \mathrm{S} 1
$$

Where: $R_{\min }$ and $R_{\max }$ correspond to propene signal values at the beginning and end of an experiment, and $T$ to sample temperature.

$\underline{\text { Redhead Analysis }}$

The Polanyi-Wigner equation (Eq. S2) was fit to the propene coverage data, calculated from the baseline-subtracted propene data, using nonlinear regression (MATLAB R2021b built-in function nlinfit; $\mathrm{E}_{\mathrm{a}}$ initial guess of $100 \mathrm{~kJ} \mathrm{~mol}^{-1}$ ). Any negative rate values, which occurred due to the baseline subtraction, were set to zero before calculating the coverage; data points outside the linear temperature ramp range $\left(\mathrm{T}_{\text {sample }} \sim 30\right.$ to $200^{\circ} \mathrm{C}$ ) were discarded before analysis.

When fitting the equation, we assumed no entropic activation $\left(\Delta \mathrm{S}=0 \mathrm{~kJ}-\mathrm{mol}^{-1}-\mathrm{K}^{-1}\right)$ and first-order reaction $(n=1)$.

$$
\begin{array}{cc}
\text { rate }=\frac{d \theta}{d T}=-\frac{k_{B} T}{h} \cdot \frac{\theta^{n}}{\beta} \cdot \exp \left(\frac{\Delta S}{R} \cdot-\frac{E_{A}}{R T}\right) & \text { Eq. S2 } \\
T=T_{0}+\beta T & \text { Eq. S3 }
\end{array}
$$

Where: $\theta$ is the sample coverage, $T$ the sample temperature (Eq. S3); $k_{B}, h$ and $R$ the Boltzmann, Planck and universal gas constants, respectively; $\beta$ the linear temperature ramp rate; $\Delta \mathrm{S}$ the entropy of activation, $\mathrm{E}_{\mathrm{A}}$ the enthalpy of activation, and $n$ the desorption order. 
a
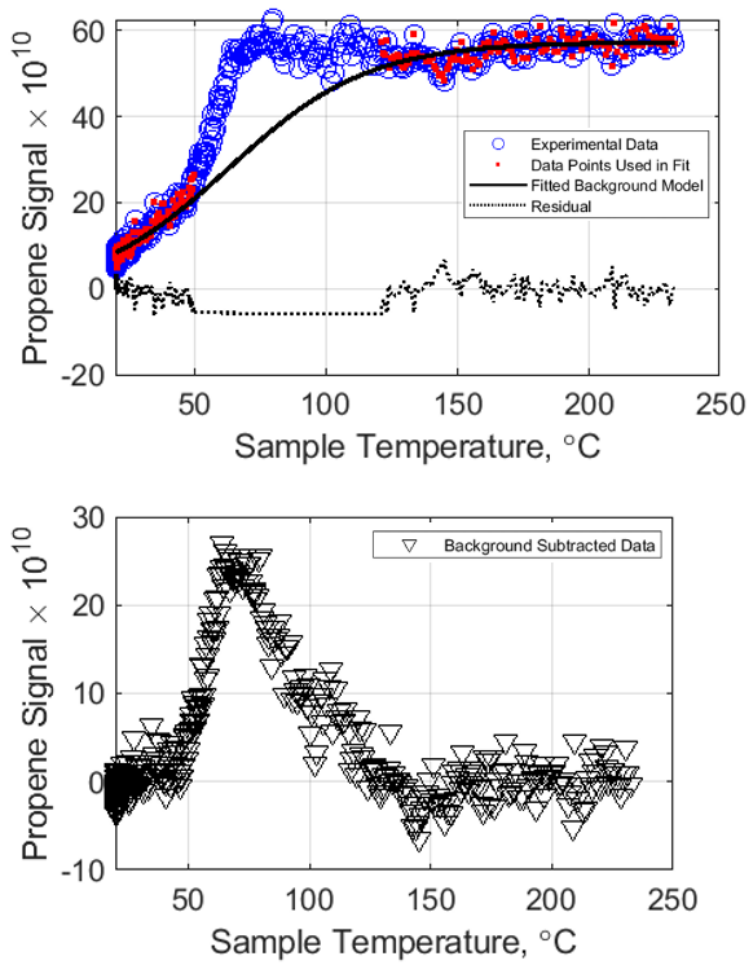
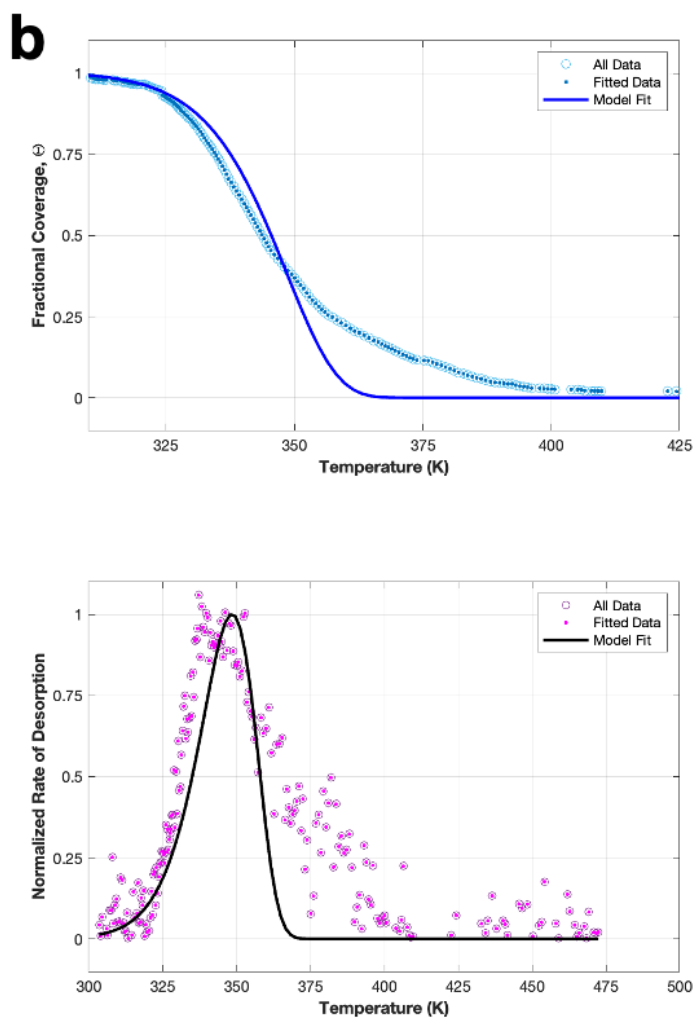

Figure S25. Isopropanol dehydration TPSR data processing and Redhead analysis example using data from: $V_{\text {CAT }}=+3 \mathrm{~V}$, trial 2. (a) Sigmoidal background fit to raw data (top) and final subtracted propene data (bottom). Experimental data (blue circles) is the propene signal $(\mathrm{m} / \mathrm{z}=41)$ with isopropanol contribution removed. (b) Redhead model fit to propene coverage (top) and rate (bottom). 


\section{Calculations - Dielectric Constant, Capacitance, and Charge}

The goal is to obtain the dielectric constant of the high-k dielectric material of the catalytic condenser based on the design of the device including the area, A of $1.0 \mathrm{~cm}^{2}$, the spacing between layers, $d$ of $70 \mathrm{~nm}$, and capacitance $(C)$. It can be calculated by Eq. $\mathbf{S} \mathbf{4}$ and $\mathbf{S 5}$.

$$
\begin{array}{ll}
C=\frac{\varepsilon A}{d}[=] \frac{\left(\frac{F}{c m}\right)\left(\mathrm{cm}^{2}\right)}{(\mathrm{cm})}[=] F & \text { Eq. S4 } \\
\varepsilon=\frac{C d}{A}[=] \frac{(F)(\mathrm{cm})}{\left(\mathrm{cm}^{2}\right)}[=] \frac{F}{\mathrm{~cm}} & \text { Eq. S5 }
\end{array}
$$

The permittivity of the $\mathrm{HfO}_{2}$ layer, $\varepsilon$, is the product of the dielectric constant, $\kappa$, and the vacuum permittivity, $\varepsilon_{0}$, which equals to $8.854 \times 10^{-12} \mathrm{~F} / \mathrm{m}$.

$$
\begin{array}{ll}
\kappa \varepsilon_{0}=\frac{C d}{A}[=] \frac{(F)(\mathrm{cm})}{\left(\mathrm{cm} \mathrm{m}^{2}\right)}[=] \frac{F}{\mathrm{~cm}} & \text { Eq. S6 }
\end{array}
$$

To evaluate the capacitance of the device, the capacitive current normalized to the area is measured experimentally as a function of voltage under different voltage sweep rate $(1.25 \mathrm{~V} / \mathrm{s}, 1.00 \mathrm{~V} / \mathrm{s}, 0.75$ $\mathrm{V} / \mathrm{s}$, and $0.50 \mathrm{~V} / \mathrm{s}$ ) as shown in Fig. S26 below. The absolute value of the horizontal line (either positive or negative capacitive current) for each sweep rate is extracted, and it is plotted against the sweep rate as shown in Fig. S27. The gradient obtained from this graph is the capacitance.

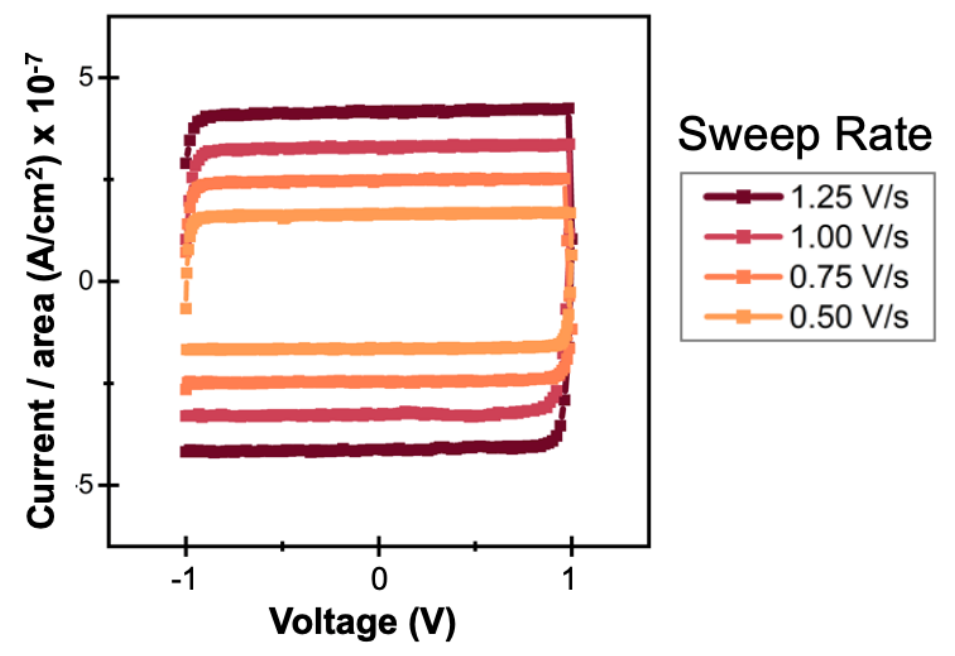

Figure S26. Sample capacitive current as a function of voltage at different sweep rates. 


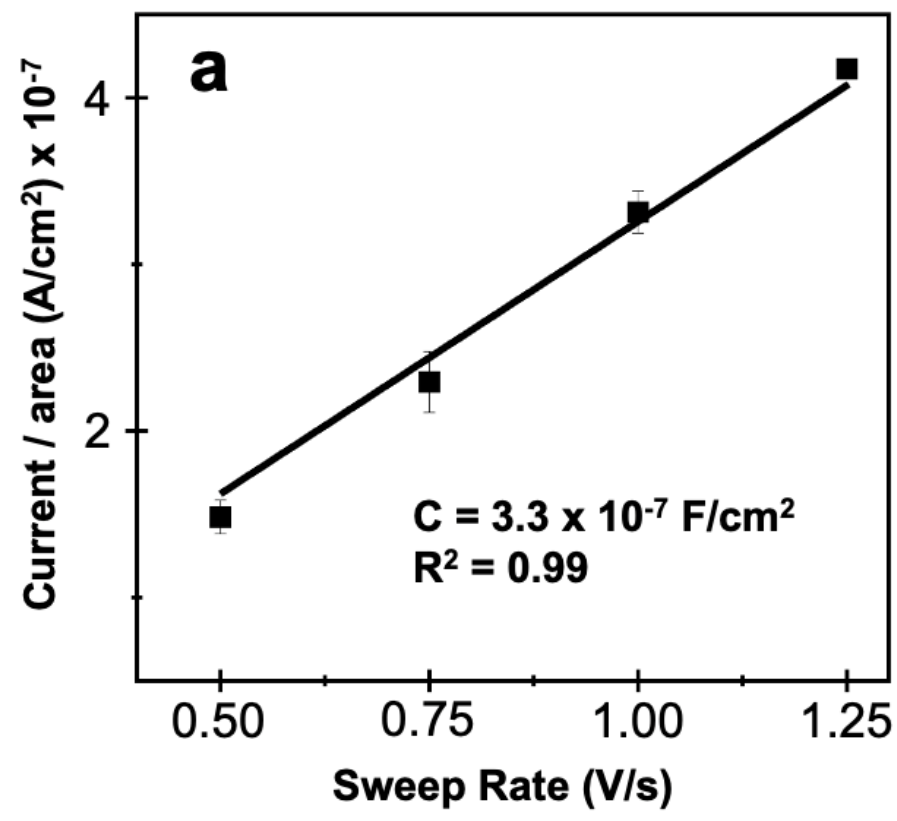

Figure S27. Sample of capacitive current as a function of sweep rates. The gradient of the graph is the capacitance/area.

Using the values above as an example: $\left(3.3 \times 10^{-7} \mathrm{~F} / \mathrm{cm}^{2}=3.3 \times 10^{-3} \mathrm{~F} / \mathrm{m}^{2}\right)$

$$
\begin{aligned}
& \kappa=\frac{C d}{A \varepsilon_{0}}=3.3 \times 10^{-3} \mathrm{~F} / \mathrm{m}^{2} \frac{70 \times 10^{-9} \mathrm{~m}}{8.854 \times 10^{-12} \mathrm{~F} / \mathrm{m}}[=] \text { unitless } \\
& \kappa=26
\end{aligned}
$$

The charge accumulated in the device (coulombs per $\mathrm{cm}^{2}$ ) can then be calculated by Eq. S7,

$$
\begin{aligned}
Q_{\text {ind }} & =C * V_{\text {cat }}[=]\left(\frac{F}{\mathrm{~cm}^{2}}\right) *(V)[=]\left(\frac{C}{V * c m^{2}}\right)(V)[=] \frac{C}{\mathrm{~cm}^{2}} \\
Q_{\text {ind }} & =\left(3.3 * 10^{-7} \frac{F}{\mathrm{~cm}^{2}}\right)(+3 V)=9.9 * 10^{-7} \frac{C}{\mathrm{~cm}^{2}}=6.2 * 10^{12} \frac{\mathrm{h}^{+}}{\mathrm{cm}^{2}}
\end{aligned}
$$

where $\mathrm{h}^{+}$is the number of electron holes formed. 


\section{Calculations - Device Speed}

The goal is to predict the time required for electrons to move across the device over a distance of about one centimeter $(\mathrm{L} \sim 1 \mathrm{~cm})$, which is the size of the device. The time constant associated with "establishing a channel" across the device can be calculated using the electron mobility, $\mu$, and the lateral source-drain bias (V) as shown in Eq. S8,

$$
\tau=\frac{L^{2}}{\mu V}[=] \frac{c m^{2}}{\left(\frac{c m^{2}}{V * s}\right)(V)}[=] s \quad \text { Eq. S8 }
$$

The electron mobility of graphene deposited on $\mathrm{HfO}_{2}$ used in the catalytic condenser device was determined from experiment as shown in Fig. S10, where the current was measured as a function of the applied voltage on a graphene surface with $\sim 1 \mathrm{~cm}$ between the two probes. This was also compared to commercial graphene on an insulator $\mathrm{SiO}_{2}$. The mobility $\mu$ is determined from $n_{e} e$ (ne is the number of charge carriers, and e is a constant of $1.602 \times 10^{-19} \mathrm{C}$ ), capacitance $\boldsymbol{C}$, conductivity $\sigma$ (measured current/voltage), and applied voltage, V, as shown in Eq. S9.

$$
\mu=\frac{\sigma}{n_{e} e}=\frac{\sigma}{(\mathrm{C} * V)}[=] \frac{\left(\frac{A}{V}\right)}{\left(F / \mathrm{cm}^{2}\right)(V)}[=] \frac{\left(\frac{\mathrm{C}}{V S}\right)}{\left(\mathrm{C} / V * c m^{2}\right)(V)}[=] \frac{\mathrm{cm}}{V * S}^{2}
$$

For the transferred graphene device, the electron mobility was determined by measurement to be $\sim 1600 \mathrm{~cm}^{2} \mathrm{~V}^{-1} \mathrm{~s}^{-1}$ for a device capacitance of $3.6 \times 10^{-8} \mathrm{~F} / \mathrm{cm}^{2}$ with a $+1 \mathrm{~V}$ bias.

$$
\mu=\frac{\sigma}{n_{e} e}=\frac{\left(56 \times 10^{-6} A / V\right)}{\left(3.6 \times 10^{-8} F / \mathrm{cm}^{2}\right)(1 V)}=1555 \mathrm{~cm}^{2} /\left(\mathrm{V}^{*} \mathrm{~s}\right) \quad \text { Eq. S } 10
$$

This corresponds to a $\tau$ of $643 \mu \mathrm{s}$ at $+1 \mathrm{~V}$ over $1 \mathrm{~cm}$ length.

Alternatively, we can calculate the time constant of the resistance $(\mathrm{R})$ and the capacitance $(C)$ as,

$$
\begin{array}{ll}
\tau=R * C * A[=](\text { Ohms })\left(\frac{F}{\mathrm{~cm}^{2}}\right)\left(\mathrm{cm}^{2}\right)[=]\left(\frac{V s}{\mathrm{C}}\right) *\left(\mathrm{C} / V * \mathrm{~cm}^{2}\right) *\left(1 \mathrm{~cm}^{2}\right)[=] s & \text { Eq. S11 } \\
\tau=R * C * A=(17,857 \text { Ohms })\left(3.6 * 10^{-8} \frac{F}{\mathrm{~cm}^{2}}\right) *\left(1 \mathrm{~cm}^{2}\right)=642 \mu \mathrm{s} & \text { Eq. S12 }
\end{array}
$$




\section{Additional description of computational methods}

The dehydrated $\gamma-\mathrm{Al}_{2} \mathrm{O}_{3}(100)$ surface was used herein as a first-order model of the surface of the exposed alumina film. Previous studies have shown that the (100) and (110) surfaces of $\gamma$ alumina are the dominant alumina surfaces under reaction conditionssurfaces. ${ }^{[4]}$ A systematic series of ab initio thermodynamic simulations which explored the effects of temperature and water pressure showed that the lowest energy (100) $\gamma-\mathrm{Al}_{2} \mathrm{O}_{3}$ surface is dehydrated while the (110) $\gamma$ $\mathrm{Al}_{2} \mathrm{O}_{3}$ surface is terminated with $8.9 \mathrm{OH}$ intermediates per $\mathrm{nm}^{-2}$ at temperatures that range from $350-550^{\circ} \mathrm{C}$ and $3.0 \mathrm{OH} \mathrm{nm}$ at temperatures greater than $550^{\circ} \mathrm{C}$. ${ }^{[4]}$ Herein we examine the adsorption and reactivity of isopropanol on the lowest energy dehydrated (100) $\gamma-\mathrm{Al}_{2} \mathrm{O}_{3}$ surface proposed by Lamier et al. ${ }^{[4]} \mathrm{A}$ periodic slab that is $2 \times 2$ times the primitive unit cell and comprised of seven layers of the (100) $\gamma-\mathrm{Al}_{2} \mathrm{O}_{3}$ surfaces was used for all calculations. The bottom-most layer of the slab was held fixed to bulk optimized Al-O structure during the geometry optimizations. All of thelayers above were allowed to fully relax during the optimizations. A periodic cell with dimensions of $11.074 \times 16.714 \times 28.000 \AA$ was used in the simulations, which corresponds to a vacuum region of $\sim 22 \AA$ in z-direction for the separation of top and bottom layers of the slab. The alumina (100) surface of is comprised of 4 pentacoordinated aluminum atoms (Alva, Alvb, Alvb'

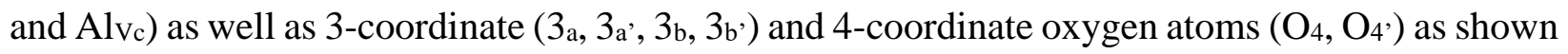
in Figure S28.

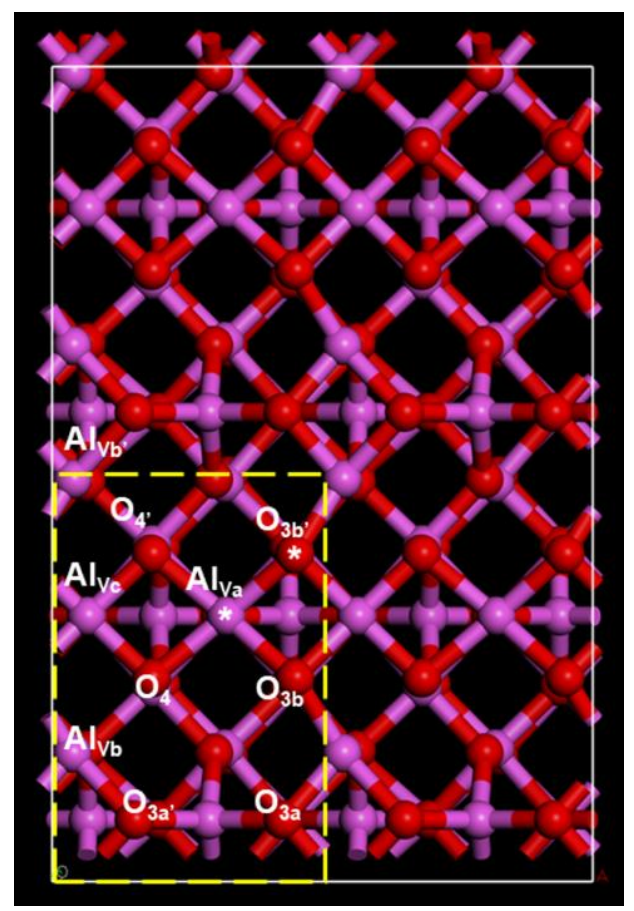

Figure S28. Top view of the $\gamma$-Al2O3 (100) slab surface $(2 \times 2$ times the primitive unit cell shown inside yellow box) used for density functional theory calculations, showing the AlVa and O3b' pair sites (labeled with asterisks), and other $\mathrm{Al} / \mathrm{O}$ sites. Color scheme: $\mathrm{Al}$ - magenta, $\mathrm{O}$ - red, $\mathrm{C}$ - grey, and $\mathrm{H}$ - white. 
All of the calculations reported were carried out using the plane wave density function theory calculations using the Vienna ab initio simulation program (VASP ${ }^{[5,6,7]}$. The generalized gradient approximation form of the Perdew, Burke, and Ernzerhof (PBE) functional was used to determine the energies, and dispersion corrections were included via the D3 corrections developed by Grimme ${ }^{[8,9]}$. An energy cutoff of $400 \mathrm{eV}$ was used in the construction of plane waves, and projector augmented wave potentials (PAW) were used to model interactions between core and valence electrons ${ }^{[10,11]}$. A periodic slab of $2 \times 2$ times the primitive unit cell and consisting of seven layers of $\gamma-\mathrm{Al}_{2} \mathrm{O}_{3}$ (100) was used for all calculations, with the bottom-most layer held fixed. All electronic energies were converged to within a tolerance of $10^{-6} \mathrm{eV}$ using a $2 \times 1 \times 1$ gamma-centered $k$-point grid. The geometries of the structures were optimized until the maximum force on each atom was calculated to be less than $0.05 \mathrm{eV} / \mathrm{A}$. The climbing image nudged elastic band (Cl-NEB) method $^{[12]}$ was used to obtain the transition state (TS) structures, by optimizing the energies for a series of structures along the reaction path using a force tolerance of $0.08 \mathrm{eV} / \AA$.

In order to examine the influence of charge transfer from the substrate to the alumina, we carried out charge calculations in VASP where the charge is introduced into the alumina surface while a neutralizing back charge is distributed over the background.

The adsorption/binding of isopropanol and the subsequent dehydration isopropoxy and hydrogen intermediates and propylene and water products were examine on the Alva and O sites on the surface. The binding energies are calculated as differences in electronic energies as, $\Delta \mathrm{E}_{\text {ads }}$ $=\left(E_{\text {adsorbed IPA }}-E_{I P A}-E_{\text {bare slab }}\right)$. The activation energies are calculated as $E_{a}=E_{T S}-E_{\text {adsorbed IPA, }}$ with the adsorbed IPA on Alva site as the reactant state. 


\section{Effect of charge modulation on energetics for isopropanol dehydration to propylene}

We modulate the surface charge of $\gamma$-alumina (100) in order to examine the Lewis acidity and its influence on the adsorption energies and dehydration barriers. In order to model the charge modulation on the alumina surface, electrons were either added to or removed from the alumina slab. A neutralizing background charge is used to maintain charge neutrality of the periodic cell. Electron removal from the system leads to a more positively charged surface, which is thought to improve the Lewis acidity of the catalyst surface. Herein, we examine the reaction energies and activation barriers for the dehydration of isopropanol over the $\mathrm{Alva}_{\mathrm{a}} \mathrm{O}_{3 \mathrm{~b}}$ site pair. Previously reported calculations indicate that the lowest energy path proceeds via a concerted E2 mechanism. Isopropanol binds via its hydroxyl oxygen to the Alva site and weakly interacts with $\mathrm{O}_{3 \mathrm{~b}}$ ' of $\gamma$ alumina via one of its $\beta-\mathrm{H}$ atoms. The binding energy of isopropanol is used herein as a measure of the Lewis acidic site strength. Stronger isopropanol binding (more negative binding energies) are obtained for systems from which electrons are removed whereas weaker isopropanol binding occurs when electrons are added to the system (Fig. S29 and Table S2). The charges on all aluminum atoms in the top layer become more positive as we move from systems where electrons are added to the systems where electrons are removed. In summary, an increase in accumulation of positive charge on slab, results in increase in Lewis acidity of the catalyst as evidenced from a stronger isopropanol binding. A lower activation barrier for isopropanol dehydration via E2 mechanism was obtained for the system with more positively charged surface $(q=0.5|\mathrm{e}|)$ i.e., having a higher Lewis acidity.

Many metal oxides, including $\gamma$-alumina have Lewis acid-base pair sites that are both catalytically active with high Lewis acidity as well as basicity, that can catalyze competing acid and base catalyzed chemical reactions, leading to loss of selectivity. We find that when Alva is made more positively charged (increased Lewis acidity), the neighboring $\mathrm{O}_{3 b}$, becomes less negatively charged (decreased Lewis basicity). More generally, through charge modulation, our results point to an opportunity of tuning both Lewis acidic and basic sites on the metal-oxide catalyst surface wherein we can simultaneously increase the Lewis acidity of the metal (in this case, $\mathrm{Al}$ ) while decreasing the Lewis basicity of the adjacent $\mathrm{O}$ site to selectively improve rates of acid catalyzed reactions and reduce rates of competing base catalyzed reactions, for example. 


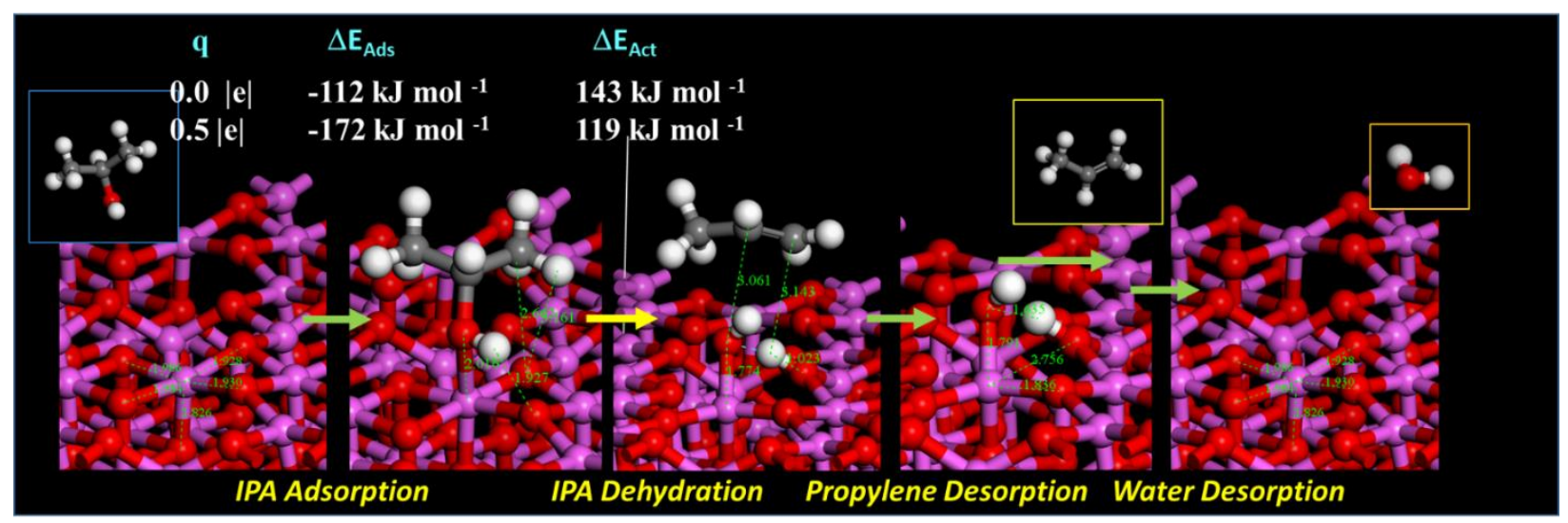

Figure S29. Isopropanol (IPA) dehydration to form propylene and water over $\mathrm{Al}_{\mathrm{Va}}$ and $\mathrm{O}_{3 \mathrm{~b}}$ ' pair sites of $\gamma$ alumina. The IPA adsorption, IPA dehydration, and propylene/water desorption steps are shown in black, maroon, and gold arrows respectively. The binding and activation energies are shown for $q=0.0$ (black) and $+0.5|\mathrm{e}|$ (purple) per primitive cell, where e is the elementary charge. Color scheme: $\mathrm{Al}$ - magenta, $\mathrm{O}$ red, $\mathrm{C}$ - grey, and $\mathrm{H}$ - white. The distances shown are in angstroms. 
Table S2. Electronic energies (in $\mathrm{eV}$ ) of bound reactant and product states relative to the bare surface for different charges ( $q$, either added or removed) on the slab. The gas phase reaction energy, $\Delta \mathrm{E}=\mathrm{E}_{\text {propylene }}+\mathrm{E}_{\text {water }}-\mathrm{E}_{\mathrm{IPA}}=0.711 \mathrm{eV}\left(68.6 \mathrm{~kJ} \mathrm{~mol}^{-1}\right)$.

\begin{tabular}{|c|c|c|c|c|c|c|}
\hline $\begin{array}{l}\text { Charge } \\
\text { on } \\
\text { system }\end{array}$ & $\begin{array}{c}\boldsymbol{q}_{\text {system }} \\
\text { charge } \\
\text { per } \\
\text { system } \\
\text { i.e., } 2 \times 2 \\
\times 1 \text { cell } \\
(|\mathbf{e}|)\end{array}$ & $\begin{array}{c}q \text {, charge } \\
\text { per } \\
\text { primitive } \\
\text { cell }(|\mathrm{e}|)\end{array}$ & $\begin{array}{c}\text { Bare surface } \\
\qquad(100) \\
+ \text { IPA } \\
\left(\mathrm{kJ} \mathrm{mol}^{-1}\right)\end{array}$ & $\begin{array}{c}\text { Bound } \\
\text { reactant } \\
\text { state } \\
\text { (equivalent } \\
\text { to IPA } \\
\text { binding } \\
\text { energy) } \\
\text { (kJ } \text { mol }^{-1} \text { ) }\end{array}$ & 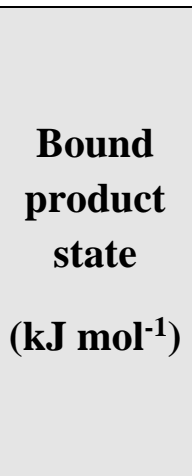 & $\begin{array}{l}\text { Difference } \\
\text { between } \\
\text { bound } \\
\text { product and } \\
\text { bound } \\
\text { reactant state } \\
\text { energies } \\
\left(\mathrm{kJ} \mathrm{mol}^{-1}\right)\end{array}$ \\
\hline $\begin{array}{c}\text { Most } \\
\text { Positive }^{\#}\end{array}$ & +4 & +1.00 & 0.0 & -251.1 & - & - \\
\hline $\begin{array}{c}\text { More } \\
\text { Positive }\end{array}$ & +2 & +0.50 & 0.0 & -171.8 & -103.3 & 68.3 \\
\hline Positive & +1 & +0.25 & 0.0 & -139.6 & -073.5 & 66.1 \\
\hline Neutral & 0 & 0.00 & 0.0 & -112.3 & -056.1 & 56.0 \\
\hline Negative & -1 & -0.25 & 0.0 & -92.93 & -49.4 & 43.4 \\
\hline $\begin{array}{c}\text { More } \\
\text { Negative }\end{array}$ & -2 & -0.50 & 0.0 & -86.0 & -44.0 & 42.0 \\
\hline $\begin{array}{c}\text { Most } \\
\text { Negative }\end{array}$ & -4 & -1.00 & 0.0 & -72.0 & -26.2 & 45.9 \\
\hline
\end{tabular}

\#Note: At very high q i.e., $\mathrm{q}=+1.00$, the bound product state with weakly adsorbed propylene did not converge during geometry optimization as it disfavored staying near the reaction center. 


\section{Supporting Information References}

Note: These references are also cited in the main manuscript

(1) Suk, J. W.; Kitt, A.; Magnuson, C. W.; Hao, Y.; Ahmed, S.; An, J.; Swan, A. K.; Goldberg, B. B.; Ruoff, R. S. Transfer of CVD-Grown Monolayer Graphene onto Arbitrary Substrates. ACS Nano 2011, 5 (9), 6916-6924. https://doi.org/10.1021/nn201207c.

(2) Reina, A.; Son, H.; Jiao, L.; Fan, B.; Dresselhaus, M. S.; Liu, Z. F.; Kong, J. Transferring and Identification of Single- and Few-Layer Graphene on Arbitrary Substrates. J. Phys. Chem. C 2008, 112 (46), 17741-17744. https://doi.org/10.1021/jp807380s.

(3) Wang, Y.; Udyavara, S.; Neurock, M.; Daniel Frisbie, C. Field Effect Modulation of Electrocatalytic Hydrogen Evolution at Back-Gated Two-Dimensional MoS2 Electrodes. Nano Lett. 2019, 19 (9), 6118-6123. https://doi.org/10.1021/acs.nanolett.9b02079.

(4) Blanck, S.; Martí, C.; Loehlé, S.; Steinmann, S. N.; Michel, C. (Dis)Similarities of Adsorption of Diverse Functional Groups over Alumina and Hematite Depending on the Surface State. J. Chem. Phys. 2021, 154 (8). https://doi.org/10.1063/5.0038412.

(5) Kresse, G.; Hafner, J. Ab Initio Molecular Dynamics for Liquid Metals. Phys. Rev. B 1993, 47 (1), 558-561. https://doi.org/10.1103/PhysRevB.47.558.

(6) Kresse, G.; Hafner, J. Ab Initio Molecular-Dynamics Simulation of the Liquid-Metal-Amorphous-Semiconductor Transition in Germanium. Phys. Rev. B 1994, 49 (20), 1425114269. https://doi.org/10.1103/PhysRevB.49.14251.

(7) Kresse, G.; Furthmüller, J. Efficient Iterative Schemes for Ab Initio Total-Energy Calculations Using a Plane-Wave Basis Set. Phys. Rev. B - Condens. Matter Mater. Phys. 1996, 54 (16), 11169-11186. https://doi.org/10.1103/PhysRevB.54.11169.

(8) Perdew, J. P.; Burke, K.; Ernzerhof, M. Generalized Gradient Approximation Made Simple. Phys. Rev. Lett. 1996, 77 (18), 3865-3868. https://doi.org/10.1103/PhysRevLett.77.3865.

(9) Grimme, S.; Antony, J.; Ehrlich, S.; Krieg, H. A Consistent and Accurate Ab Initio Parametrization of Density Functional Dispersion Correction (DFT-D) for the 94 Elements H-Pu. J. Chem. Phys. 2010, 132 (15). https://doi.org/10.1063/1.3382344.

(10) Joubert, D. From Ultrasoft Pseudopotentials to the Projector Augmented-Wave Method. Phys. Rev. B - Condens. Matter Mater. Phys. 1999, 59 (3), 1758-1775. https://doi.org/10.1103/PhysRevB.59.1758.

(11) Blöchl, P. E. Projector Augmented-Wave Method. Phys. Rev. B 1994, 50 (24), 1795317979. https://doi.org/10.1103/PhysRevB.50.17953.

(12) Henkelman, G.; Jónsson, H. Improved Tangent Estimate in the Nudged Elastic Band Method for Finding Minimum Energy Paths and Saddle Points. J. Chem. Phys. 2000, 113 (22), 9978-9985. https://doi.org/10.1063/1.1323224. 